\title{
Site surveys related to IODP Expedition 301: ImageFlux (SO149) and RetroFlux (TN116) expeditions and earlier studies ${ }^{1}$
}

\author{
L. Zühlsdorff, ${ }^{2}$ M. Hutnak, ${ }^{3}$ A.T. Fisher, ${ }^{3,}{ }^{4}$ V. Spiess, ${ }^{2}$ E.E. Davis, ${ }^{5}$ \\ M. Nedimovic, ${ }^{6}$ S. Carbotte, ${ }^{6} \mathrm{H}$. Villinger, ${ }^{2}$ and K. Becker ${ }^{3}$
}

\begin{abstract}
Chapter contents
Abstract....................

Setting, planning, and goals. ......... 1

Methods .................... 2

Results and discussion. . . . . . . . . 7

Summary and conclusions. . . . . . . . 15

Acknowledgments................ 16

References...................... 16

Figures..................... . 19
\end{abstract}

'Zühlsdorff, L., Hutnak, M., Fisher, A.T., Spiess, V., Davis, E.E., Nedimovic, M., Carbotte, S., Villinger, $\mathrm{H}_{\text {., }}$ and Becker, K., 2005. Site surveys related to IODP Expedition 301: ImageFlux (SO149) and RetroFlux (TN116) expeditions and earlier studies. In Fisher, A.T., Urabe, T., Klaus, A., and the Expedition 301 Scientists, Proc. IODP, 301: College Station TX (Integrated Ocean Drilling Program Management International, Inc.). doi:10.2204/ iodp.proc.301.102.2005

2Department of Geosciences, University of Bremen, Bremen, Germany.

'Expedition 301 Scientists' Addresses. ${ }^{4}$ Institute for Geophysics and Planetary Physics, University of California, Santa Cruz CA, USA. ${ }^{5}$ Pacific Geoscience Center, Geological Survey of Canada, Sydney BC, Canada.

${ }^{6}$ Lamont-Doherty Earth Observatory, Columbia University, Palisades NY, USA.

\section{Abstract}

Integrated Ocean Drilling Program Expedition 301 was preceded during 2000 and 2002 by three surveys that helped to delineate seafloor and basement relief, sediment thickness, and the nature of ridge-flank hydrothermal conditions and processes on the eastern flank of the Juan de Fuca Ridge. These surveys generated swath map, seismic, and thermal data used to select locations for primary and secondary drilling targets, building from several decades of earlier work. We show compilations and examples of data from several characteristic settings in and around the Expedition 301 work area and use these observations to evaluate sedimentation patterns and thermal conditions in basement. There remain important unanswered questions in this area concerning fluid circulation within the upper oceanic crust, the magnitude of lithospheric heat input, the quantitative significance of advective heat loss from the crust, and relations between basement relief, sedimentation, and sediment alteration. These questions may be resolved through collection of a modest amount of additional data focusing on a few critical locations.

\section{Setting, planning, and goals}

The Endeavour segment of the Juan de Fuca Ridge (JFR) generates lithosphere a few hundred kilometers west of the Olympic Peninsula, Washington State (USA) (Figs. F1, F2). The study area contains structural features common to most ridge flanks: extrusive igneous basement overlain by sediments, abyssal hill topography, high-angle faulting, and basement outcrops. The topographic relief of the young oceanic crust produces barriers to turbidites originating from the continental margin to the east, resulting in the accumulation of thick sediments that bury the eastern flank of the JFR (Davis et al., 1992; Underwood et al., 2005). Igneous basement is exposed to the west, where the crust is young, and the sedimented seafloor to the east is relatively flat, except over basement outcrops. Low-permeability sediment limits advective heat loss from most of the ridge flank, leading to strong thermal, chemical, and alteration gradients in igneous basement. Basement relief is dominated by linear ridges and troughs, oriented subparallel to the spreading center, and was produced mainly by faulting, variations in magmatic supply at the ridge, and off-axis volcanism (Davis and Currie, 1993; Karsten et al., 1998, 1986). Basement relief across this ridge flank tends to be smoother near 
the active spreading center $( \pm 100-200 \mathrm{~m})$, and rougher $( \pm 300-700 \mathrm{~m})$ to the east.

Integrated Ocean Drilling Program (IODP) Expedition 301 is the first part of a two-expedition drilling program, with associated nondrilling experiments, intended to assess the nature of fluid pathways in the crust and the dynamic influences of fluid circulation on this hydrothermally active ridge flank. Expedition 301 and related experiments will help to identify the distribution of hydrologic properties in the crust; the extent to which crustal compartments are connected or isolated (laterally and with depth); linkages between ridge-flank circulation, alteration, and geomicrobial processes; and quantitative relations between seismic and hydrologic properties. These and other scientific questions, and the methods used to address them, are discussed elsewhere (Fisher et al., "Site U1301," and "Expedition 301 summary" chapters). The main goals of this paper are to

- Show locations where swath mapping, seismic, and heat flow data were collected during recent oceanographic expeditions in preparation for Expedition 301 and related experiments;

- Present and describe examples of these data that are characteristic of local and regional hydrothermal environments;

- Analyze selected sets of collocated seismic and thermal data to resolve hydrothermal conditions in shallow basement; and

- Define important questions that remain to be resolved in this area.

Rosenberger et al. (2000) and Davis et al. (1997a) summarized survey results through 1996, and several other papers have discussed subsets of available data, including drilling results from Ocean Drilling Program (ODP) Leg 168 (e.g., Davis et al., 1992, 1999; Underwood et al., 2005; Wheat et al., 2000; Wheat and Mottl, 1994). Readers interested in a detailed presentation of regional geology and hydrogeology are directed to these studies and to other references cited throughout this paper.

There were two oceanographic expeditions in 2000 intended to provide site survey data for Expedition 301. Sonne expedition SO149 (ImageFlux) was led by V. Spiess, L. Zühlsdorff, and H. Villinger (University of Bremen, Germany) and collected swath-map, seismic, and heat flow data. Thomas G. Thompson expedition TN116 (RetroFlux) was led by A. Fisher (University of California at Santa Cruz), E.E. Davis (Pacific Geoscience Center), C.G. Wheat (University of Alaska Fairbanks), and M. Mottl (University of Hawaii) and collected mainly heat flow data and sediment cores, with a small amount of swath mapping.
In addition, Maurice Ewing expedition EW0207, led by S. Carbotte (Lamont-Doherty Earth Observatory of Columbia University), R. Detrick (Woods Hole Oceanographic Institution), and G. Kent (Scripps Institution of Oceanography), collected multichannel seismic (MCS) and swath-bathymetry data. This 2002 program included detailed surveys along the axis of the JFR and a suite of ridge-flank profiles ( $1500 \mathrm{~km}$ total length), of which the northernmost crossed the Expedition 301 work area.

We had originally hoped to complete the ImageFlux survey in advance of the RetroFlux survey, to allow time for processing and interpretation of swath-map and seismic data prior to collection of cores and heat flow data. The two surveys ended up being run at the same time, but we were able to coordinate activities at sea by email, radio, and a hard-copy data swap so as to avoid having both ships working too closely together and to take advantage of new discoveries as the surveys progressed.

\section{Methods Swath mapping}

Prior to Expedition 301 site surveys, vessel-based swath coverage of this area was limited mainly to isolated tracks across the ridge flank (by ships heading to/from the active spreading center to the west) and to small areas containing particular features such as basement outcrops. The Ridge Multibeam Synthesis Project (RMBS) compiled data from numerous surveys, but Generic Mapping Tools grid files included only the near-ridge area (ocean-ridge.ldeo.columbia.edu/general/html/home.html). Additional lines of swath data in the Expedition 301 field area were acquired during the 1996 Sonne survey (Rosenberger et al., 2000), but these data had never been merged with the RMBS synthesis.

Bathymetric data collected by the Sonne in 1996 and 2000 were acquired at typical survey speeds of 5.5$7.0 \mathrm{kt}$ while shooting seismic profiles and 10-11 kt during transits between work areas. The hullmounted Hydrosweep DS2 system produces usable data up to two times water depth with a horizontal resolution on the order of $90 \mathrm{~m}$ (at $2700 \mathrm{~m}$ depth and depending on ship's speed and other factors). To suppress refraction effects on the outer beams without knowing the local sound velocity profile, the Hydrosweep system uses a calibration mode to compare depth values of the central and outer beams in order to calculate a mean sound velocity. Using this configuration, residual depth errors are minimized to values $<0.5 \%$ of the water depth, on the order of 5$15 \mathrm{~m}$ for typical water depths in this area (Grant and Schreiber, 1990). 
Because the RetroFlux expedition mainly worked within a few small areas, with the ship held stationary during coring and heat flow operations, the Hydrosweep system on the Thomas G. Thompson was activated only during transits and for a few short, dedicated swath-map surveys run at 7-10 kt. This resulted in the collection of relatively little additional data. Operating parameters and data resolution for RetroFlux bathymetric data are very similar to those described above for the Sonne. Some additional data were collected in the Expedition 301 area during the EW0207 survey, but because these data generally covered areas that had already been surveyed, no attempt was made to include EW0207 multibeam data in the composite grid.

After individual file processing, described below, the data collected during recent Sonne cruises (1996, 2000) and the RetroFlux expedition were combined with raw multibeam files that had previously been used to assemble the RMBS synthesis and additional ridge-flank data archived by researchers with the National Oceanographic and Atmospheric Administration Vents program (A. Bobbitt and C. Fox, pers. comm., 2000-2001). Earlier generations of Seabeam and Hydrosweep data were usually navigated by Loran $\mathrm{C}$ and contained systematic positioning errors, but the quality of bathymetric data was often very high. The earlier data included multiple crossings of several interesting features and helped to define targets for mapping and other work during the RetroFlux and ImageFlux surveys.

Processing of bathymetric data began with the public-domain software package MBsystem (Caress and Chayes, 1996). Navigation was corrected, and hydrosweep data were ping-edited to flag the outer 510 beams for removal and eliminate a variety of artifacts, including abnormal depth values and gradients. Pronounced "rails" (depth-shifts parallel to the ship track) were present in much of the data, and in other places there was an abrupt step, curl-up, or curl-down, typically affecting the outer beams. The rail effect was reduced using a tool developed by $\mathrm{H}$. v. Lom (University of Bremen), and other artifacts were removed by hand-editing individual beams. Some swaths also showed subtle roll bias, which was corrected before file merging. This careful data processing was necessary because most bathymetric structures in the study area (apart from seamounts) and data artifacts have similar bathymetric scales. For typical survey depths of 2200-3700 m, the resulting usable swath width was generally $4-6 \mathrm{~km}$.

Edited data files from the numerous surveys were combined to form a single bathymetric grid. Sound velocity profiles created with the Levitus database (Caress and Chayes, 1996; Levitus, 1982) were as- signed by area to assure consistency in absolute depths determined during different surveys. Data were gridded at various resolutions to evaluate resolution and data quality. We experimented with additional processing to remove artifacts, using bandpass and other filters, but because the bathymetric differences across the field area are generally so small, even modest additional filtering often resulted in a confounding loss of resolution of key features. For this reason, we elected to use a composite, $100 \mathrm{~m}$ grid file that includes minimal filtering beyond that associated with obvious beam artifacts. The composite bathymetric data set provides almost complete coverage of a $8000 \mathrm{~km}^{2}$ region on the eastern flank of the JFR (Fig. F2). Redundancy is particularly high around First Ridge and Second Ridge, where there is also the densest coverage of seismic data, as described below.

\section{Seismic data}

\section{Sonne}

Nearly 500 seismic lines, comprising $>1$ TB of data, were collected as part of the ImageFlux survey. The MCS system operated by the University of Bremen was optimized for high resolution and imaging of sedimentary structures and layers at a fine scale. Three different seismic sources were run at the same time, with results recorded separately along each line: a small-chamber water gun $(0.16 \mathrm{~L} ; 200-1600$ $\mathrm{Hz}$; Sodera), a generator-injector $(\mathrm{GI})$ gun $(2 \times 1.7 \mathrm{~L}$; 30-200 Hz; Sodera), and a GI gun with reduced chamber volume $(2 \times 0.4 \mathrm{~L} ; 100-500 \mathrm{~Hz})$. Guns of larger chamber volume provide greater depth penetration, revealing the larger-scale structural framework within sediments and uppermost basement, whereas guns with smaller chamber volumes provide higher resolution, revealing finer details of the upper 200-300 m of sediment.

The three guns were triggered at time intervals of 10$13 \mathrm{~s}$ (depending on water depth), resulting in a shot distance of $\sim 25-34 \mathrm{~m}$ (depending on ship speed) for the alternating mode operation of each gun type. Using an optimized trigger scheme, shot spacing is the same for each gun type and $>50 \%$ greater than it would be for only a single gun. Recording time was 3 $\mathrm{s}$ for GI gun records (0.25 ms sample rate) and $1.5 \mathrm{~s}$ for water gun records ( $0.125 \mathrm{~ms}$ sample rate), which is sufficiently long to include the sediment/basement interface reflection. Using a $600 \mathrm{~m}$ long Syntron multichannel streamer (plus two $50 \mathrm{~m}$ stretch sections), with 48 recording groups separated by 12.5 $\mathrm{m}$, a common midpoint (CMP) fold of 8-10 was achieved for CMP spacing of $10 \mathrm{~m}$. This provides an excellent compromise between trace density, image quality, and noise reduction. Six remotely controlled 
birds kept the streamer at $3 \mathrm{~m}$ depth $( \pm 0.5 \mathrm{~m})$, and magnetic compass readings allowed for the determination of the position of each streamer group relative to the ship's course, taking variations in streamer geometry into account. Geographic positions of each shot location were provided by closely sampled (1 s) differential Global Positioning System (GPS) recordings, and custom software calculated receiver positions and statics and carried out binning. Standard data processing included editing, bandpass filtering to eliminate low-frequency noise, correction for geometrical spreading, stacking, and time migration. These tasks were completed with the public domain package Seismic Un*x (Stockwell, 1997).

Parasound $4 \mathrm{kHz}$ echo-sounding data were collected on the Sonne during 1996 and 2000 surveys at the same time that MCS data were acquired. The Parasound system is hull-mounted and compensates for heave, pitch, and roll. Footprint size is only $7 \%$ of water depth, diffraction hyperbolas are suppressed, and both lateral and vertical resolutions are significantly higher in comparison to conventional sediment profiling systems. Parasound data provide an extremely high resolution image of the shallowest tens of meters of sediment.

Two aspects of the ImageFlux seismic survey require additional discussion. In the First Ridge region (Figs. F1, F2), an area of $\sim 6.4 \mathrm{~km} \times 2.3 \mathrm{~km}$ was covered by parallel profiles separated by $25 \mathrm{~m}$, including Leg 168 Sites 1030 and 1031 and Expedition 301 alternate Site FR-1. The goal of this exercise was to use closely spaced lines to extract detailed information about the three-dimensional geometry of structures in sediments and basement rocks. The closely spaced lines are oriented west-northwest, in the direction of maximum variation of basement structure. Traces of all two-dimensional (2-D) lines were binned and stacked based on a predefined grid consisting of cells that are $10 \mathrm{~m}$ wide (in the inline direction) and $25 \mathrm{~m}$ long (in the crossline direction). Thus, common-cell sorting was applied rather than CMP sorting, and cell coverage is between 5- and 10-fold. Trace interpolation could be avoided because of the small inline spacing. However, because of the limited crossline dimension of the grid, only a 2-D time migration was applied in the inline direction. Quality control for processing, and a link to the larger seismic grid on the eastern JFR flank, were provided by a number of long crossing lines.

In the Second Ridge area, another grid $(\sim 5.4 \mathrm{~km} \times 3.6$ $\mathrm{km})$ was covered with more widely spaced $(100 \mathrm{~m})$ profiles. This area includes ODP Sites 1026 and 1027 and IODP Site U1301. These profiles were also oriented west-northwest, in the direction of primary structural dip, and were integrated in the larger seis- mic grid covering this area. Although the line spacing is not as close as that in the First Ridge area and, therefore, the data were not processed on a grid, the data provide useful insights concerning basement structure in the vicinity of ODP and IODP drill sites. Groundtruth for GI gun data collected during Sonne cruise SO149 was provided by modeling reflection patterns from Leg 168 core-scale density logs, as described by Zühlsdorff and Spiess (2001).

\section{Maurice Ewing}

MCS data were acquired during the EW0207 cruise across the Deep Ridge area, where two secondary drilling targets are located. These data were collected using a $6 \mathrm{~km}$ long, 480 channel Syntron digital streamer with receiver groups spaced at $12.5 \mathrm{~m}$. Streamer depth and feathering were monitored with a mix of 13 depth-controlling and 11 compassenhanced DigiCourse birds, plus a GPS receiver on the tail buoy. A 10 gun, 49.2 L air gun array was used as the source of acoustic energy with shot-by-distance at a $37.5 \mathrm{~m}$ spacing. Listening time was $10.24 \mathrm{~s}$ with a sampling rate of $2 \mathrm{~ms}$. The recorded signal has a bandwidth ranging from $\sim 2$ to $>100 \mathrm{~Hz}$. The nominal CMP bin spacing is $6.25 \mathrm{~m}$, and the CMP fold is 81.

The prestack processing strategy adopted for the EW0207 MCS data consisted of

- Standard straight-line CMP bin geometry

- F-K and bandpass (2, 7, 100, and $125 \mathrm{~Hz}$ ) filtering to remove the low-frequency cable noise

- Amplitude correction for geometrical spreading

- Surface-consistent minimum phase predictive deconvolution to balance the spectrum and remove short period multiples

- Surface-consistent amplitude correction to correct for anomalous shot and receiver group amplitudes not related to wave propagation

- Trace editing

- Velocity analysis using the velocity spectrum method

- Normal moveout and dip moveout corrections to align signals for stacking

- CMP mute to remove overly stretched data

The prepared prestack data, with and without the automatic gain control, were then stacked. The poststack processing included seafloor mute, primary multiple mute to reduce migration noise, bandpass filtering $(2,7,100$, and $125 \mathrm{~Hz})$, and time migration to collapse diffractions and position the recorded reflection events at their true subsurface locations. 
Extracting an image of the crustal Layer $2 \mathrm{~A}$ event from the EW0207 data requires a somewhat different processing scheme because this event is not a true reflection (Harding et al., 1993). The prestack data preparation is identical up to the velocity analysis, which is done on bandpass-filtered $(2,7,40$, and 60 $\mathrm{Hz}$ ) constant-velocity stacks. When the normal moveout velocities that best flatten the retrograde branch of the Layer $2 \mathrm{~A}$ refraction are chosen, the data traces with source-receiver offsets from 1500 to $4000 \mathrm{~m}$ are stacked. The stacked Layer $2 \mathrm{~A}$ event is time-migrated and coherency-filtered. Surgical mute is used to extract the Layer $2 \mathrm{~A}$ event, which is merged with the reflection section to form a final, composite seismic image.

\section{Heat flow data}

\section{Acquisition}

RetroFlux heat flow transects during the RetroFlux expedition were typically colocated along existing or planned seismic reflection profiles so that we could merge thermal data with sediment thickness and basement structure, as discussed later. Because the ImageFlux and RetroFlux expeditions were at sea at the same time, we did not always have seismic data in hand when heat flow transects were run. In some cases, seismic profiling followed collection of heat flow data; in a few cases, heat flow data were collected even though we knew that we would not have colocated seismic data to use for later analyses.

Multipenetration heat flow data were collected using an 11 thermistor violin-bow heat flow probe with in situ thermal conductivity capability (Davis et al., 1997a). Prior attempts to measure heat flow in the southeastern part of the survey area had been unsuccessful because the heat flow lance would not penetrate sandy or lithified sediments. For the RetroFlux program, we used a conventional weight stand and $3.5 \mathrm{~m}$ outrigger lance (sensor spacing $=30 \mathrm{~cm}$ ), but also brought out a heavier weight stand to be used with a $2.0 \mathrm{~m}$ outrigger lance (sensor spacing $=15$ $\mathrm{cm}$ ). This modified system operated successfully in areas where previous attempts failed, but in some instances, the probe continued to settle episodically during measurement.

Heat flow transects typically consisted of 15-20 individual penetrations spaced $50-500 \mathrm{~m}$ apart, with data collected during a $12-24 \mathrm{~h}$ station. Temperatures of the 11 sediment thermistors, bottom seawater, and logger electronics, plus pressure, tilt, and reference resistance, were logged at $10 \mathrm{~s}$ intervals and stored in nonvolatile memory. A subset of the data was telemetered back to the ship in real time for monitoring of instrument performance. In situ thermal conductivity was determined during $\sim 60 \%$ of the penetrations. For the other stations, we used local thermal conductivity versus depth functions determined from surrounding measurements, as discussed below. Additional thermal conductivity measurements were made with a needle-probe system on gravity and piston cores recovered during the survey.

\section{Processing and uncertainties}

Heat flow data were processed using methods based on those described by Villinger and Davis (1987) and Davis et al. (1997a). Modifications to the approach include

- Use of local thermal conductivity versus depth functions for stations that lacked in situ measurements;

- Iterative processing for these stations, with new conductivity values assigned for each estimate of penetration depth, followed by recalculation of equilibrium temperatures;

- Use of the "scatter" parameter (variance normalized by number of thermistors) (Villinger and Davis, 1987) to guide selection of the number of thermistors used in each heat flow determination; and

- Monte Carlo analysis of all penetrations (100-200 realizations in each ensemble), incorporating uncertainties in thermal conductivity, equilibrium temperatures, and the thickness of layers having different thermal conductivities.

Reported heat flow values are means from the Monte Carlo analyses.

Stein and Fisher (2001) describe the general processing scheme in detail, including estimation of uncertainties, which was implemented after the RetroFlux expedition using a graphically driven program that allowed viewing and editing of individual thermistor records. Interactive thermistor-by-thermistor processing was essential because many measurements included data that did not follow the standard pattern of heating and cooling after probe penetration. These were most common when making measurements in turbidites using the short, heavy probe, and resulted from a combination of probe motion and the extreme frictional heating and high thermal conductivity associated with sandy layers.

Additional uncertainties or systematic errors that were not estimated by Monte Carlo analysis include the effects of sedimentation and instrument tilt. Sedimentation corrections of $15 \%-20 \%$ may be appropriate for individual measurements made where sediments are thickest (e.g., Davis et al., 1999). We did not apply sedimentation corrections because this would make it difficult to compare data collected 
during different surveys unless a sediment thickness estimate accompanies each measurement, and this would not be possible for measurements that are not colocated with seismic data. In addition, we focused our studies on local variations in heat flow, associated mainly with basement relief, that are often larger than the maximum sedimentation correction. Accounting for the thermal influence of sedimentation may be important for assessing the extent to which heat flow values deviate from lithospheric conductive models, as discussed later.

The tilt sensor on one of the heat flow instruments used during the RetroFlux survey failed, but the mean tilt correction for measurements made with a working tilt sensor was $<2 \%$, suggesting that errors are likely to be small for penetrations where there are no tilt data. This is consistent with the very close spacing between most measurements (50-200 m) made during a single lowering of the probe from the ship, which helped to keep the probe hanging vertically immediately prior to penetration into the seafloor.

\section{Estimation of temperatures at depth}

Heat flow data were continued downward to estimated temperatures within the sediment and uppermost basement based on the interpretation that heat transport within the sediment is dominantly vertical and conductive (Davis et al., 1999). Data used for this analysis included seismic profiles, thermal conductivities, core-scale seismic velocities, and sediment thicknesses determined during Leg 168.

Two-way traveltime (TWT) was converted to subseafloor depth using velocity data collected from recovered sediments, adjusted to agree with depth to basement determined during drilling (Davis et al., 1999, 1997). The resulting range in apparent sediment seismic velocities is $1500-1700 \mathrm{~m} / \mathrm{s}$. Separate relations were developed for the western and eastern ends of the Leg 168 drilling transect ( $z$ in meters, $t$ in seconds):

$$
z=817 t+98 t^{2}-81 t^{3}
$$

and

$$
z=937 t-108 t^{2}+187 t^{3},
$$

respectively.

A constant sediment velocity was assumed for sediment thicknesses greater than that encountered during drilling $(\sim 600 \mathrm{~m})$. The greatest uncertainties in calculated depths to basement occur where picking the top of basement from the seismic data is difficult, as is common when the upper basement surface is irregular or steeply inclined or the seismic resolution is otherwise poor.
Uncertainties in estimated temperatures at depth arise from errors in individual heat flow determinations, TWT between the seafloor and uppermost basement picked from seismic profiles, cumulative thermal resistance versus traveltime relations, and the assumption that heat transport within the sediment section is one dimensional (1-D) and vertical (Davis et al., 1999). Heat flow uncertainties came from the Monte Carlo analysis discussed above. We picked upper and lower limits for the seafloor and basement reflectors along each profile, based on clarity in the processed seismic data, and used this range to estimate uncertainties associated with this part of the analysis. The thermal resistance versus traveltime relations are well calibrated in areas where we have drilling data, and we have never found thermal or geochemical evidence from nonconductive heat transport through sediments in this region except where sediments are extremely thin. Total uncertainties in temperatures estimated at the sediment/basement interface and in the location of isotherms at depth within the sediment section are likely to be $\sim 15 \%-25 \%$.

The thermal structure within oceanic basement is less well constrained. Vertical heat flow within upper basement could range from essentially fully conductive to fully advective. One of the goals of Expedition 301 and associated experiments is to determine the extent to which the upper $300-400 \mathrm{~m}$ of basement is isothermal, as a result of vigorous convection, or transports heat conductively. We will not know whether conditions in upper basement are vertically conductive or advective until after data are recovered from temperature sensors deployed at depth within long-term observatories (Fisher et al., 2005). For illustrative purposes, we assume that thermal conditions in uppermost basement are conductive, with an effective thermal conductivity of $1.6 \mathrm{~W} / \mathrm{m} \cdot \mathrm{K}$ (e.g., Becker et al., 1983; Busch et al., 1992; Karato, $1983)$ and a $P$-wave velocity of $4500 \mathrm{~m} / \mathrm{s}$ (e.g., Carlson, 1998; Jacobson, 1992; Rohr, 1994).

Selected heat flow transects are compared to 2-D conductive calculations of heat transport using a finite-element model (Zyvoloski et al., 1996). The grids for these models were created using digitized data from colocated seismic profiles. The goal in creating these models was to determine the extent to which local variability in seafloor heat flow might be attributed to conductive refraction associated with seafloor and basement relief and the contrast in basement and sediment thermal properties. Particularly in locations where there is significant basement relief, the 1-D assumptions associated with downward continuation of near-surface thermal data may be violated and conductive $2-\mathrm{D}$ models provide a 
useful reference to which observations can be compared to assess the potential significance of hydrothermal processes.

\section{Results and discussion}

The discussions that follow refer to several regions that include and extend beyond Leg 168 and Expedition 301 work areas (Figs. F1, F2). Expedition 301 worked mainly in the Second Ridge area, above the same buried basement high where Site 1026 is located. Secondary drilling sites included the First Ridge area, close to Sites 1030 and 1031, and the Deep Ridge area, east of Second Ridge, but these were never occupied during Expedition 301. We also discuss (briefly) data from the Southern outcrop area, located 30-55 km south of the Second Ridge area, and an additional area of bathymetric highs located $\sim 50 \mathrm{~km}$ north of the Second Ridge sites. More extensive presentation and discussion of data from these two areas will appear elsewhere.

\section{Swath mapping}

The regional swath map illustrates several notable features (Fig. F2). The JFR is clearly visible at the western edge of the survey area, with the Cobb Offset near $47^{\circ} 40^{\prime} \mathrm{N}$ being particularly prominent. Much of the seafloor east of the ridge is relatively flat, resulting from a thick accumulation of sediment, but care must be taken in interpreting the regional map because the depth scale emphasizes ridge bathymetry rather than flank bathymetry. Local maps reveal considerably greater detail.

One of the most important goals of swath mapping in this region was to assess whether there were basement outcrops in the survey area in addition to those mapped previously. Outcrops are hydrogeologically important because they provide permeable pathways between basaltic oceanic crust and the overlying ocean, allowing both recharging and discharging fluids to bypass low-permeability sediments (e.g., Davis et al., 1992; Fisher et al., 2003a; Johnson et al., 1993; Villinger et al., 2002). Regional swath coverage (Fig. F2) confirms that the basement outcrops in the Second Ridge area are separated from the next nearest outcrops by tens of kilometers. There remain gaps in swath coverage north of the Second Ridge outcrops, and a few small patches to the west, hopefully to be filled by future surveys.

Grizzly Bare outcrop is the largest outcrop found on this part of the ridge flank, located near the southeastern edge of the survey area (Figs. F2, F3). This feature is $3.5 \mathrm{~km}$ across and rises $450 \mathrm{~m}$ above the surrounding sediment plain. Because regional sedi- ment thickness is $500 \mathrm{~m}$, the total height of the edifice above the basaltic crust is $950 \mathrm{~m}$. The next largest outcrop is Grinnin' Bare outcrop, $33 \mathrm{~km}$ north-northwest of Grizzly Bare outcrop. Unlike Grizzly Bare outcrop, which is symmetric and conical, Grinnin' Bare outcrop appears to have lost about one-fourth of its exposed mass along a steeply dipping failure surface on the eastern side of the edifice. The missing material is not visible at the seafloor and must have been buried by subsequent sedimentation. Grinnin' Bare outcrop is $2 \mathrm{~km}$ across at its widest point and rises $300 \mathrm{~m}$ above the surrounding seafloor and $800 \mathrm{~m}$ above the surrounding basaltic crust.

North-northeast of Grizzly Bare outcrop are the three basement outcrops that originally attracted attention on this ridge flank: Papa Bare outcrop, Mama Bare outcrop, and Baby Bare outcrop (Davis et al., 1992; Mottl et al., 1998; Wheat and Mottl, 1994). These three outcrops are high points along two adjacent, otherwise buried basement ridges, and all are elongate from the south-southwest to the northnortheast, subparallel to the underlying structure of the upper crust and the active spreading center to the west. Papa Bare outcrop is the largest of the three, extending $3 \mathrm{~km}$ in the long dimension, $1.5 \mathrm{~km}$ across the short dimension, and rising $250 \mathrm{~m}$ above the surrounding sediment. Mama Bare and Baby Bare outcrops are located above another basement ridge $\sim 7 \mathrm{~km}$ to the west. Mama Bare outcrop is $8 \mathrm{~km}$ west-southwest of Papa Bare outcrop and is $2.0 \mathrm{~km}$ long and $0.7 \mathrm{~km}$ wide. It rises $150 \mathrm{~m}$ above the surrounding sediments. Baby Bare outcrop is the smallest of the three outcrops- $1.0 \mathrm{~km}$ long, $0.5 \mathrm{~km}$ wide, and rising $70 \mathrm{~m}$ above the surrounding seafloor. Baby Bare outcrop is located $15 \mathrm{~km}$ south of Mama Bare outcrop, and Site 1026 is located about halfway between these two features (Fig. F3). Baby Bare and Mama Bare outcrops are located on crust dated by seafloor magnetic anomalies at $3.5 \mathrm{Ma}$, whereas Papa Bare outcrop is located on 3.8 Ma seafloor (Becker et al., 2000; Wilson, 1993).

The relationship between the Second Ridge outcrops and outcrops to the south is unclear. Grizzly Bare outcrop is located south-southwest of Baby Bare and Mama Bare outcrops, along roughly the same heading as that between the latter outcrops and consistent with the strike of basement topography and magnetic anomalies (Shipboard Scientific Party, 1997a; Wilson, 1993). This suggests that Grizzly Bare, Baby Bare, and Mama Bare outcrops might be located on the same buried abyssal hill. Thermal and chemical data suggest that there is fluid flow in basement between Grizzly Bare and Baby Bare outcrops, perhaps in part because of enhanced basement per- 
meability in the along-strike direction (Fisher et al., 2003a; Wheat et al., 2000). However, seismic lines run between Grizzly Bare and Baby Bare outcrops show that the buried ridge below Baby Bare and Mama Bare outcrops dies out to the south, reappearing immediately north of Grizzly Bare outcrop. In addition, regional marine magnetic anomalies (Wilson, 1993) indicate that Grizzly Bare outcrop may be located on crust that is 100-200 k.y. younger than that below Baby Bare and Mama Bare outcrops. The age of Grizzly Bare outcrop is unknown; Baby Bare outcrop is thought to have formed from an off-axis eruption, being as much as 800 k.y. younger than the crust on which it sits (Becker et al., 2000; Karsten et al., 1998).

Bathymetric data from the Second Ridge area show that the seafloor above the ridge is slightly deeper than nearby areas to the west and east (Fig. F3; deeper blue in color immediately above the buried basement ridge). The seafloor continues to deepen to the south toward Grizzly Bare outcrop (Fig. F3; blue grades to purple). A sediment transport channel is readily apparent east of Grizzly Bare outcrop. Its surface expression is considerably less pronounced to the north, and the channel disappears within the limits of hydrosweep resolution $(\sim 5-10 \mathrm{~m})$ at $\sim 47^{\circ} 30^{\prime} \mathrm{N}$. However, the channel can be traced farther to the north in seismic data (described below).

Bathymetric data from the First Ridge area reveal several notable features (Fig. F4). The seafloor above the largest buried basement high is broadly elevated. Another basement high, which is less pronounced bathymetrically, strikes from northwest to southeast and merges with the first basement high in the south. A local, triangular topographic high indicates where turbidities coming in from the north are trapped between these basement peaks, forming a thick sediment package (e.g., Spiess et al., 2001; Spinelli et al., 2004; Underwood et al., 2005). Small distributary channels are visible on the southwestern edge of this topographic high. There is a bathymetric depression on the western flank of the main basement high associated with the location of a small, buried basement ridge, as revealed by seismic data. The strike of this feature is oblique to the dominant structural trend in the First Ridge area.

There are three prominent bathymetric highs north and northwest of the First Ridge area, at $\sim 48^{\circ}-$ $48^{\circ} 10^{\prime} \mathrm{N}$ (Fig. F4). One is located northeast of the First Ridge area, along the dominant structural trend of the buried basement high, and two others are located to the west, 11-15 km north of the Leg 168 drilling transect. Careful examination of swath data and seismic data indicate that these bathymetric highs are basement outcrops. Two of these features were crossed by seismic lines during the 1996 Sonne survey (Rosenberger et al., 2000). There is at least one additional small bathymetric high that may include areas of basement exposure at $47^{\circ} 47^{\prime} \mathrm{N}$, $128^{\circ} 37^{\prime} \mathrm{W}$. Seismic and heat flow data were collected across this small feature as part of the ImageFlux and RetroFlux surveys, but no data or samples were collected near the outcrops north of the First Ridge area.

In addition to mapping the seafloor around primary and secondary drilling targets at the Second Ridge and First Ridge areas, two additional bathymetric highs were examined $\sim 50 \mathrm{~km}$ north of the Second Ridge area (Figs. F2, F5). These were discovered fortuitously by swath-mapping during a transit by the Sonne in 1996 and were examined in greater detail during the 2000 ImageFlux and RetroFlux expeditions. The smaller feature is elongate southwest to northeast and is known as Zona Bare outcrop. It is 2 $\mathrm{km}$ long, $1 \mathrm{~km}$ wide, and rises 30-40 $\mathrm{m}$ above the surrounding seafloor. The southwestern edge of the outcrop is steeper than the other sides, whereas the top is virtually flat. To the northwest is a larger area of elevated seafloor known as Rattlesnake Ridge. The seafloor here is as much as $100 \mathrm{~m}$ shallower than the surrounding area, but the slopes along the sides of the feature are gentle and there does not seem to be basement exposed. Considerable time was spent coring and collecting heat flow data around these two features during the RetroFlux expedition, but there is only limited seismic coverage in this area; more detailed analysis of these features will be presented elsewhere.

\section{Seismic surveys}

\section{Second Ridge area}

The main seismic grid across the Second Ridge area consists of numerous parallel lines (average length $=$ $\sim 19 \mathrm{~km}$ ) that were oriented across structural strike and are spaced $\sim 2 \mathrm{~km}$ apart (Fig. F6). The area between the southernmost of these lines (GeoB00-192) and the northernmost line (GeoB00-218) extends roughly between $47^{\circ} 40^{\prime} \mathrm{N}$ and $47^{\circ} 52^{\prime} \mathrm{N}$ and includes Papa Bare, Mama Bare, and Baby Bare outcrops. Within a portion of this larger grid, approximately between Leg 168 Hole 1026C and a location $4.6 \mathrm{~km}$ north, line spacing was decreased to $0.5 \mathrm{~km}$ to investigate a buried basement high known as Wuzza Bare subcrop (Fig. F3). A grid of closely spaced profiles was later added in the vicinity of Leg 168 Sites 1026 and 1027 and Site U1301. This grid consists of 26 $100 \mathrm{~m}$ spaced lines $\sim 5.4 \mathrm{~km}$ long. Another set of six parallel lines, spaced $\sim 600 \mathrm{~m}$ apart, was located west of the main grid to study a buried basement high called Isita Bare subcrop (Fig. F3). A small number of seismic lines oriented south-southwest to north- 
northeast were run as well, the most important of which are GeoB00-490, close to drill sites above the peak of the buried basement ridge, and GeoB00-459, connecting Baby Bare and Mama Bare outcrops to newly recognized Zona Bare outcrop.

The main goal of the site survey at Second Ridge was to map basement morphology to allow for a more complete geological interpretation and better selection of locations for IODP drilling. A basement relief map created by interpolation between basement picks from the seismic data shows several parallel buried basement ridges and troughs, one of which connects Baby Bare and Mama Bare outcrops and, possibly, Zona Bare outcrop to the north (Fig. F7B). A more detailed basement map (Fig. F7C) based on the grid of the most closely spaced seismic lines indicates that the ridge in the vicinity of Sites 1026 and U1301 splits into two parts with a small depression in between. Sites 1026 and U1301 are located on the eastern part of the ridge, where basement elevations are greatest. Basement elevations around the drill sites are considerably lower than elevations north and south along the ridge.

Baby Bare and Mama Bare outcrops are volcanic constructions built on top of a ridge-flank abyssal hill (Becker et al., 2000). The northern part of the basement ridge, including Mama Bare outcrop, is 150$200 \mathrm{~m}$ higher in elevation than the shallower part. The peak of the basement ridge plunges toward the south just south of Mama Bare outcrop; the basement slope becomes gentler across Sites 1026 and U1301. Baby Bare outcrop is located at the southern edge of a region characterized by very high basement relief. The expression of the abyssal hill is more subdued south of Baby Bare outcrop. The relatively flat summit and low elevation of the buried basement ridge around Sites 1026 and U1301 suggest that they are located beyond the limits of volcanic construction that created Mama Bare and Baby Bare outcrops (Fig. F3).

The deepest band of coherent reflections in seismic lines across the Second Ridge area mark the sediment/basement interface (Fig. F8). Basement morphology is very similar between Line GeoB00-483, at the northern end of the area of dense coverage on Second Ridge, and Line GeoB00-466, to the southern end of this area, crossing Site U1301 (Figs. F6, F8A, F8B, F8C, F8D, F8E). This consistency is also apparent in the basement relief map (Fig. F7) and in crossing Line GeoB00-490 (Figs. F6, F8F).

The upper part of the sediment section is dominated by a large sediment transport channel, known from drilling experience at Sites 1026, 1027, and U1301 to be filled mainly with sandy turbidites transported from the north (Davis et al., 1997; Underwood et al.,
2005). The channel is defined by prominent seismic reflectors that extend to $\sim 200 \mathrm{~ms}$ below the seafloor above the local basement topographic low (Fig. F8A, F8B, F8C, F8D, F8E). The deepest part of the channel is located approximately halfway between the buried basement ridge upon which Papa Bare outcrop is located and the basement ridge upon which Mama Bare and Baby Bare outcrops and Sites 1026 and U1301 are located. The channel deposits are thinner above the buried basement high around Sites 1026 and U1301, but the channel can be traced 1-2 km west of the buried basement peak (Fig. F8).

Sediments recovered from near the base of these channel deposits at Site 1027, 200 ms below the seafloor, are $\sim 0.28 \mathrm{~m}$.y. old on the basis of microfossil stratigraphy (Shipboard Scientific Party, 1997b; Underwood et al., 2005). The strong correlation between channel geometry and basement relief suggests that the distribution of turbidite sedimentation in the Second Ridge area has been influenced significantly by basement structure. Some influence of basement relief on sedimentation patterns may continue today, as indicated by small variations in bathymetry (Fig. F8). Drilling into these coarse, poorly consolidated sediments is not difficult, but recovery tends to be low when using rotary coring systems. The sediments are easily washed away during drilling and casing operations, which can lead to difficulties in stabilizing reentry cone and casing systems, as experienced during both Leg 168 and Expedition 301.

The deepest part of the sediment column in this area is characterized by lower reflection amplitudes than the upper part, probably due to seismic attenuation and the lack of coarse-grained turbidites within the oldest part of the sediment column (e.g., Shipboard Scientific Party, 1997b; Underwood et al., 2005). Normal growth faults showing upwardly decreasing offsets are commonly observed in seismic images from this area (Fig. F8). The nature of off-axis tectonic activity, and its influence on sediment deformation around Second Ridge, are currently being investigated.

Wuzza Bare subcrop is located southwest of Papa Bare outcrop and is covered by a few tens of meters of sediment, much like Isita Bare subcrop to the west (Figs. F3, F7, F8G). Basement at Wuzza Bare subcrop comes closest to the sediment surface on Line GeoB00-208 (Fig. F8G). On the same line, Parasound data show the most pronounced expression in subsurface reflectivity (Fig. F8G). An acoustic "washout" zone of $\sim 200 \mathrm{~m}$ width is observed $\sim 10 \mathrm{~m}$ below seafloor but does not reach the surface as a coherent unit. A similar feature is observed on parallel line GeoB00-205, $200 \mathrm{~m}$ to the north, but the top of the washout is $10-20 \mathrm{~m}$ deeper. This suggests that the 
center of the anomaly in Parasound reflectivity (and probably the center of the basement high) may be located close to Line GeoB00-208. This interpretation is consistent with heat flow data collected along both of these seismic lines, as discussed later.

A thin veneer of acoustically transparent sediments is seen in Parasound profiles crossing this area (Fig. F8G). At Wuzza Bare subcrop and to the east, this layer may be $<1 \mathrm{~m}$ thick, but it thickens westward to $\sim 2 \mathrm{~m}$ at $1.5 \mathrm{~km}$ distance from the peak of the buried basement high (Fig. F8G). The veneer appears to be thickest within the large sediment transport channel described above, and it may represent the last stage of localized sediment distribution in this area, following nearly complete infilling of the original bathymetric (basement) low.

\section{First Ridge area}

Parallel seismic lines across strike in the First Ridge area cover a region between $47^{\circ} 47^{\prime} \mathrm{N}$ and $47^{\circ} 57^{\prime} \mathrm{N}$, with the closest lines being only $25 \mathrm{~m}$ apart (Figs. F4, F9). Five additional lines were shot along strike, two of them extending to the southern end of First Ridge survey area. The seafloor across the First Ridge area is relatively smooth compared to the rugged basement below (Fig. F10). Although relief is not truly 2-D, structural variations on scales of a few tens of meters (at both the seafloor and at the sediment/basement interface) tend to occur across strike (northwestsoutheast) rather than along strike (northeast-southwest). The data suggest that the First Ridge area can be roughly divided into three parts: northern and southern parts with moderate basement topography (Fig. F10B, F10C, F10D, F10F) and a center part between Site 1030 and a location $~ 800 \mathrm{~m}$ south of Site 1031, where basement is rougher (Fig. F10E). Seismic data in the southern part show a second buried ridge that strikes southeast and eventually merges with main basement high in the south. Turbiditic sediments coming in from the north appear to be trapped between the two ridges, forming a local topographic high (Fig. F10F). The dense grid of seismic profiles, located in the northern part of the First Ridge area, reveals a third buried basement high that is smaller and slightly oblique to the dominant basement trend. The seafloor between the buried ridges shows a linear depression at the western flank of the main basement high (Fig. F10A, F10B, F10C, F10D, F10E).

The area covered by the densest seismic grid can be divided into three smaller parts. At the northern end, the basement high is characterized by a single peak structure (Fig. F10D, F10E). Older sedimentary layers are clearly separated by the basement ridge, whereas the turbidites associated with younger layers can be traced across the ridge. The layers are folded, fractured, or faulted and show vertical offsets above the basement peak. The folding and faulting seen within the sediments in this area are much less pronounced than the folding and faulting found at the southern end of the dense profile grid, where the presence of two buried basement highs results in greater deformation (Fig. F10A).

Layer inclination at the southern edge of the dense seismic grid is larger than that to the north, and vertical offsets of individual horizons are also greater. There is a transition between the northern and southern parts of the dense seismic grid where the basement ridge splits into two parts (Fig. F10B, F10C). The continuity of some layers suggests that overspilling occurs across the basement high (i.e., layers associated with turbidites coming from one side of the ridge thin out on the other side with increasing distance from the ridge). The stratigraphic pattern of turbiditic sedimentation across the buried basement highs is complex and warrants greater study.

Narrow zones of decreased reflection amplitudes (washouts) are observed in many profiles across the First Ridge area (Fig. F10). These washouts are most pronounced in the high-resolution Parasound data but are also present in GI gun data (Zühlsdorff et al., 1999). Mapping on the basis of Parasound data revealed that zones of lower reflectivity form a coherent pattern that can be traced along much of the buried basement high. Comparison of the Parasound and GI gun data further shows that zones of decreased amplitudes are well correlated with local basement peaks or related to pervasive distortion or disruptions of sedimentary layering (Zühlsdorff and Spiess, submitted). As in the Second Ridge area, the correlation on seismic profiles between these distinct sedimentary features and underlying basement relief suggests that there is a strong control of basement structure on sedimentary processes. Other studies have explored possible connections to fluid seepage, local lithologic variability, and postdepositional deformation (Giambalvo et al., 2000; Spinelli et al., 2004; Zühlsdorff and Spiess, 2001, submitted; Zühlsdorff et al., 1999). It is possible that similar patterns in the seismic profiles result from different causes, but the occurrence of these features across a broad geographic area suggest that they may result from common mechanisms. Future studies in this area may address this issue through additional measurements and sampling.

\section{Southern outcrop area}

At the southeastern edge of the survey area, seismic lines approach and cross Grizzly Bare and Grinnin' 
Bare outcrops. These seismic lines are 37-56 km long and separated by $6-11 \mathrm{~km}$. In addition to parallel lines oriented across strike, two long crossing lines were run, forming a large triangle with Grizzly Bare outcrop at the apex to the south and Grinnin' Bare outcrop at the northwestern corner (Figs. F2, F3). As a result, both outcrops were covered by at least three crossing lines. No Expedition 301 drilling was planned in the Southern outcrop area, so we discuss only general mapping and seismic results in this area. Part of one seismic line is shown in the discussion of heat flow results.

Grizzly Bare outcrop is circular in plan view from its base $\sim 500 \mathrm{~m}$ below the sediment surface and up to its summit. This seamount rises $>600 \mathrm{~ms}$ TWT $(\sim 450$ $\mathrm{m})$ above the surrounding sediments. Significant reflection energy is observed on top of Grizzly Bare outcrop in Parasound data, and there may be a thin cap of hemipelagic or pelagic sediment, as seen above Baby Bare outcrop to the north (Becker et al., 2000).

Two large sediment transport channels are observed at the seafloor in this area, a narrower one passing east of Grizzly Bare outcrop (clearly visible on Fig. F3) and a broader one passing between Grizzly Bare and Grinnin' Bare outcrops and trending to the southwest. Both of these channels may extend from far to the north across the survey area, based on correlations between adjacent seismic profiles. The easternmost channel has a more pronounced seafloor expression south of $47^{\circ} 30^{\prime} \mathrm{N}$ and appears to be the southward continuation of the large filled channel observed at Second Ridge that passes across Site 1027 (Figs. F3, F8). The westernmost channel may pass west of the Second Ridge area, explaining why it is not observed in seismic lines from that region.

\section{Deep Ridge area}

Seismic reflection images formed by processing MCS data collected on the EW0207 expedition were used to select locations for the Deep Ridge sites, 110-140 $\mathrm{km}$ east of the active spreading center (Figs. F2, F11). Both Deep Ridge sites are located on basement highs to minimize drilling time to basement and because basement highs in this region tend to be overpressured and thus may eventually provide good basement fluid and microbiological samples once thick sediments are penetrated.

The thickness of the sedimentary cover in the Deep Ridge area varies from 750 to $>1000 \mathrm{~m}$ (Fig. F11). A series of small-throw normal faults are imaged within the sediment section, possibly indicating differential compaction or recent tectonic activity outside the axial region. Fault offsets gradually diminish upsection with sediment age, from older to younger, possibly suggesting growth faulting caused by longterm slip within basement. The interface between the sediments and igneous basement has the strongest acoustic impedance, although this is not always evident in the reflection image because of the applied automatic gain control and because, where the basement topography is rough, much of the acoustic energy is scattered and not returned. A Layer 2A event, found $\sim 200 \mathrm{~ms}$ below the top of the igneous basement, is imaged across part of this area. Based on estimates of upper crustal $P$-wave velocities from wireline logs at Site U1301 during Expedition 301, this event corresponds to a subbasement depth of $\sim 500 \mathrm{~m}$, roughly consistent with earlier interpretations based on regional MCS data (Rohr, 1994).

\section{Heat flow data}

\section{Regional values and references for subsequent analyses}

Researchers have made $\sim 1700$ multipenetration heat flow measurements on 0.1-5.0 Ma seafloor on the eastern flank of the JFR since 1978, with most of these measurements colocated along seismic reflection profiles (Fig. F2). The 2000 RetroFlux program included acquisition of 437 heat flow values. All of the multipenetration measurements made in this region suggest that conditions within shallow sediments are dominantly conductive. Submersible measurements made on Baby Bare outcrop (Becker et al., 2000; Wheat et al., 2004) are excluded from the totals cited above, and from the following presentation and discussion, because those measurements are influenced strongly by local patterns of fluid and heat transport associated with the basaltic edifice.

Measurements made away from the hydrothermal influence of outcrops and basement relief allow assessment of the "background" thermal state of the upper oceanic crust. Standard lithospheric cooling models generally give a (time) $)^{-1 / 2}$ relationship between heat flow and plate age (e.g., Davis and Lister, 1974; Parsons and Sclater, 1977; Stein and Stein, 1994). These models were calibrated mainly using bathymetric data and secondarily using thermal data; thermal data from young seafloor were excluded because of the confounding influence of hydrothermal circulation. Global data compilations tend to exhibit considerable variability, particularly at young ages, and this is generally attributed to hydrothermal circulation. Circulation can advectively mine heat from the crust but can also redistribute heat locally in basement even if there is little or no advective heat loss. The $\sim 1700$ heat flow measurements presented in this compilation are not uniformly distributed (Figs. F2, F3, F4, F5); most data have been collected near features of hydrogeologic 
interest, including areas close to buried and exposed basement highs. Given this bias, it is not possible to determine unambiguously either the lithospheric heat input across this ridge flank or the magnitude of local and regional anomalies associated with advection. Nevertheless, this young, heavily sedimented ridge flank has the greatest density of highquality multipenetration heat flow measurements in the world, and it is worth considering what the data may indicate about both regional heat input and the extent of thermal anomalies.

A histogram of multipenetration heat flow measurements across this area, including seafloor aged 0.15.0 Ma, shows what appears to be a Poisson distribution, with a mode at $200 \mathrm{~mW} / \mathrm{m}^{2}$ and a long tail extending to values $\sim 4 \mathrm{~W} / \mathrm{m}^{2}$ (Fig. F12A). The highest values are associated with local basement highs, some of which are buried and some of which penetrate the sediment as outcrops, and the lowest values are generally found close to areas having extensive basement exposure, where fluid recharge is thought to occur (e.g., Davis et al., 1992; Fisher et al., 2003a; Wheat and Mottl, 1994).

Davis et al. (1999) showed a long transect of seismic data and calculated heat flow across this ridge flank, extending from 20 to $100 \mathrm{~km}$ east of the spreading center and passing through or near Leg 168 drilling sites. Observed and calculated heat flow rises rapidly from west to east along the western $20 \mathrm{~km}$ of this transect, across a hydrothermal transition (HT) area (Fig. F4), where thermal conditions respond to increasing sediment thickness and associated hydrogeologic isolation of the basement aquifer. Despite considerable local variability, the rest of the calculated heat flow profile tends to follow standard lithospheric cooling curves. The calculated heat flow at the eastern end of the transect, across Sites 1026 and 1027 , varies locally as a function of depth to basement but is typically $\sim 250-260 \mathrm{~mW} / \mathrm{m}^{2}$ after correcting for sedimentation effects (fig. 10 from Davis et al., 1999).

The current compilation allows examination of heat flow north and south of the Leg 168 transect. We focused this effort on the Second Ridge area, where there is the greatest distribution of high-quality, colocated heat flow and seismic data across similarly aged seafloor. There are distinct, local thermal anomalies associated with both discharging and recharging outcrops in this area (e.g., Davis et al., 1992; Fisher et al., 2003a; Thomson et al., 1995; Wheat et al., 2004), but their influences appear to extend only a few kilometers from individual basement features.

In order to determine the background heat flow for this part of the ridge flank, we examined measurements on $3.5 \pm 0.1$ Ma seafloor and hand-filtered the data to exclude all values that are (1) not colocated with seismic data that image basement or (2) located within $2 \mathrm{~km}$ of significant basement relief, including outcrops. The remaining 300 values come from locations extending across nearly $60 \mathrm{~km}$ from north of Mama Bare outcrop to just north of Grizzly Bare outcrop (Fig. F3). The filtered data show a remarkably narrow Gaussian distribution (Fig. F12B), as might be expected if variations in heat flow result mainly from conductive refraction and local redistribution of heat by hydrothermal circulation. The mean of the filtered values is $181 \pm 16 \mathrm{~mW} / \mathrm{m}^{2}$.

Even if one assumes the lowest standard lithospheric reference of $477 \times$ (age) $^{-1 / 2}$ (Parsons and Sclater, 1977), a value of $251-259 \mathrm{~mW} / \mathrm{m}^{2}$ is predicted for $3.5 \pm 0.1$ Ma seafloor and other reference curves suggest lithospheric values as great as $277 \mathrm{~mW} / \mathrm{m}^{2}$ (e.g., Stein and Stein, 1994). The typical sediment thickness associated with the 300 filtered values is 500 $600 \mathrm{~ms}$, equivalent to $450-550 \mathrm{~m}$, requiring a sedimentation correction of $15 \%-16 \%$ (Davis et al., 1999), but this correction brings the filtered mean up to only $\sim 215 \mathrm{~mW} / \mathrm{m}^{2}$, a deviation from the reference curves of $15 \%-20 \%$. This result differs from that determined across Sites 1026 and 1027 by Davis et al. (1999); the present analysis suggests that the transect across Sites 1026 and 1027 is somewhat "warmer" than most of the seafloor having a similar age in this area.

The discrepancy between the filtered, sediment-corrected, mean heat flow on $3.5 \pm 0.1$ Ma seafloor in this area $\left(\sim 215 \mathrm{~mW} / \mathrm{m}^{2}\right)$ and that predicted by standard lithospheric cooling models ( 250-280 mW/ $\mathrm{m}^{2}$ ) is greater than uncertainties associated with either the heat flow measurements or with sedimentation or other reasonable corrections. There are several possible explanations, none of which is completely satisfying. One possibility is that the lithospheric cooling curve appropriate for $3.5 \pm 0.1$ Ma seafloor on this ridge flank falls below standard global models by $15 \%-20 \%$. Although we might not be surprised to find regional differences in lithospheric cooling trends (and this might help to explain some of the variability seen in global compilations), the possibility of sampling bias or advective heat loss from basement cannot be dismissed.

A second explanation is that the filtered values do not represent mean conductive conditions but show the influence of $\sim 15 \%-20 \%$ advective heat loss. The problem with this explanation is that there are very few basement outcrops in this area, and driving forces are much too small to move significant fluxes of crustal fluid through thick sediments overlying basement (e.g., Fisher et al., 2003a; Giambalvo et al., 2000; Spinelli et al., 2004; Wheat and Mottl, 1994). 
Examination of thermal transects near both recharging and discharging basement outcrops show that typical upper basement temperatures are $\sim 65^{\circ} \mathrm{C}$ within a few kilometers of the outcrops. It is this basement temperature and the typical sediment thickness, accumulation rate, and properties in the area that define the characteristic heat flow of $\sim 180$ $\mathrm{mW} / \mathrm{m}^{2}$. The total heat output of Baby Bare outcrop is 1-3 MW (Mottl et al., 1998; Thomson et al., 1995; Wheat et al., 2004); this much heat could be accounted for by suppressing seafloor heat flow by 40 $\mathrm{mW} / \mathrm{m}^{2}$ to a radial distance of $4-5 \mathrm{~km}$ from the outcrop, but low values extend far beyond this distance.

Other areas where seafloor heat flow is suppressed by $15 \%-20 \%$ as a result of lateral advection in basement (requiring fluid flow rates on the order of meters per year or more) typically show spatial trends related to patterns of fluid flow: lower values are found in areas of recharge (or deepening basement) and higher values are found in areas of discharge (or shoaling basement) (e.g., Davis et al., 1999; Fisher et al., 2003b; Langseth and Herman, 1981). In the filtered data set from this area, there is no spatial trend to the data. If the observed mean of $\sim 180 \mathrm{~mW} / \mathrm{m}^{2}$ results from advective extraction of heat from basement, this would have to occur through a mechanism that extracts heat remarkably evenly at distances $\geq 10 \mathrm{~km}$ from points of recharge or discharge.

A final explanation for the low background heat flow value is that there is a bias in data locations toward lower values. If anything, there is a bias in measurements toward higher values because basement highs are common targets within the survey area and isothermality of shallow basement tends to increase heat flow above these features. The data set was filtered specifically to avoid areas having significant basement topography, either local highs or lows. We expanded the filter to exclude additional areas within $4 \mathrm{~km}$ of the nearest basement high, reducing the number of filtered measurements to 70 , and calculated essentially the same result. Even areas that are $10 \mathrm{~km}$ from the nearest known basement high are consistent with a background value of $\sim 180$ $\mathrm{mW} / \mathrm{m}^{2}$, sedimentation corrected to $\sim 215 \mathrm{~mW} / \mathrm{m}^{2}$. It will be challenging to resolve this conundrum given the available data because one must assume a reference in order to quantify the magnitude of a thermal anomaly. It would be ideal to collect additional thermal data from 3.4-3.6 Ma seafloor in this region at locations tens of kilometers from outcrops-for example between the Second Ridge area and the southern outcrops (Fig. F3), where there are high-quality seismic data and little basement relief.

For the purposes of subsequent analyses in the Second Ridge area, we use a background heat flow value of $180 \mathrm{~mW} / \mathrm{m}^{2}$ as a boundary condition at the base of finite-element models. For the First Ridge and other areas closer to the active spreading center to the west, we use a conventional lithospheric cooling curve having the form

$$
\mathrm{q}\left(\mathrm{mW} / \mathrm{m}^{2}\right)=500 \times[\text { age }]^{-1 / 2}(\mathrm{Ma}) .
$$

This is justified in younger areas where deviations from lithospheric cooling curves are large; rebound from cooling at the ridge may be incomplete (e.g., Fisher, 2003), and crustal heat extraction is clearly dominated by advection. Because they are so clearly influenced by advective heat loss, it is unlikely that observations from these younger areas will ever be used to constrain lithospheric cooling curves.

\section{Example heat flow profiles}

In this section, we show examples of colocated heat flow and seismic profiles that illustrate characteristics typical of several environments on this ridge flank, beginning with the near-axis area and then moving to older sites. In each of the associated figures, we show three panels. The top panel shows measured heat flow and values calculated using conductive, 2-D numerical models based on the geometries and crustal properties indicated by survey and drilling data. Because these models do not include hydrothermal circulation, differences between basal heat input and output at the seafloor result entirely from conductive refraction as a result of basement and seafloor relief and variations in thermal properties. This approach is conceptually similar to that used by Davis et al. (1999), except that it takes into account 2-D (nonvertical) heat conduction and uses a heat flow (rather than constant temperature) lower boundary condition. The middle panels show uppermost basement temperatures calculated by downward continuation of seafloor heat flow values, assuming dominantly vertical heat conduction. These calculations include uncertainty bars based on the accumulation of potential errors, as discussed earlier. Upper basement temperatures calculated with the 2$\mathrm{D}$ conductive models are also shown. The lower panels are displays of seismic data used to generate the other parts of the figures, with superimposed isotherms.

Three profiles illustrate characteristic features on 0.1-1.5 Ma seafloor close to the active spreading center, from north to south across the HT and First Ridge areas (profile locations are shown in Fig. F4). Figure F13 shows heat flow along seismic Line 950802g in the northern HT area. Basement is generally flat below $\sim 180 \mathrm{~m}$ of sediment, and seafloor elevation varies by $<10-20 \mathrm{~m}$. Heat flow is $202-240$ $\mathrm{mW} / \mathrm{m}^{2}, \sim 50 \%$ of that predicted by standard litho- 
spheric cooling models. Extrapolated temperatures along the sediment/basement interface remain uniform at $32^{\circ}-38^{\circ} \mathrm{C}$. This segment of data is typical of locations where the seafloor is flat and there is little buried basement relief; regional heat flow suppression results from rapid lateral fluid flow in basement (e.g., Davis et al., 1992, 1999; Stein and Fisher, 2003).

Figure F14 shows a $23 \mathrm{~km}$ long profile extending from the edge of basement exposure west of the HT area to several kilometers east of the First Ridge area. Similar profiles were shown in earlier studies, illustrating how crust in this area warms with increasing age (e.g., Davis et al., 1992, 1997); we show this example because it allows comparison of earlier and newly acquired seismic data. Measured heat flow increases systematically along the transect, from $\sim 100$ $\mathrm{mW} / \mathrm{m}^{2}$ near the edge of basement exposure to $>600$ $\mathrm{mW} / \mathrm{m}^{2}$ above the first buried basement ridge, and upper basement temperatures increase systematically from $<10^{\circ}$ to $\sim 45^{\circ} \mathrm{C}$. Heat flow is suppressed by $>80 \%$ relative to lithospheric predictions near the exposed basement in the west but achieves predicted values where basement shoals. Basement isotherms at the western end of the transect are strongly depressed. A local $\sim 50 \mathrm{~mW} / \mathrm{m}^{2}$ increase in heat flow west of common depth point (CDP) 175, Line 950804e (Fig. F14, immediately adjacent to the area of exposed basalt) may result in part from thermal refraction associated with basement and seafloor relief and in part from the thinning of the conductive sediment layer as locally isothermal basement rises to the seafloor (Fig. F14A).

Heat flow values across the First Ridge area along this transect are locally variable, but on average, they are consistent with lithospheric cooling models. Basement temperatures remain essentially isothermal at $45^{\circ} \mathrm{C}$ across most of seismic Line GeoB00-252 (Fig. F14B). This uniformity in upper basement temperatures, despite differences in basement elevation of $100 \mathrm{~m}$, is consistent with vigorous, local hydrothermal circulation in basement.

Figure F15 shows heat flow measurements colocated along seismic Line GeoB00-240 crossing the eastern part of the HT and First Ridge areas. Measured seafloor heat flow across the HT area is generally $~ 320$ $\mathrm{mW} / \mathrm{m}^{2}$, well below the lithospheric prediction, but rises abruptly above the buried basement high to $>800 \mathrm{~mW} / \mathrm{m}^{2}$. Upper basement temperatures remain remarkably uniform at $\sim 25^{\circ} \mathrm{C}$ across the entire profile. These values are somewhat lower than those seen along Line GeoB00-252 to the north (Figs. F4, F14B), largely because the sediment cover becomes thinner to the south. Basement temperatures near the eastern end of the transect are also somewhat greater than calculated numerically with a 2-D conductive model, suggesting that heat is redistributed locally by fluid circulation in basement.

Three additional heat flow and seismic transects illustrate characteristic conditions in the Second Ridge area (profile locations shown in Fig. F3). Heat flow data are colocated along seismic Line GeoB00-194, south of Baby Bare outcrop and Site U1301 (Fig. F16). The seafloor in this region is generally flat, but basement elevation varies by hundreds of meters. Sediment thins to $\sim 280-300 \mathrm{~m}$ above the $\sim 1500 \mathrm{~m}$ wide basement peak along Line GeoB00-194 (between CDP 675 and 825; Fig. F16), and basement continues to shoal toward the north, eventually emerging as Baby Bare outcrop $4.5 \mathrm{~km}$ away. Seafloor heat flow varies between 150 and $280 \mathrm{~mW} / \mathrm{m}^{2}$ along this profile, with higher values corresponding to measurements made directly above the basement high. Upper basement temperatures are projected to dip slightly over the peak of the basement high but are generally near $60^{\circ}-70^{\circ} \mathrm{C}$ despite significant differences in basement elevation. Upper basement temperatures are $\sim 20^{\circ} \mathrm{C}$ warmer than predicted on the basis of conductive models, assuming a background heat flow for this area of $180 \mathrm{~mW} / \mathrm{m}^{2}$. As described in earlier studies, the homogeneity in basement temperatures in this area, which would vary by $\sim 50^{\circ} \mathrm{C}$ if heat flow were entirely conductive, requires vigorous local hydrothermal circulation (e.g., Davis and Becker, 2004; Davis et al., 1997b; Spinelli et al., 2004).

Seismic Line 92-1 (Becker et al., 2000) crosses Second Ridge $\sim 3 \mathrm{~km}$ north of Baby Bare outcrop and $2 \mathrm{~km}$ south of Site U1301 (Figs. F3, F17). As along Line GeoB00-194 $7.5 \mathrm{~km}$ to the south, heat flow is elevated immediately above the buried basement high, but once again calculated temperatures in uppermost basement are consistent at $\sim 60^{\circ}-70^{\circ} \mathrm{C}$. This profile shows heat flow returning to a background value of $\sim 180 \mathrm{~mW} / \mathrm{m}^{2}$ within several kilometers of the main basement high.

Seismic Lines Geob00-205 and 208 pass across the Wuzza Bare subcrop, a former basement outcrop that is presently buried $\sim 5 \mathrm{~km}$ north-northeast of Site U1301 (Figs. F3, F7, F18). This buried basement high is not directly associated with abyssal hill topography like Baby Bare or Mama Bare outcrops but appears to be a more isolated volcanic edifice (Fig. F7). Wuzza Bare subcrop rises $>450 \mathrm{~m}$ above surrounding basement to within $\sim 40-50 \mathrm{~m}$ of the seafloor, perhaps closer because the nearest seismic line does not necessarily pass immediately above the buried summit. Seafloor heat flow increases above Wuzza Bare subcrop, from $\sim 150$ to $>2500 \mathrm{~mW} / \mathrm{m}^{2}$ along Line GeoB00-208. Values are somewhat lower along Line 
GeoB00-205, 200 $\mathrm{m}$ to the north. Making heat flow measurements in this area was challenging because coarse-grained turbidites and debris flow deposits near the seafloor made penetration difficult and led to uneven frictional heating and cooling of thermistors in the heat flow probe. In addition, picking the depth of basement from seismic profiles is challenging across Wuzza Bare subcrop because the sediment/basement interface is steeply sloping and sometimes indistinct. As a result, uncertainties in seafloor heat flow and upper basement temperatures along this transect are greater than those on most other parts of the ridge flank (Fig. F18). Estimated basement temperatures are generally $50^{\circ}-100^{\circ} \mathrm{C}$ along Line GeoB00-208. Estimated temperatures are lower along Line GeoB00-205, but this must result, at least in part, from the 1-D and 2-D assumptions inherent in these calculations and from the seismic line not crossing the buried summit.

A final example of seismic and thermal data illustrates extreme conditions that develop near relatively isolated basement outcrops in locations where hydrothermal fluids recharge and discharge (Fig. F19). Baby Bare and Grizzly Bare outcrops are located $52 \mathrm{~km}$ apart and both are surrounded by flat seafloor below which there is $500-600 \mathrm{~m}$ of sediment. Fluids exiting from Baby Bare outcrop are known to be very young, despite being highly altered, and geochemical considerations preclude the possibility that these fluids recharged through nearby sediment or basement rocks (Mottl et al., 1998; Wheat et al., 2000; Wheat and Mottl, 2000). Instead, recharge of fluids that eventually exit through Baby Bare outcrop is thought to occur through Grizzly Bare outcrop (Fisher et al., 2003a). Thermal surveys of these outcrops show strongly contrasting conditions in basement: temperature contours are swept upward by venting fluids at Baby Bare outcrop, but are swept downward by recharging fluids at Grizzly Bare outcrop (Fig. F19). The thermal influence of both recharging and discharging outcrops appears to extend only a few kilometers from the limit of basement exposure. Considering the forces available to drive recharge, discharge, and transport between the two outcrops (the difference in fluid pressure at the base of recharging and discharging columns of fluid) and the volume flux of fluid exiting Baby Bare outcrop (Mottl et al., 1998; Thomson et al., 1995; Wheat et al., 2004), the bulk permeability of the basement rocks along the flow path must be on the order of $10^{-12}$ to $10^{-9} \mathrm{~m}^{2}$ (Fisher et al., 2003a). These values are consistent with independent estimates made from packer and open hole thermal tests and results of numerical models of coupled heat and fluid flow in basement (e.g., Becker and Davis, 2003; Becker and Fisher, 2000; Davis et al., 1997b; Fisher et al., 1997; Spinelli and Fisher, 2004).

\section{Summary and conclusions}

Several decades of mapping, seismic, and heat flow expeditions have made the eastern flank of the JFR one of the best-surveyed hydrothermally active regions in the world. This ridge flank provides numerous "type examples" of coupled fluid-heat processes within the oceanic crust and provides a useful reference to which other ridge flanks can be compared. Geophysical surveys have helped to identify numerous characteristic features and have facilitated planning for drilling operations to explore the nature, dynamics, and influence of fluid flow through upper oceanic crust. However, despite considerable effort, there remain important open questions regarding sediment deposition and modification processes; the scales, patterns, and rates of fluid circulation in basement; and magnitudes of lithospheric and advective heat loss in this region, all of which could be addressed with a modest amount of additional sediment sampling and geophysical data acquisition.

Swath mapping of this ridge flank illustrates how thick accumulations of turbidites and hemipelagic sediment blanket the seafloor across long distances, reducing the locations where basement is exposed directly to the ocean. The relative scarcity of basement outcrops on sites older than $\sim 1.5 \mathrm{Ma}$ has benefited several studies of ridge-flank circulation because it makes it possible to resolve first-order flow paths and flow rates between sites of fluid recharge and discharge. However, the specific roles of individual outcrops in extracting lithospheric heat in this area remain to be quantified, as do the crustal properties required to allow these outcrops to serve as efficient crustal ventilators. Several outcrops are good candidates for future work to assess the significance of these features to local and regional hydrogeologic conditions, including newly mapped features.

Seismic coverage across this region has been essential for determining sediment thickness and basement geometry, understanding relations between seafloor outcrops and underlying basement structure, and planning and interpreting thermal surveys. Seismic data have also allowed investigation of numerous sedimentary processes, particularly the influence of basement relief on sediment deposition and subsequent modification. High-resolution seismic data have helped to map out abrupt contrasts in sediment properties, many of which are associated with basement highs and fluid seepage at the seafloor, and 
provided information about relations with faulting (in sediments and basement), folding, and associated porosity anomalies.

Key issues to be addressed in future studies include the distribution of individual sedimentary units, many of which can be tracked across lateral distances of kilometers, and the influence of basement tectonics on reflector structure, sediment physical properties, and thermally driven fluid upflow. It will be particularly helpful to resolve first-order relations between the occurrence of acoustic washouts, basement relief, local and regional variability in sedimentary deposition, and deformation and fluid seepage. These features are known to occur in many ridgeflank settings, and their relations and significance remain to be delineated. In the First Ridge and Second Ridge areas, where ODP and IODP sites are located, further integration of seismic and borehole data will improve interpretations of stratigraphy and the spatial distribution and seismic signature of key reflectors.

Heat flow data collected in this region help to define several thermal and hydrologic regimes. The homogenization of upper basement temperatures in these areas, as a result of vigorous circulation in basement, can result in extreme variations in conductive heat flow even where the seafloor is relatively flat. For this reason, it is essential that heat flow and seismic data be colocated if thermal measurements are to be interpreted with confidence. Where sediment is absent or relatively patchy close to the active spreading center, heat flow is strongly suppressed. Open exchange of hydrothermal fluids in these areas serves to advect much of the lithospheric heat from the crust. In addition, local convection in basement may result in redistribution of heat flow at the seafloor; this process is most apparent in areas of buried basement relief.

Farther to the east, where sediment cover is nearly complete, seafloor heat flow patterns are dominated by a combination of lithospheric cooling and local advective redistribution. Heat flow in areas that are within a few kilometers of basement outcrops may also be influenced by hydrothermal discharge and recharge, resulting in seafloor heat flow being elevated or depressed, respectively. Unfortunately, it is not possible to determine with confidence the extent of a regional heat flow anomaly in this area because it is not clear what conductive reference should be used. An analysis of data that are thought to be far enough from areas of basement exposure and significant buried relief suggests that "background" heat flow in this area could be lower than predicted by standard lithospheric cooling models. An alternative explanation is that this apparent anomaly results from biases in sampling or data filtering. Resolution of this conundrum may result from a few carefully positioned heat flow profiles along existing seismic lines across relatively flat basement, tens of kilometers from the nearest outcrops. Additional modeling will also help us to understand what observed physical conditions mean for the hydrogeologic and thermal properties of oceanic crust, as well as the nature of hydrothermal processes within extensive basement aquifers.

\section{Acknowledgments}

The 2000 RetroFlux (TN116) and ImageFlux (SO149) expeditions, as well as the 2002 expedition EW0207, were highly successful operationally and scientifically thanks in large part to the skill and dedication of the ships' officers, crew, and technical support staff. This research was supported by the German Ministry of Science and Technology (BMBF) grant KZ G0149A (LZ, VS, and HV), National Science Foundation (NSF) grant OCE98-19242, IGPP/LANL project 1317, and U.S. Science Support Program (USSSP) projects T301A7 and T301B7 (AF), and NSF grant OCE00-02488 (MN and SC).

\section{References}

Becker, K., and Davis, E.E., 2003. New evidence for age variation and scale effects of permeabilities of young oceanic crust from borehole thermal and pressure measurements. Earth. Planet. Sci. Lett., 210(3-4):499-508. doi:10.1016/S0012-821X(03)00160-2

Becker, K., and Fisher, A.T., 2000. Permeability of upper oceanic basement on the eastern flank of the Juan de Fuca Ridge determined with drill-string packer experiments. J. Geophys. Res., 105:897-912. doi:10.1029/ 1999JB900250

Becker, K., Langseth, M.G., Von Herzen, R.P., and Anderson, R.N., 1983. Deep crustal geothermal measurements, Hole 504B, Costa Rica Rift. J. Geophys. Res., 88:3447-3457.

Becker, N.C., Wheat, C.G., Mottl, M.J., Karsten, J.L., and Davis, E.E., 2000. A geological and geophysical investigation of Baby Bare, locus of a ridge flank hydrothermal system in the Cascadia Basin. J. Geophys. Res., 105:23557-23568. doi:10.1029/2000JB900204

Busch, W.H., Castillo, P.R., Floyd, P.A., and Cameron, G., 1992. Effects of alteration of physical properties of basalts from the Pigafetta and East Mariana basins. In Larson, R.L., Lancelot, Y., et al., Proc. ODP, Sci. Results, 129: College Station, TX (Ocean Drilling Program), 485499.

Caress, D.W., and Chayes, D.N., 1996. Improved processing of Hydrosweep DS mutlibeam data on the R/V Maurice Ewing. Mar. Geophys. Res., 18:631-650. doi:10.1007/ BF00313878 
Carlson, R.L., 1998. Seismic velocities in the uppermost oceanic crust: age dependence and the fate of Layer $2 \mathrm{~A}$. J. Geophys. Res., 103(B4):7069-7077. doi:10.1029/ 97JB03577

Davis, E.E., and Becker, K., 2004. Observations of temperature and pressure: constraints on ocean crustal hydrologic state, properties, and flow. In Davis, E.E., and Elderfield, H. (Eds.), Hydrogeology of the Oceanic Lithosphere: Cambridge, UK (Cambridge Univ. Press), 225271.

Davis, E.E., Chapman, D.S., Mottl, M.J., Bentkowski, W.J., Dadey, K., Forster, C., Harris, R., Nagihara, S., Rohr, K., Wheat, G., and Whiticar, M., 1992. FlankFlux: an experiment to study the nature of hydrothermal circulation in young oceanic crust. Can. J. Earth Sci., 29:925-952.

Davis, E.E., Chapman, D.S., Villinger, H., Robinson, S., Grigel, J., Rosenberger, A., and Pribnow, D., 1997a. Seafloor heat flow on the eastern flank of the Juan de Fuca Ridge: data from "FlankFlux" studies through 1995. In Davis, E.E., Fisher, A.T., Firth, J.V., et al., Proc. ODP, Init. Repts., 168: College Station, TX (Ocean Drilling Program), 23-33.

Davis, E.E., Chapman, D.S., Wang, K., Villinger, H., Fisher, A.T., Robinson, S.W., Grigel, J., Pribnow, D., Stein, J., and Becker, K., 1999. Regional heat-flow variations across the sedimented Juan de Fuca Ridge eastern flank: constraints on lithospheric cooling and lateral hydrothermal heat transport. J. Geophys. Res., 104:1767517688. doi:10.1029/1999JB900124

Davis, E.E., and Currie, R.G., 1993. Geophysical observations of the northern Juan de Fuca Ridge system: lessons in sea-floor spreading. Can. J. Earth Sci., 30:278-300.

Davis, E.E., Fisher, A.T., Firth, J.V., et al., 1997. Proc. ODP, Init. Repts., 168: College Station, TX (Ocean Drilling Program).

Davis, E.E., and Lister, C.R.B., 1974. Fundamentals of ridge crest topography. Earth Planet. Sci. Lett., 21:405-413. doi:10.1016/0012-821X(74)90180-0

Davis, E.E., Wang, K., He, J., Chapman, D.S., Villinger, H., and Rosenberger, A., 1997b. An unequivocal case for high Nusselt number hydrothermal convection in sediment-buried igneous oceanic crust. Earth Planet. Sci. Lett., 146(1-2):137-150. doi:10.1016/S0012821X(96)00212-9

Fisher, A.T., 2003. Geophysical constraints on hydrothermal circulation: observations and models. In Halbach, P., Tunnicliffe, V., and Hein, J. (Eds.), Energy and Mass Transfer in Submarine Hydrothermal Systems: Berlin (Dahlem Univ. Press), 29-52.

Fisher, A.T., Becker, K., and Davis, E.E., 1997. The permeability of young oceanic crust east of Juan de Fuca Ridge determined using borehole thermal measurements. Geophys. Res. Lett., 24(11):1311-1314. doi:10.1029/ 97GL01286

Fisher, A.T., Davis, E.E., Hutnak, M., Spiess, V., Zühlsdorff, L., Cherkaoui, A., Christiansen, L., Edwards, K.M., MacDonald, R., Villinger, H., Mottl, M.J., Wheat, C.G., and Becker, K., 2003a. Hydrothermal recharge and discharge across $50 \mathrm{~km}$ guided by seamounts on a young ridge flank. Nature (London, U. K.), 421:618-621.

doi:10.1038/nature01352

Fisher, A.T., Stein, C.A., Harris, R.N., Wang, K., Silver, E.A., Pfender, M., Hutnak, M., Cherkaoui, A., Bodzin, R., and Villinger, H., 2003b. Abrupt thermal transition reveals hydrothermal boundary and role of seamounts within the Cocos plate. Geophys. Res. Lett., 30(11):10.1029/ 2002GL016766. doi:10.1029/2002GL016766

Giambalvo, E.R., Fisher, A.T., Martin, J.T., Darty, L., and Lowell, R.P., 2000. Origin of elevated sediment permeability in a hydrothermal seepage zone, eastern flank of the Juan de Fuca Ridge, and implications for transport of fluid and heat. J. Geophys. Res.,105:913-928. doi:10.1029/1999JB900360

Grant, J.A., and Schreiber, R., 1990. Modern swath sounding and sub-bottom profiling technology for research applications: the Atlas Hydrosweep and Parasound systems. Mar. Geophys. Res., 12:9-19. doi:10.1007/ BF00310559

Harding, A.J., Kent, G.M., and Orcutt, J.A., 1993. A multichannel seismic investigation of upper crustal structure at $9^{\circ} \mathrm{N}$ on the East Pacific Rise: implications for crustal accretion. J. Geophys. Res., 98:13925-13944.

Jacobson, R.S., 1992. The impact of crustal evolution on changes of the seismic properties of the uppermost ocean crust. Rev. Geophys., 30:23-42.

Johnson, H.P., Becker, K., and Von Herzen, R.P., 1993. Near-axis heat flow measurements on the northern Juan de Fuca Ridge: implications for fluid circulation in the crust. Geophys. Res. Lett., 20:1875-1878.

Karato, S., 1983. Physical properties of basalts from Deep Sea Drilling Project Hole 504B, Costa Rica Rift. In Cann, J.R., Langseth, M.G., Honnorez, J., Von Herzen, R.P., White, S.M., et al., Init. Repts. DSDP, 69: Washington (U.S. Govt. Printing Office), 687-695.

Karsten, J., Hammond, S.R., Davis, E.E., and Currie, R.G., 1986. Detailed geomorphology of the Endeavour segment of the Juan de Fuca Ridge. Geol. Soc. Am. Bull., 97:213-221. doi:10.1130/0016-

7606(1986)97<213:DGANOT>2.0.CO;2

Karsten, J.L., Becker, N., Mottl, M.J., and Wheat, C.G., 1998. Petrology of Baby Bare and Mama Bare lavas. Geophys. Res. Lett., 25:117-120. doi:10.1029/97GL53564

Langseth, M.G., and Herman, B.J., 1981. Heat transfer in the oceanic crust of the Brazil Basin. J. Geophys. Res., 86:10805-10819.

Levitus, S., 1982. Climatological Atlas of the World Ocean: Rockville, MD (U.S. Dept. Commerce).

Mottl, M.J., Wheat, C.G., Baker, E., Becker, N., Davis, E., Feely, R., Grehan, A., Kadko, D., Lilley, M., Massoth, G., Moyer, C., and Sansone, F., 1998. Warm springs discovered on 3.5 Ma oceanic crust, eastern flank of the Juan de Fuca Ridge. Geology, 26:51-54. doi:10.1130/00917613(1998)026<0051:WSDOMO>2.3.CO;2

Parsons, B., and Sclater, J.G., 1977. An analysis of the variation of ocean floor bathymetry and heat flow with age. J. Geophys. Res., 82:803-827.

Rohr, K., 1994. Inverse of seismic velocities in upper oceanic crust and hydrothermal circulation in the Juan de 
Fuca plate. Geophys. Res. Lett., 21(19):2163-2166. doi:10.1029/94GL01913

Rosenberger, A., Davis, E.E., and Villinger, H., 2000. Data report: Hydrocell-95 and-96 single-channel seismic data on the eastern Juan de Fuca Ridge flank. In Fisher, A., Davis, E.E., and Escutia, C. (Eds.), Proc. ODP, Sci. Results, 168: College Station, TX (Ocean Drilling Program), 919.

Shipboard Scientific Party, 1997a. Introduction and summary: hydrothermal circulation in the oceanic crust and its consequences on the eastern flank of the Juan de Fuca Ridge. In Davis, E.E., Fisher, A.T., Firth, J.V., et al., Proc. ODP, Init. Repts., 168: College Station, TX (Ocean Drilling Program), 7-21.

Shipboard Scientific Party, 1997b. Rough basement transect (Sites 1026 and 1027). In Davis, E.E., Fisher, A.T., Firth, J.V., et al., Proc. ODP, Init. Repts., 168: College Station, TX (Ocean Drilling Program), 101-160.

Smith, W.H.F., and Sandwell, D.T., 1997. Global seafloor topography from satellite altimetry and ship depth soundings. Science, 277:1956-1962. doi:10.1126/ science.277.5334.1956

Spiess, V., Villinger, H., and Zühlsdorff, L. (Eds.), 2001. Report and Preliminary Results of R/V Sonne Cruise SO 149, Victoria-Victoria, 16.8.-16.9.2000: Bremen (Univ. Bremen).

Spinelli, G.A., and Fisher, A.T., 2004. Hydrothermal circulation within topographically rough basaltic basement on the Juan de Fuca Ridge flank. Geochem., Geophys., Geosyst., 5. doi:10.1029/2003GC000616

Spinelli, G.A., Zühlsdorff, L., Fisher, A.T., Wheat, C.G., Mottl, M., Spiess, V., and Giambalvo, E.R., 2004. Hydrothermal seepage patterns above a buried basement ridge, eastern flank of the Juan de Fuca Ridge. J. Geophys. Res., 109. doi:10.1029/2003JB002476

Stein, C.A., and Stein, S., 1994. Constraints on hydrothermal heat flux through the oceanic lithosphere from global heat flow. J. Geophys. Res., 99:3081-3095. doi:10.1029/93JB02222

Stein, J.S., and Fisher, A.T., 2001. Multiple scales of hydrothermal circulation in Middle Valley, northern Juan de Fuca Ridge: physical constraints and geologic models. J. Geophys. Res., 106(B5):8563-8580. doi:10.1029/ 2000JB900395

Stein, J.S., and Fisher, A.T., 2003. Observations and models of lateral hydrothermal circulation on a young ridge flank: numerical evaluation of thermal and chemical constraints. Geochem., Geophys., Geosyst., 4. doi:10.1029/2002GC000415

Stockwell, J.W., 1997. Free software in education: a case study of CWP/SU: Seismic Un*x. Leading Edge, 16:10451049. doi:10.1190/1.1437723

Thomson, R.E., Davis, E.E., and Burd, B.J., 1995. Hydrothermal venting and geothermal heating in Cascadia Basin. J. Geophys. Res., 100:6121-6141. doi:10.1029/ 95JB00030
Underwood, M.B., Hoke, K.D., Fisher, A.T., Davis, E.E., Giambalvo, E., Zühlsdorff, L., and Spinelli, G.A., 2005. Provenance, stratigraphic architecture, and hydrogeologic influence of turbidites on the mid-ocean ridge flank of northwestern Cascadia Basin, Pacific Ocean. J. Sediment. Res., 75(1):149-164. doi:10.2110/jsr.2005.012

Villinger, H., and Davis, E.E. (Eds.), 1987. HFRED: A Program for Reduction of Marine Heat Flow Data on a Microcomputer: Sydney, BC (Geological Survey of Canada), 77.

Villinger, H., Grevemeyer, I., Kaul, N., Hauschild, J., and Pfender, M., 2002. Hydrothermal heat flux through aged oceanic crust: where does the heat escape? Earth. Planet. Sci. Lett., 202(1):159-170. doi:10.1016/S0012821X(02)00759-8

Wheat, C.G., Elderfield, H., Mottl, M.J., and Monnin, C., 2000. Chemical composition of basement fluids within an oceanic ridge flank: implications for along-strike and across-strike hydrothermal circulation. J. Geophys. Res., 105(6):13437-13448. doi:10.1029/2000JB900070

Wheat, C.G., and Mottl, M., 2000. Composition of pore and spring waters from Baby Bare: global implications of geochemical fluxes from a ridge flank hydrothermal system. Geochim. Cosmochim. Acta, 64:629-642. doi:10.1016/S0016-7037(99)00347-6

Wheat, C.G., and Mottl, M.G., 1994. Hydrothermal circulation, Juan de Fuca Ridge eastern flank: factors controlling basement water composition. J. Geophys. Res., 99:3067-3080. doi:10.1029/93JB01612

Wheat, C.G., Mottl, M.J., Fisher, A.T., Kadko, D., Davis, E.E., and Baker, E., 2004. Heat and fluid flow through a basaltic outcrop on a ridge flank. Geochem., Geophys., Geosyst., 5(12). doi:10.1029/2004GC000700

Wilson, D.S., 1993. Confidence intervals for motion and deformation of the Juan de Fuca plate. J. Geophys. Res., 98:16053-16071.

Zühlsdorff, L., and Spiess, V., 2001. Modeling seismic reflection patterns from Ocean Drilling Program Leg 168 core density logs: insight into lateral variations in physical properties and sediment input at the eastern flank of the Juan de Fuca Ridge, J. Geophys. Res., 106(B8):16119-16134. doi:10.1029/2001JB900005

Zühlsdorff, L., and Spiess, V., submitted. Sedimentation patterns, forced folding and fluid upflow above a buried basement ridge-results from a high resolution seismic 3D survey. J. Geophys. Res.

Zühlsdorff, L., Spiess, V., Hübscher, C., and Breitzke, M., 1999, Seismic reflectivity anomalies in sediments at the eastern flank of the Juan de Fuca Ridge: evidence for fluid migration? J. Geophys. Res., 104(B7):15351-15364. doi:10.1029/1999JB900061

Zyvoloski, G.A., Robinson, B.A., Dash, Z.D., and Trease, L.L. (Eds.), 1996. Users Manual for the FEHMN Application: Los Alamos (Los Alamos National Laboratory).

Publication: 31 October 2005

MS 301-102 
Figure F1. Regional bathymetric map showing locations of IODP Expedition 301 sites, the ODP Leg 168 drilling transect, and selected regional tectonic features. Bathymetry from Smith and Sandwell (1997). SR = Second Ridge (primary work area during Expedition 301). DR = Deep Ridge, FR = First Ridge (secondary [backup] work areas for Expedition 301). Box shows location of Figure F2.

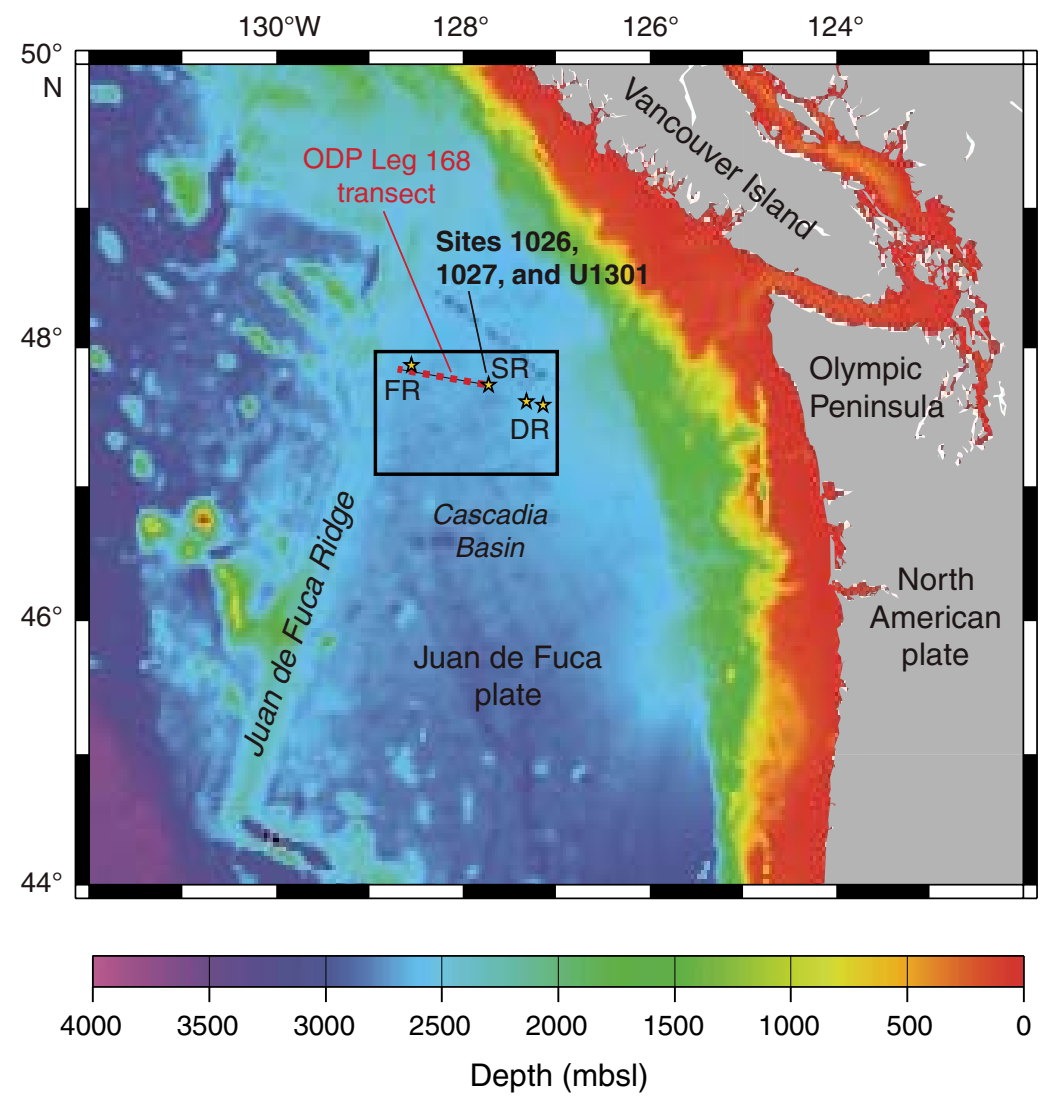


Figure F2. Bathymetry of the eastern flank of the Juan de Fuca Ridge, including Leg 168 and Expedition 301 work areas. Bathymetric data comprises a compilation of earlier surveys and results from the 2000 ImageFlux and RetroFlux surveys, as described in the text. Distribution of seismic and heat flow coverage is also shown. Heat flow data are from the following sources: RetroFlux $(2000)=$ this study; Hydrocell $(1997)=$ Davis et al., 1997a; SO111 (1996) = previously unpublished data (H. Villinger, pers. comm., 2004), FlankFlux (1992) = Davis et al., (1992) (shows locations of values omitted from Davis et al. [1997a] compilation because of concerns about data quality) (see "Supplementary Material" for the high-resolution version of this figure in its native format).

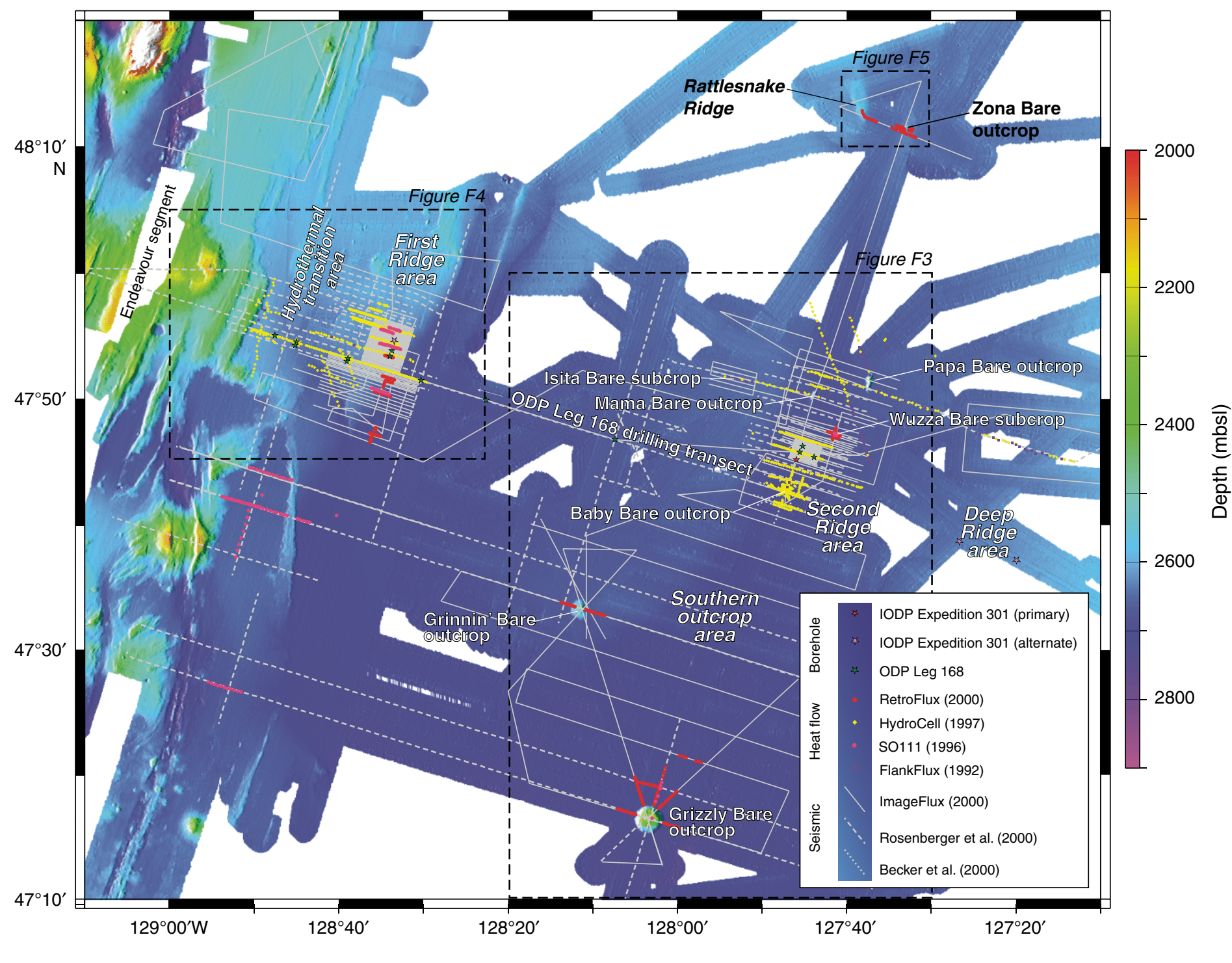


Figure F3. Swath map of Second Ridge and Southern outcrop area, showing distribution of heat flow data and track lines. Detailed track chart of Second Ridge area is shown in Figure F6. Note that seafloor in Second Ridge area is actually slightly deeper (darker blue) than that of the surrounding area and that the seafloor deepens to the south, in the direction of Grizzly Bare outcrop (purple). Also note sediment transport channel to the east of Grizzly Bare outcrop (see "Supplementary Material" for the high-resolution version of this figure in its native format).

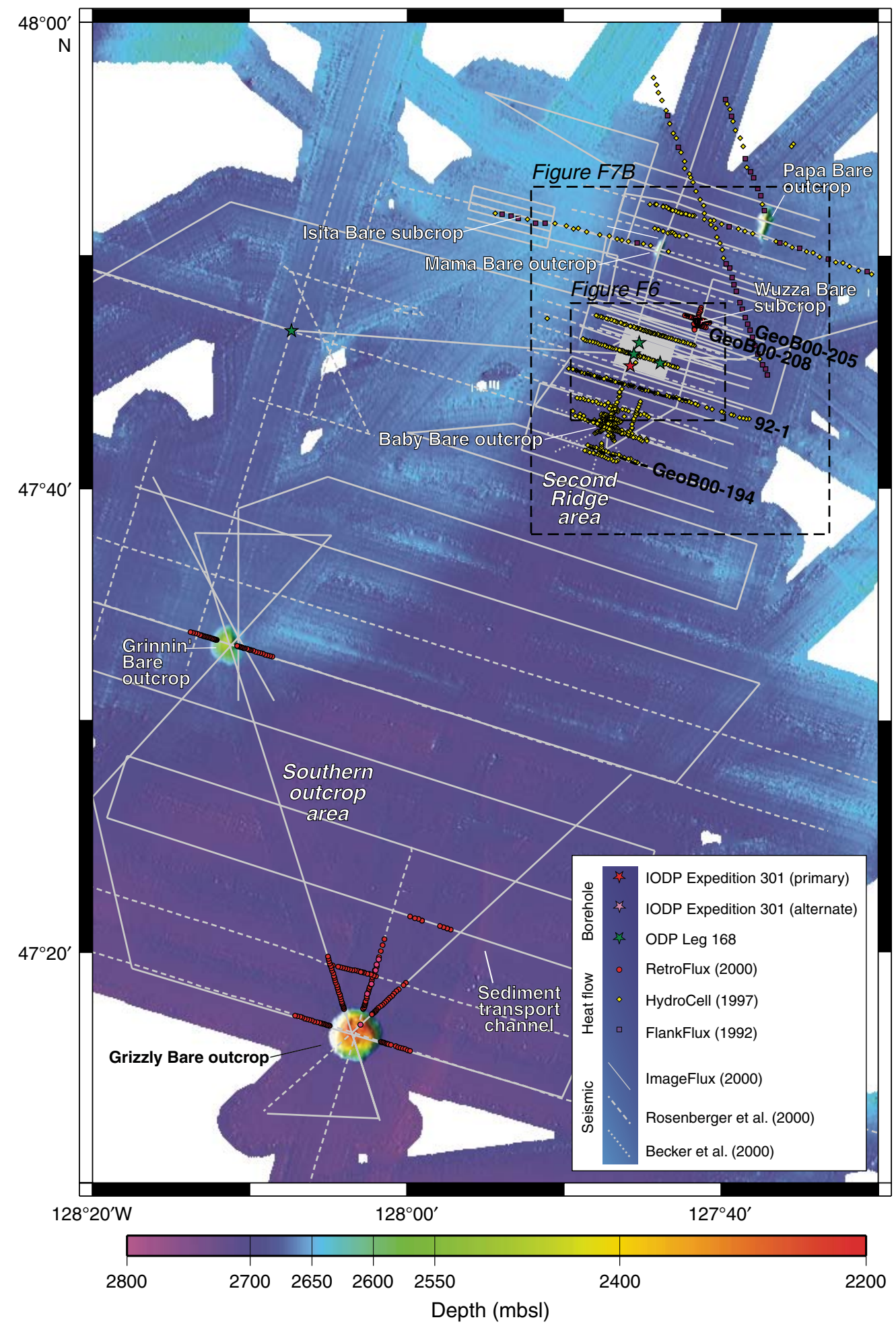


Figure F4. Swath map of the hydrothermal transition and First Ridge areas, showing distribution of heat flow data and selected track lines. Detailed track chart for First Ridge area shown in Fig. F9 (see "Supplementary Material" for the high-resolution version of this figure in its native format).

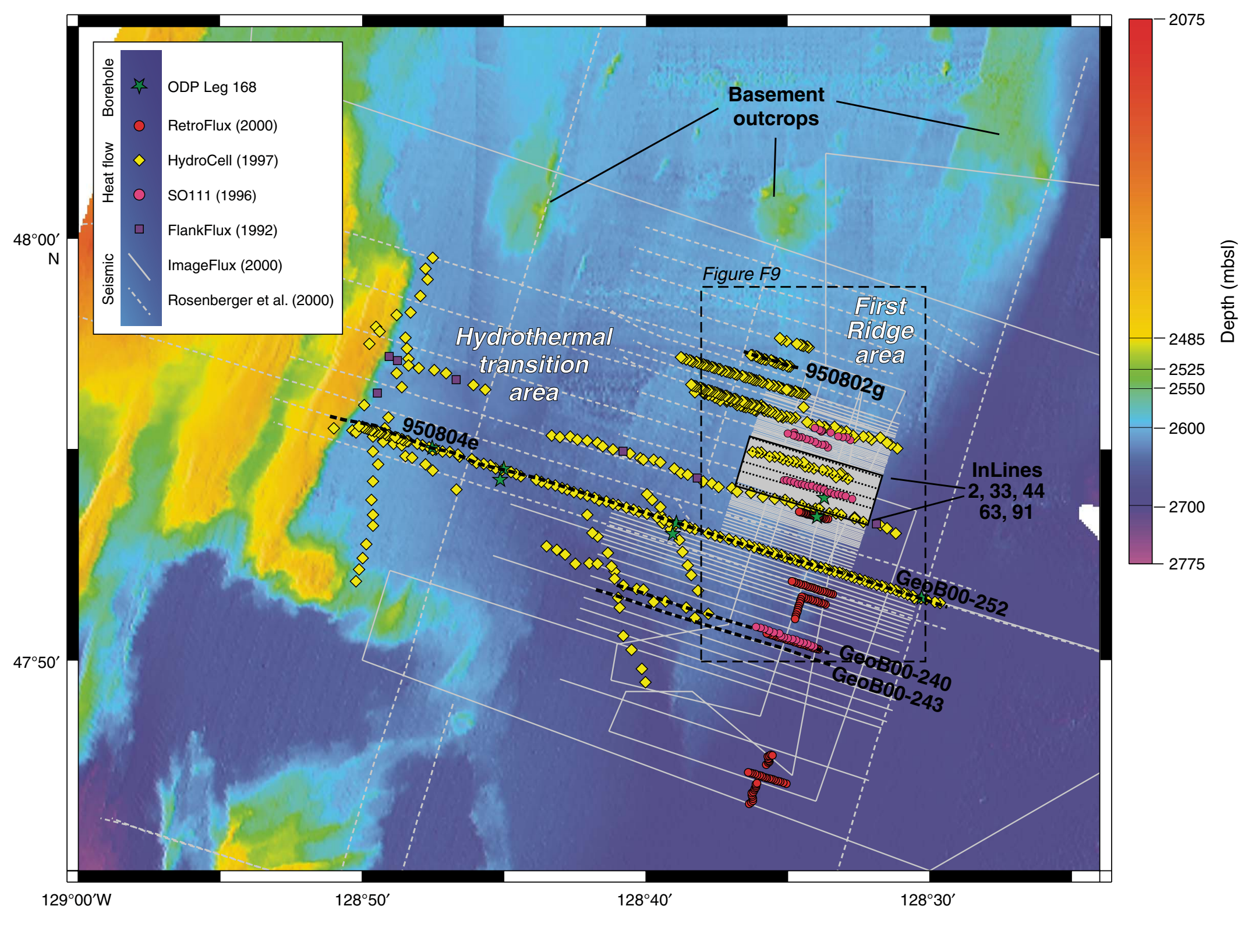


Figure F5. Swath map of northern outcrop area, including Zona Bare outcrop, showing distribution of heat flow data and track lines (see "Supplementary Material" for the high-resolution version of this figure in its native format).

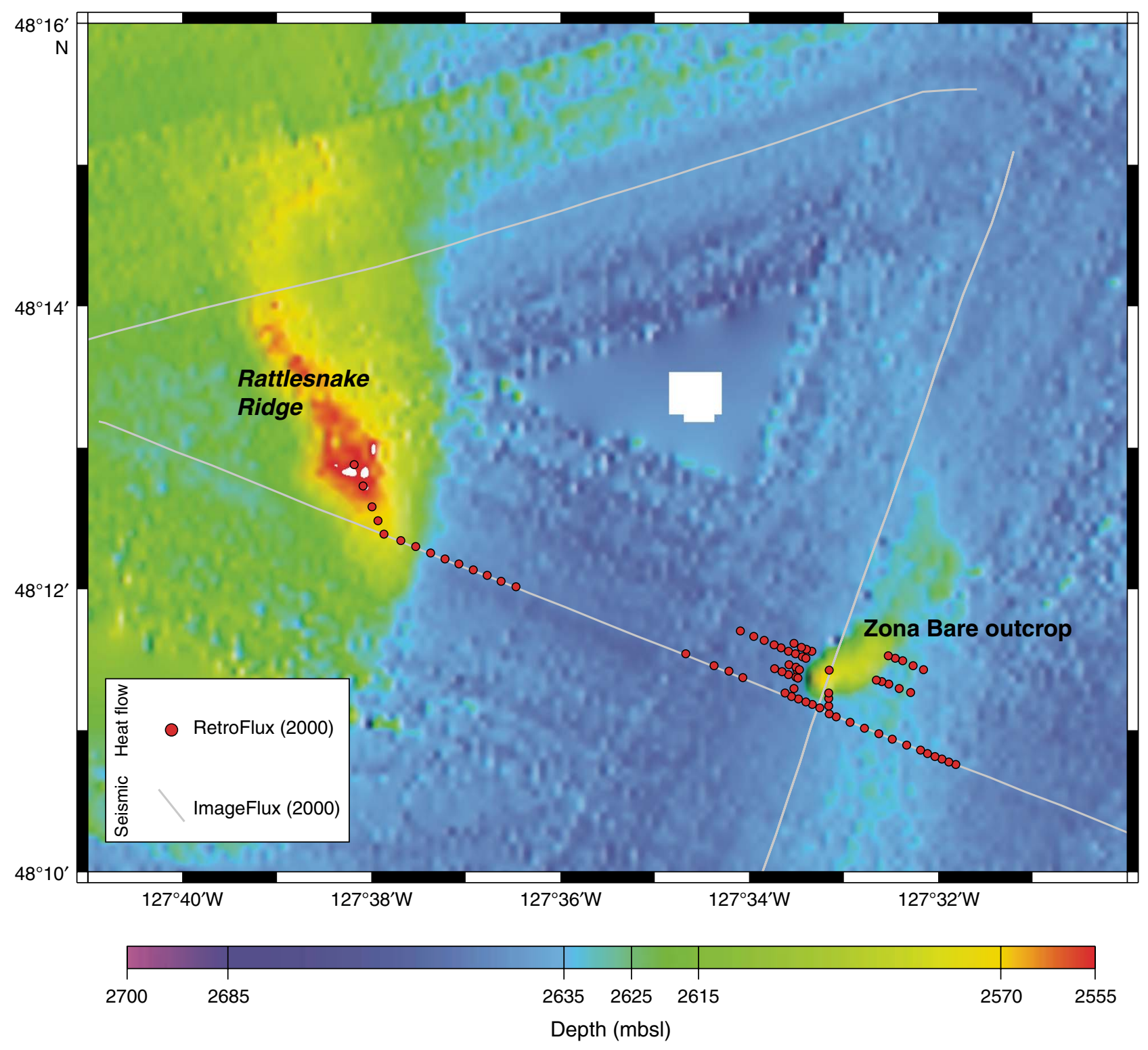


Figure F6. Track chart for Second Ridge area, showing track lines for both older and more recent surveys and ODP and IODP drill sites. Highlighted lines are shown in Figure F8.

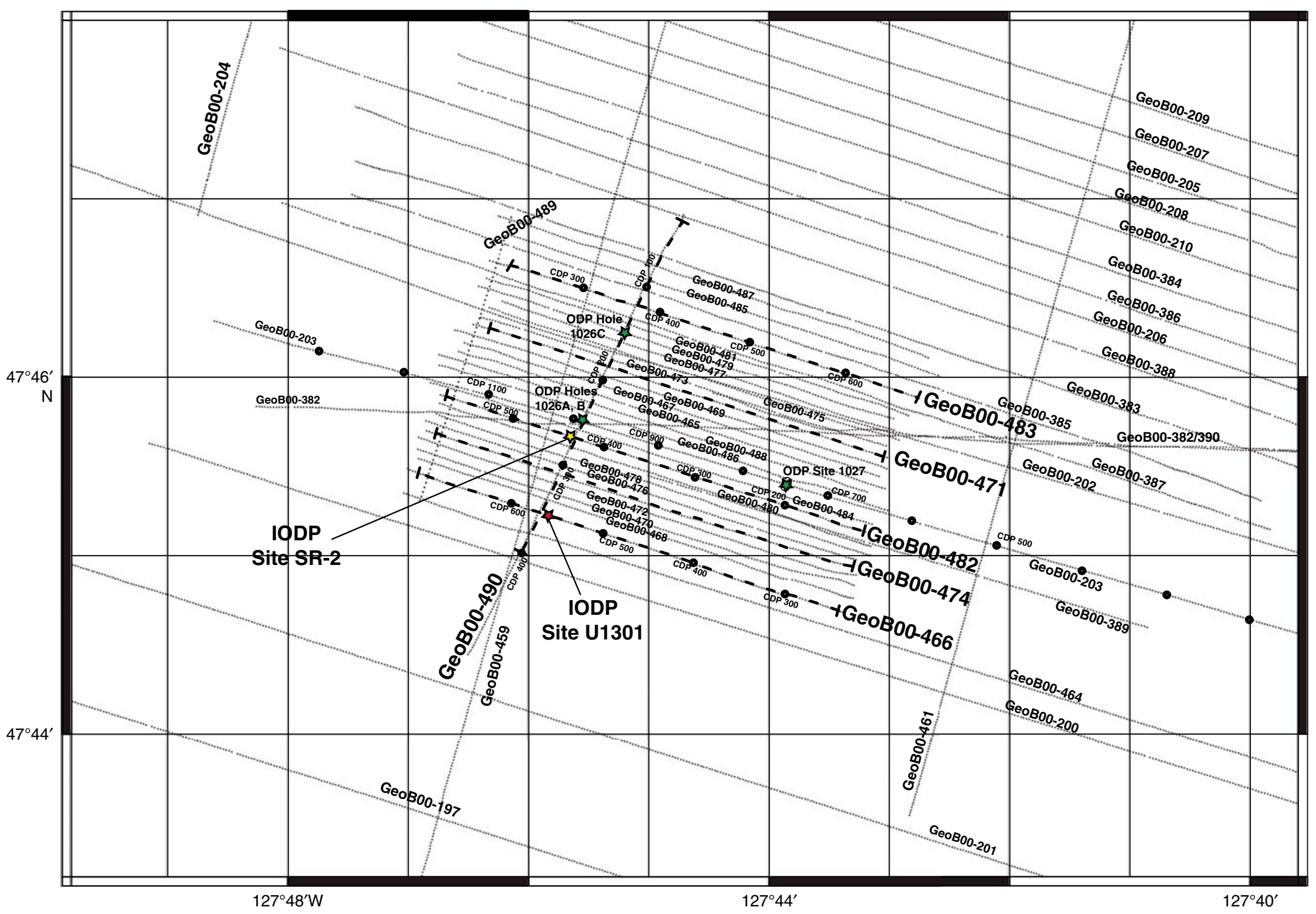


Figure F7. Bathymetric relief maps of the Second Ridge area. A. Bathymetry showing generally flat seafloor, with outcrops and ODP and IODP drill sites. B. Basement relief map created from seafloor and seismic data, showing the outcrops and general basement structure. White areas indicate basement outcrops that rise above the surrounding seafloor. C. Basement detail map of Second Ridge drill sites.
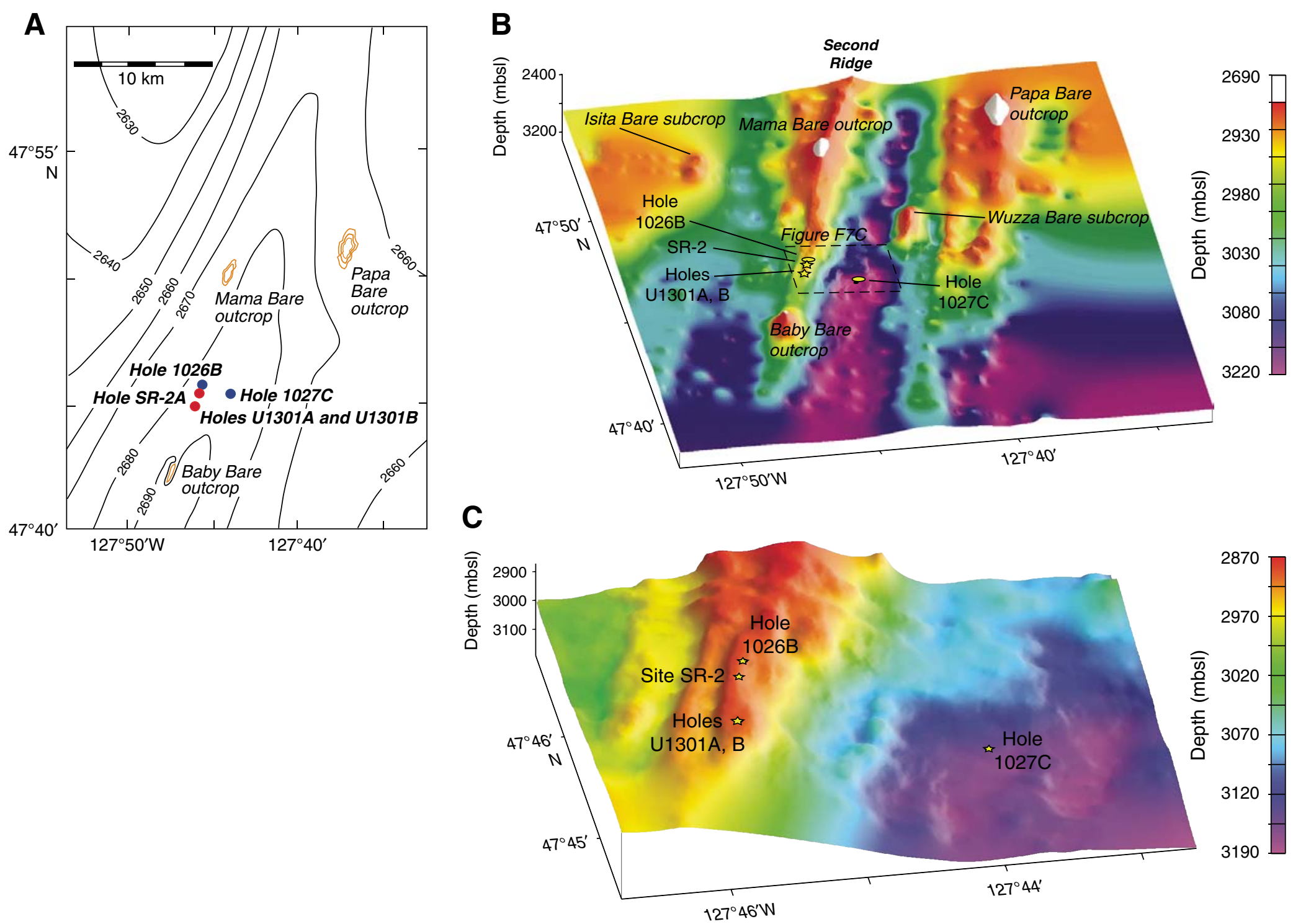
Figure F8. Example seismic lines from the 2000 ImageFlux expedition across Second Ridge Area. Line locations are shown in Figures F3 and F6. VE = vertical exaggeration. A. Line GeoB00-483, run across strike. Position of crossline GeoB00-490 is shown. Basement reflectors, the bases of filled distributary channels, and sections of dominantly sandy lithology are shown on several profiles. (Continued on next six pages.)

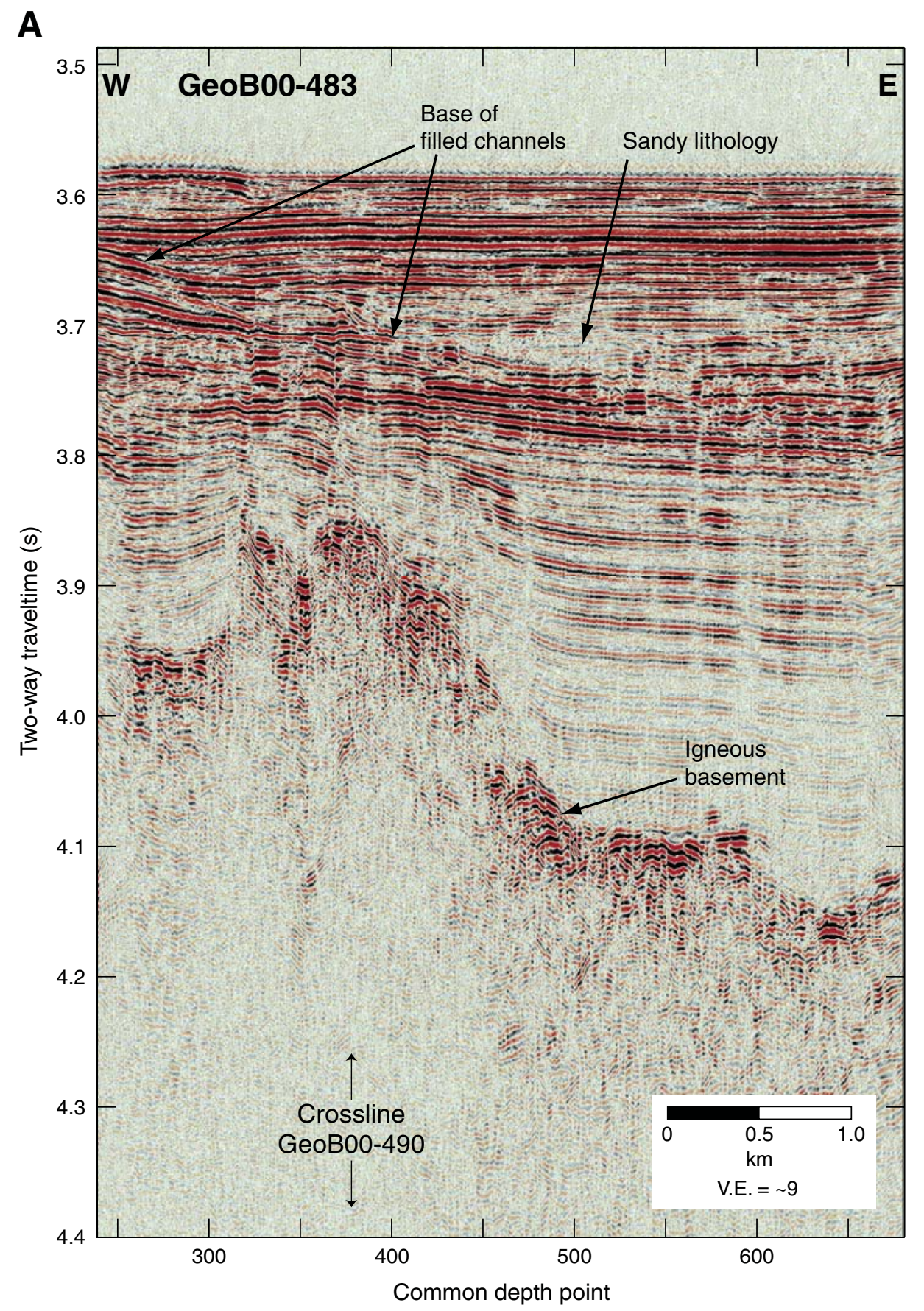


Figure F8 (continued). B. Line GeoB00-471, run across strike. Position of crossline GeoB00-490 is shown.

B

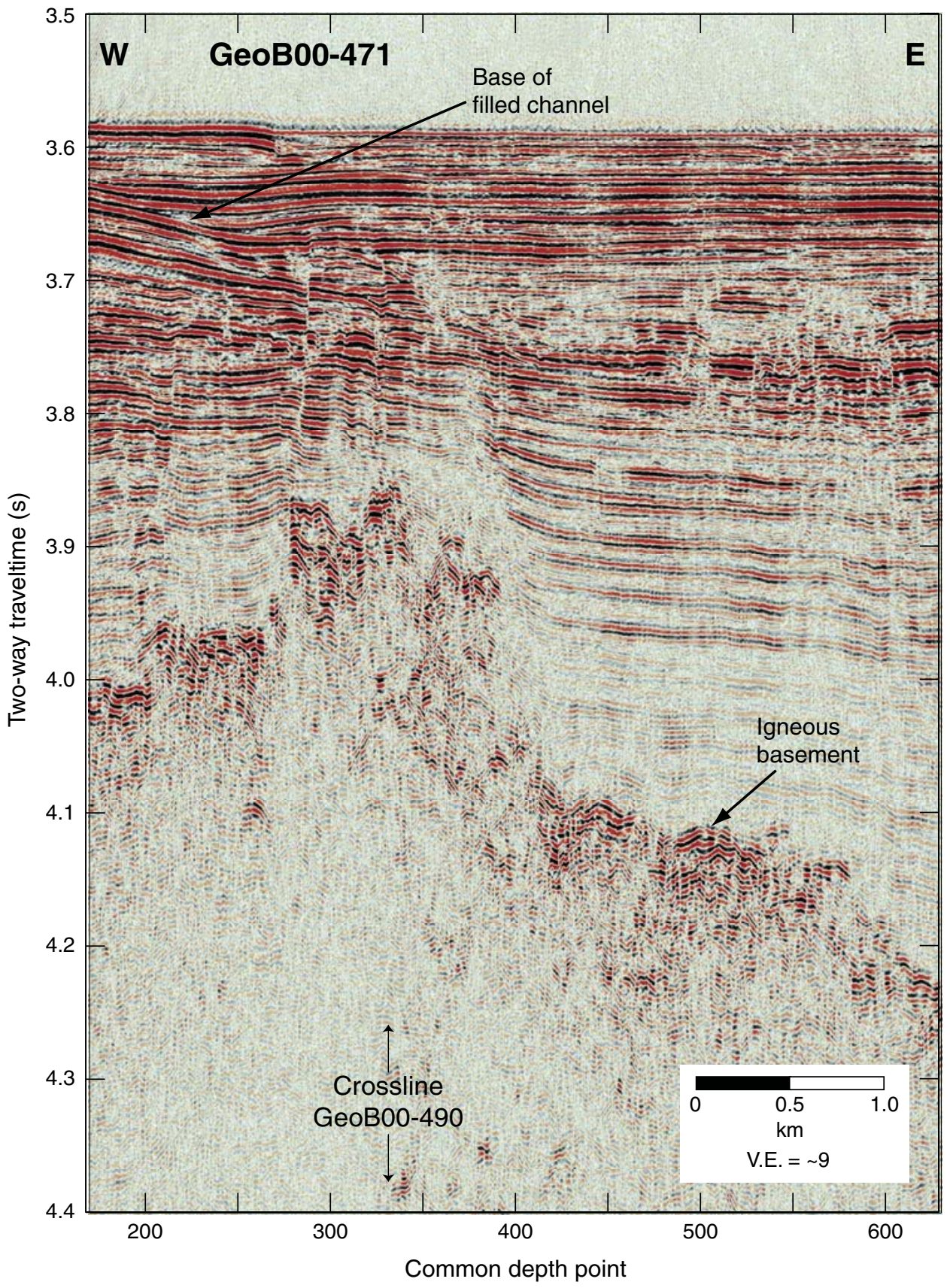


Figure F8 (continued). C. Line GeoB00-482, run across strike. Position of crossline GeoB00-490 is shown, as are locations of Sites 1026 and 1027 (offset 110-120 m north of this seismic line) and planned location for Site SR-2, where cross-hole experiments will be initiated during a future expedition.

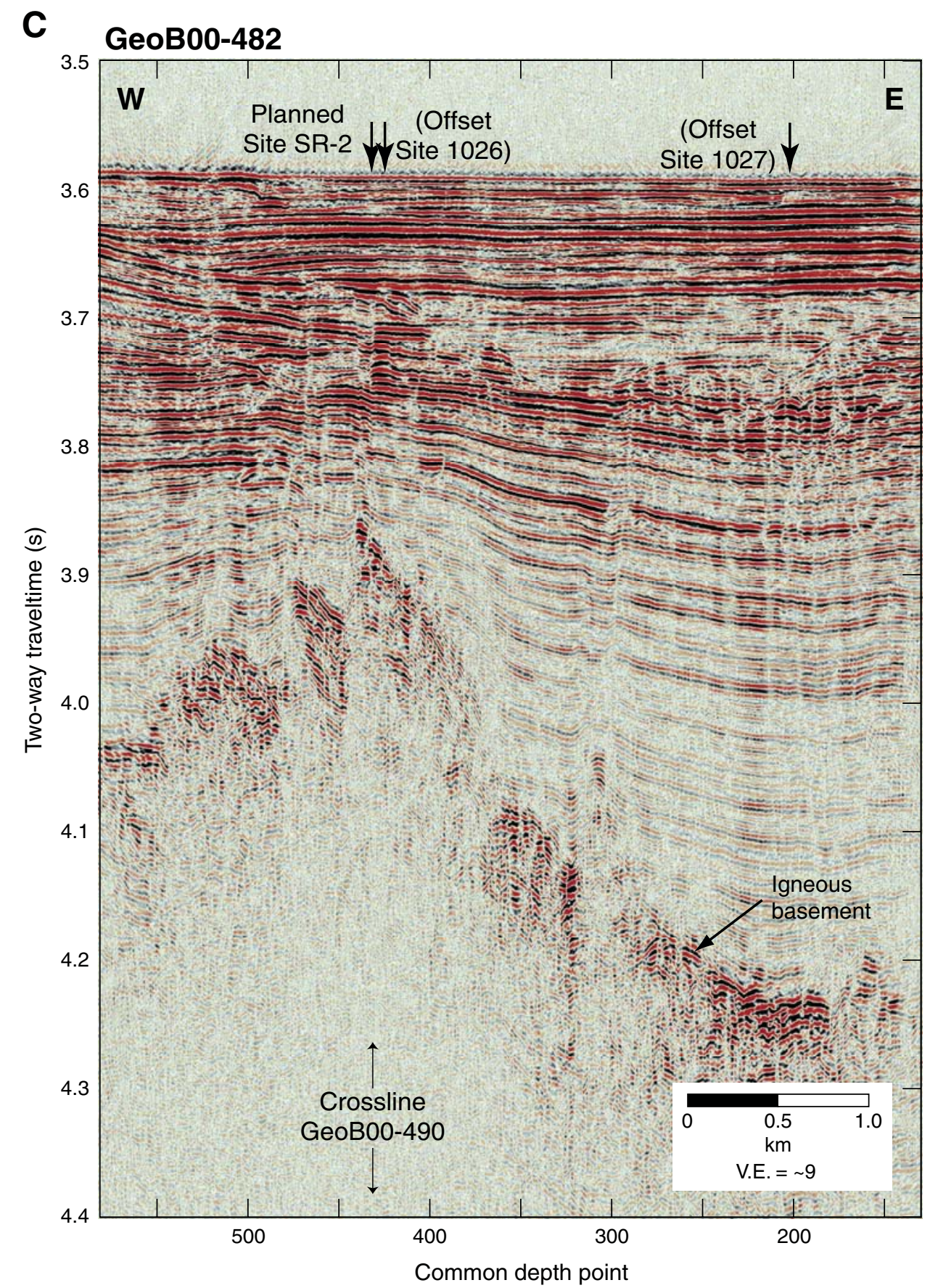


Figure F8 (continued). D. Line GeoB00-474, run across strike. Position of crossline GeoB00-490 is shown.

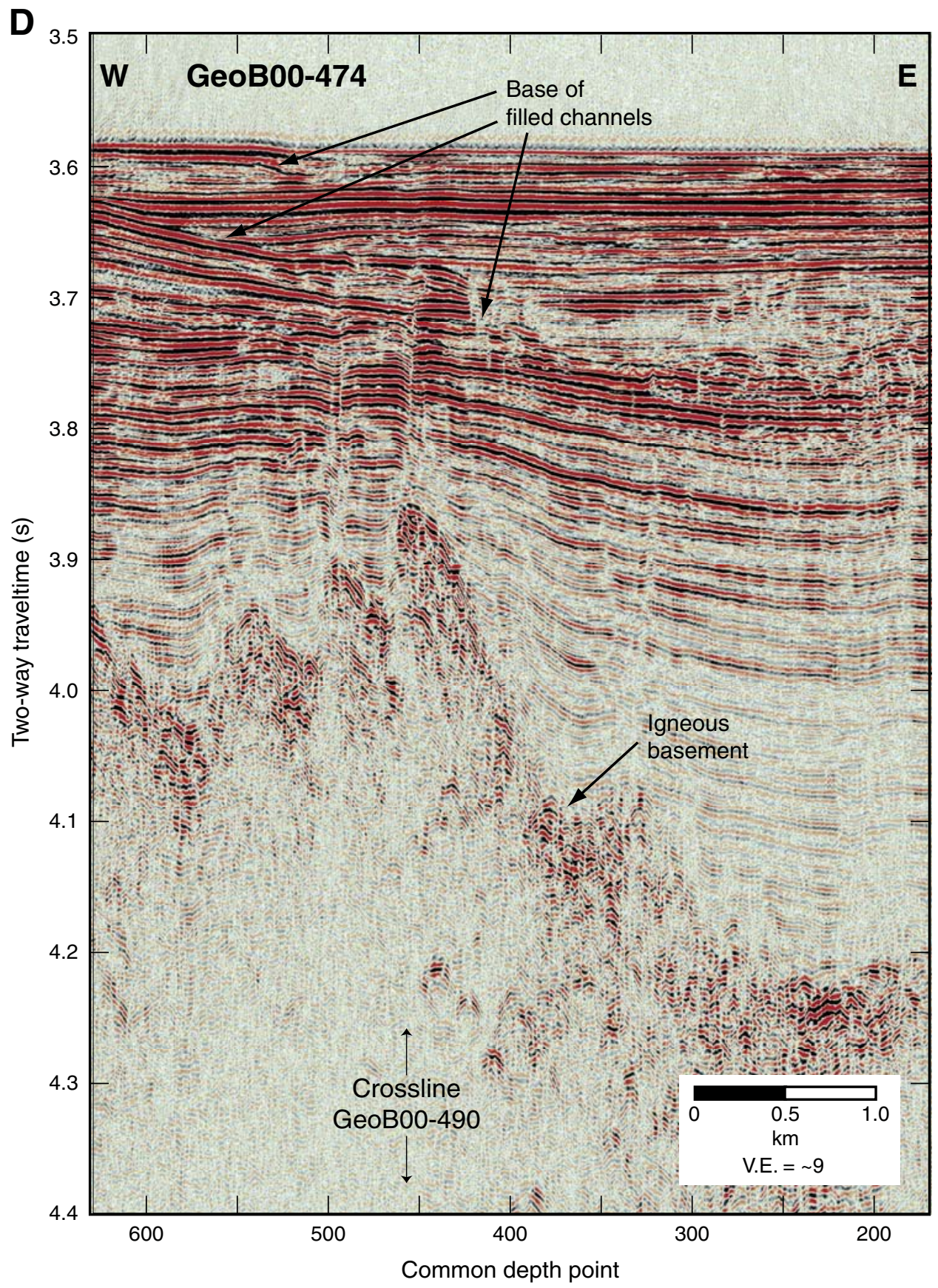


Figure F8 (continued). E. Line GeoB00-466, run across strike. Position of crossline GeoB00-490 is shown, as is position of Site U1301.

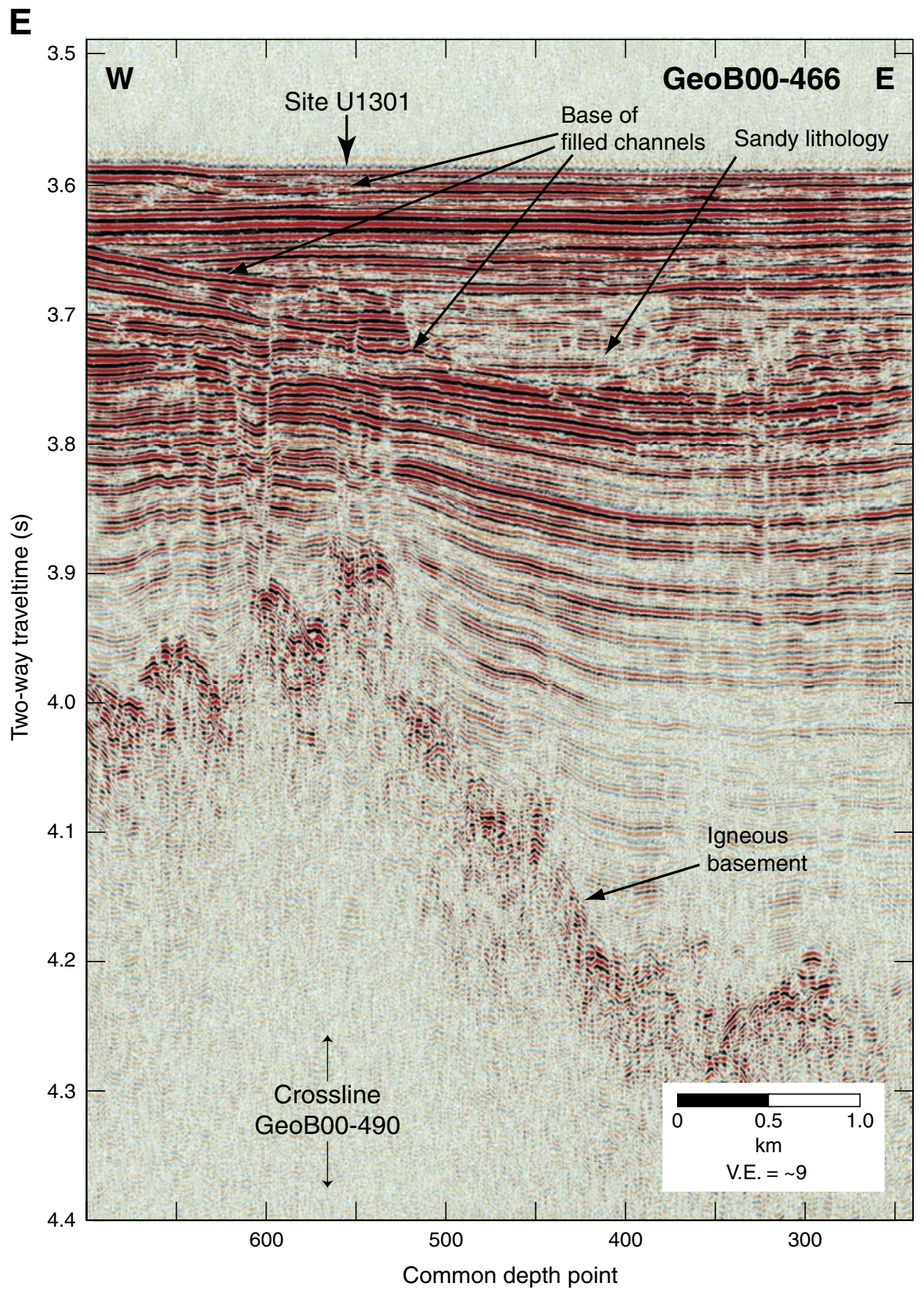


Figure F8 (continued). F. Line GeoB00-490, run along strike near the crest of buried basement ridge. Positions of five across strike lines are shown.

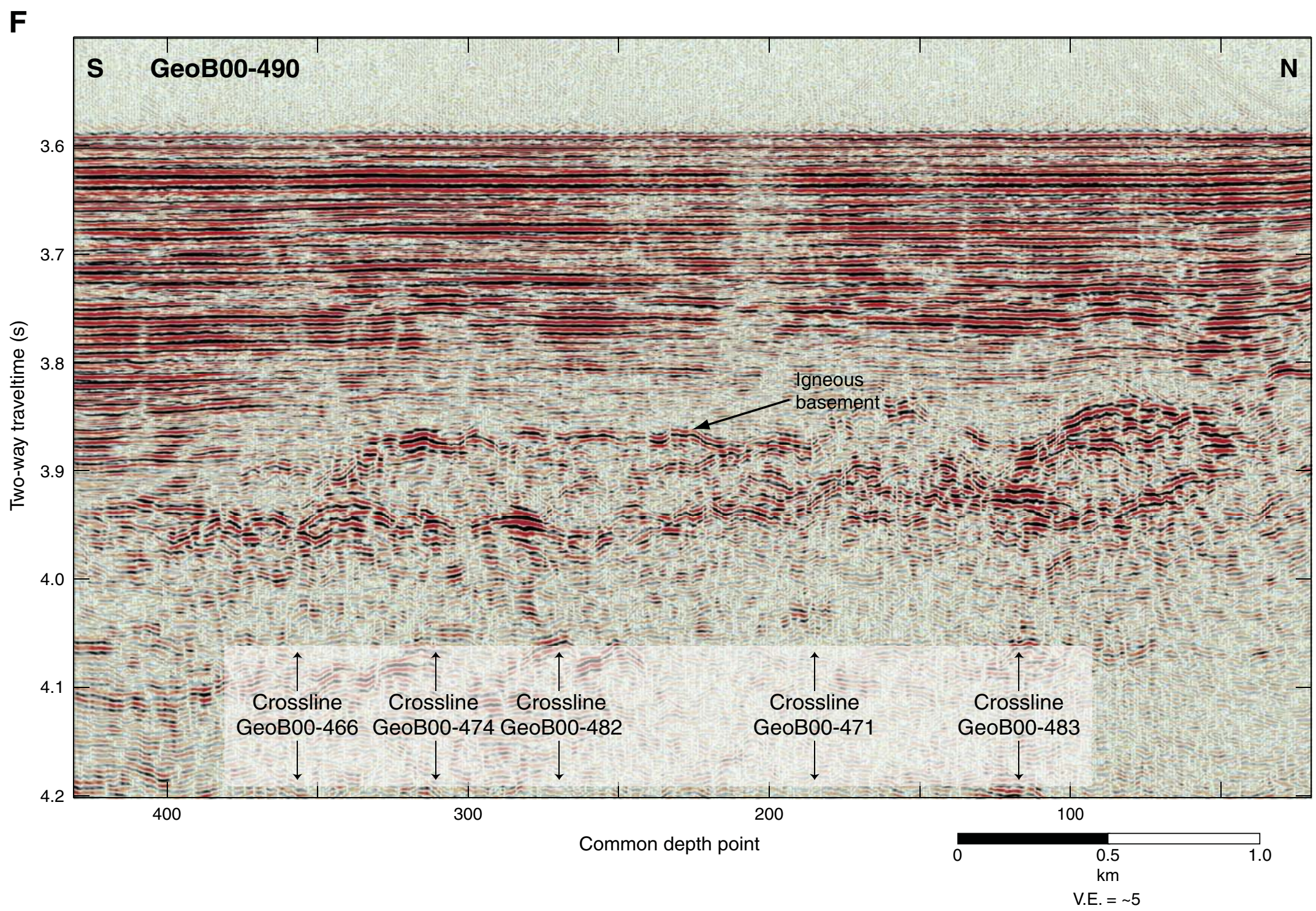


Figure F8 (continued). G. Part of Line GeoB00-208 and associated Parasound data across Wuzza Bare subcrop. Note acoustic washout immediately above the buried basement high, extending from depth almost to the seafloor.
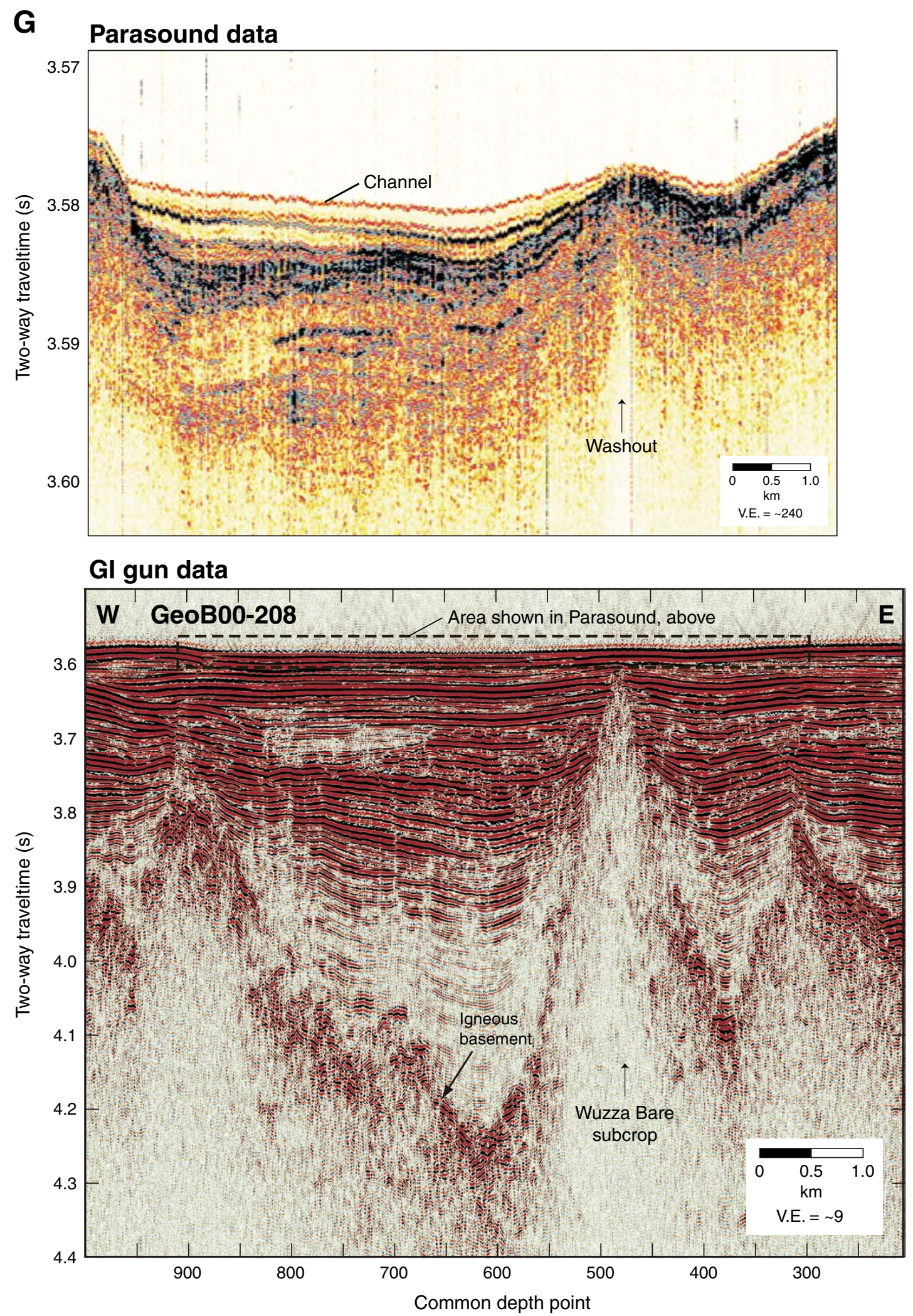
Figure F9. Track chart for First Ridge area, showing newer and older survey locations, ODP drill sites, and secondary IODP sites. Highlighted lines are shown in Figure F10.

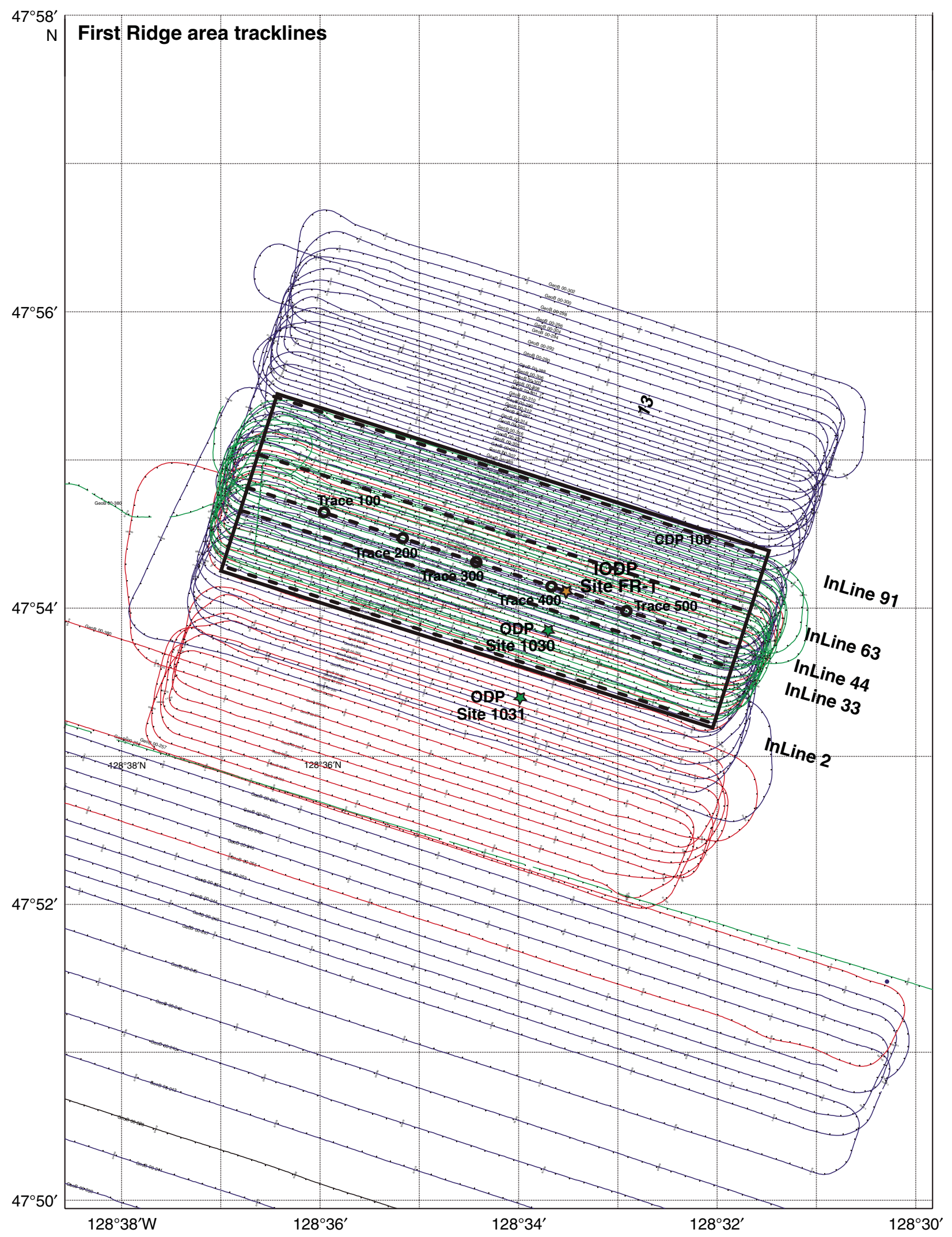


Figure F10. Example seismic lines. MCS and Parasound data, from the 2000 ImageFlux expedition across First Ridge area. Line locations are shown in Figures F4 and F9. VE = vertical exaggeration. A. InLine 2. (Continued on next five pages.)
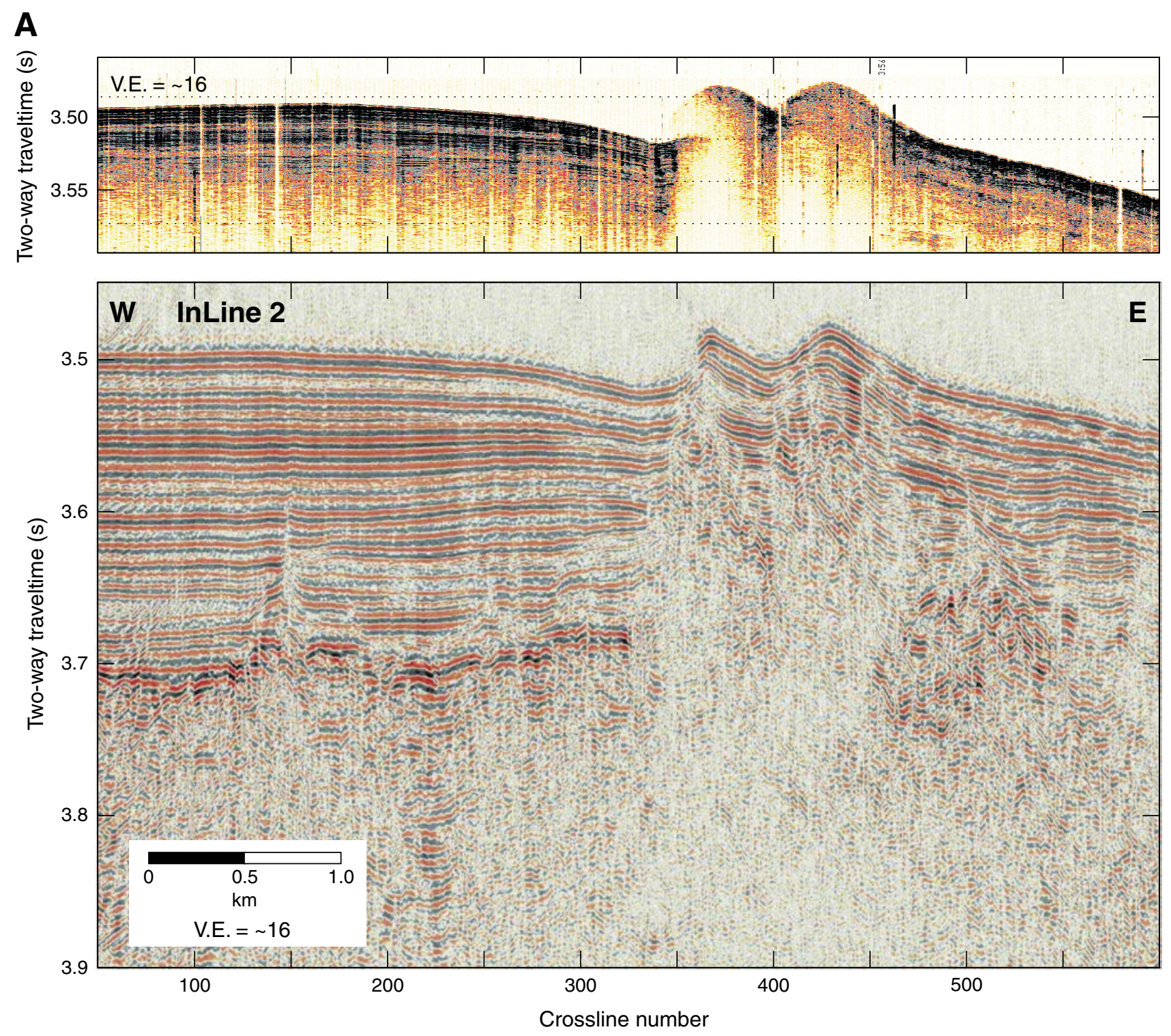
Figure F10 (continued). B. InLine 33.
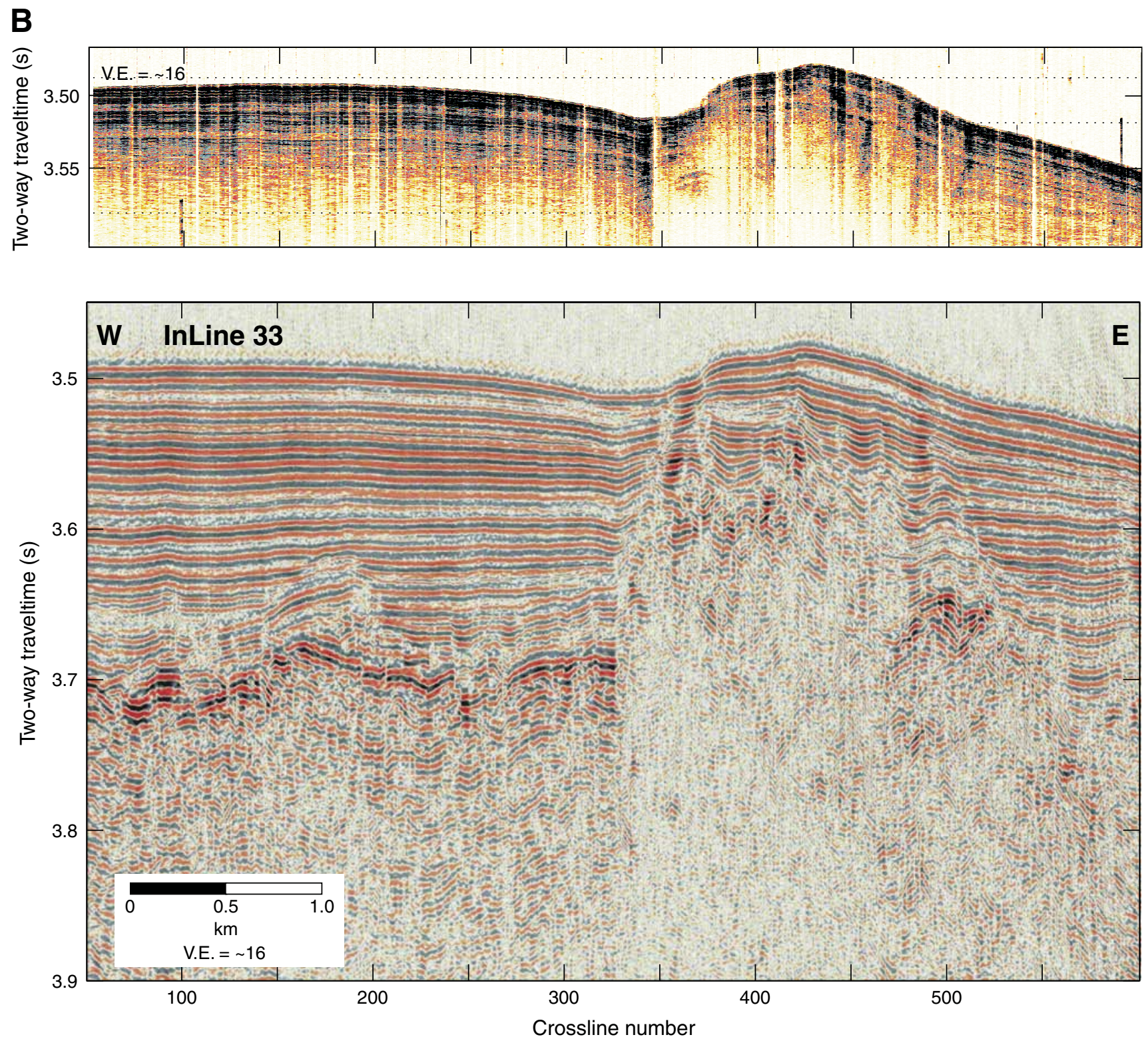
Figure F10 (continued). C. InLine 44.
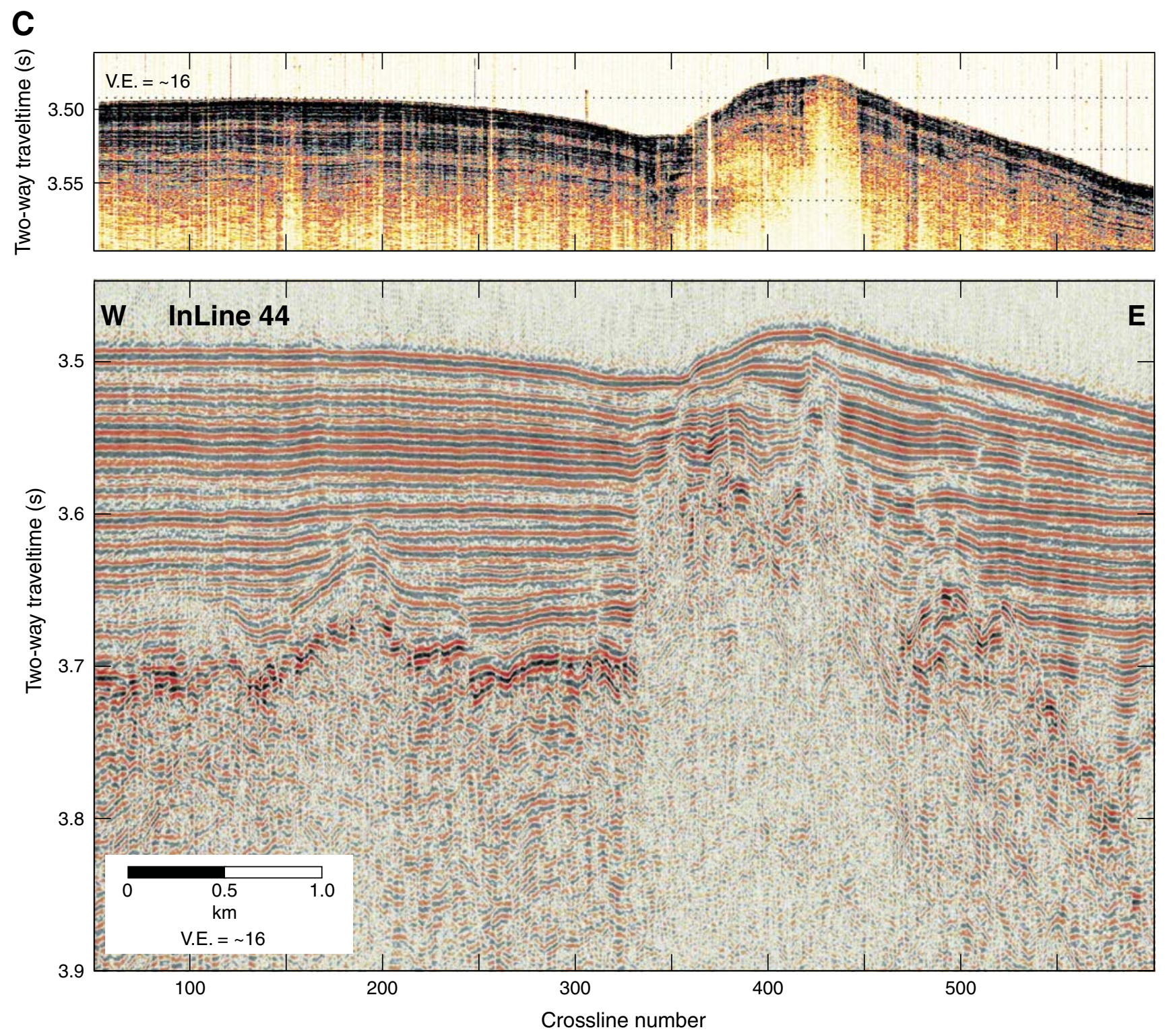
Figure F10 (continued). D. InLine 63.

D
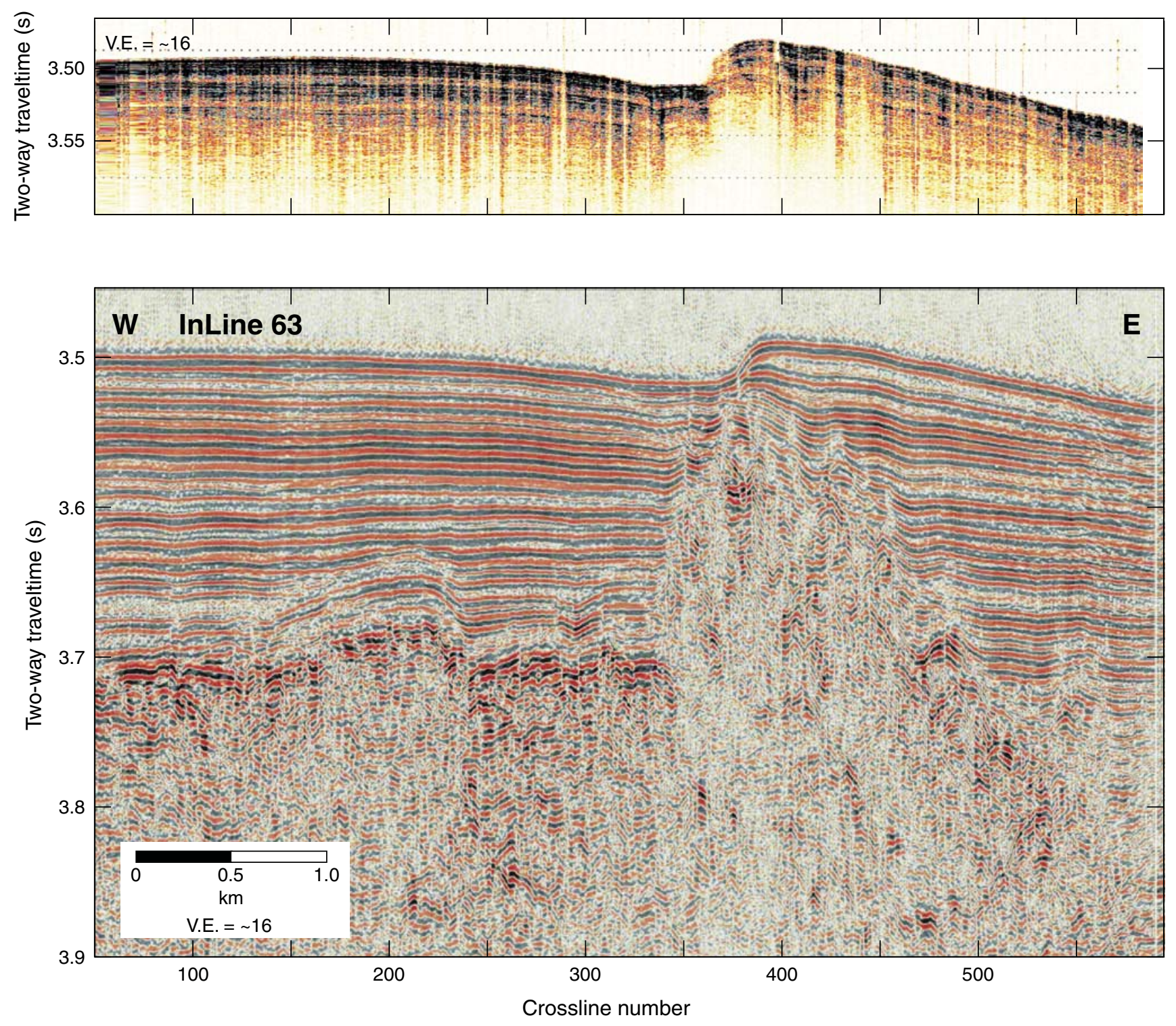
Figure F10 (continued). E. InLine 91.
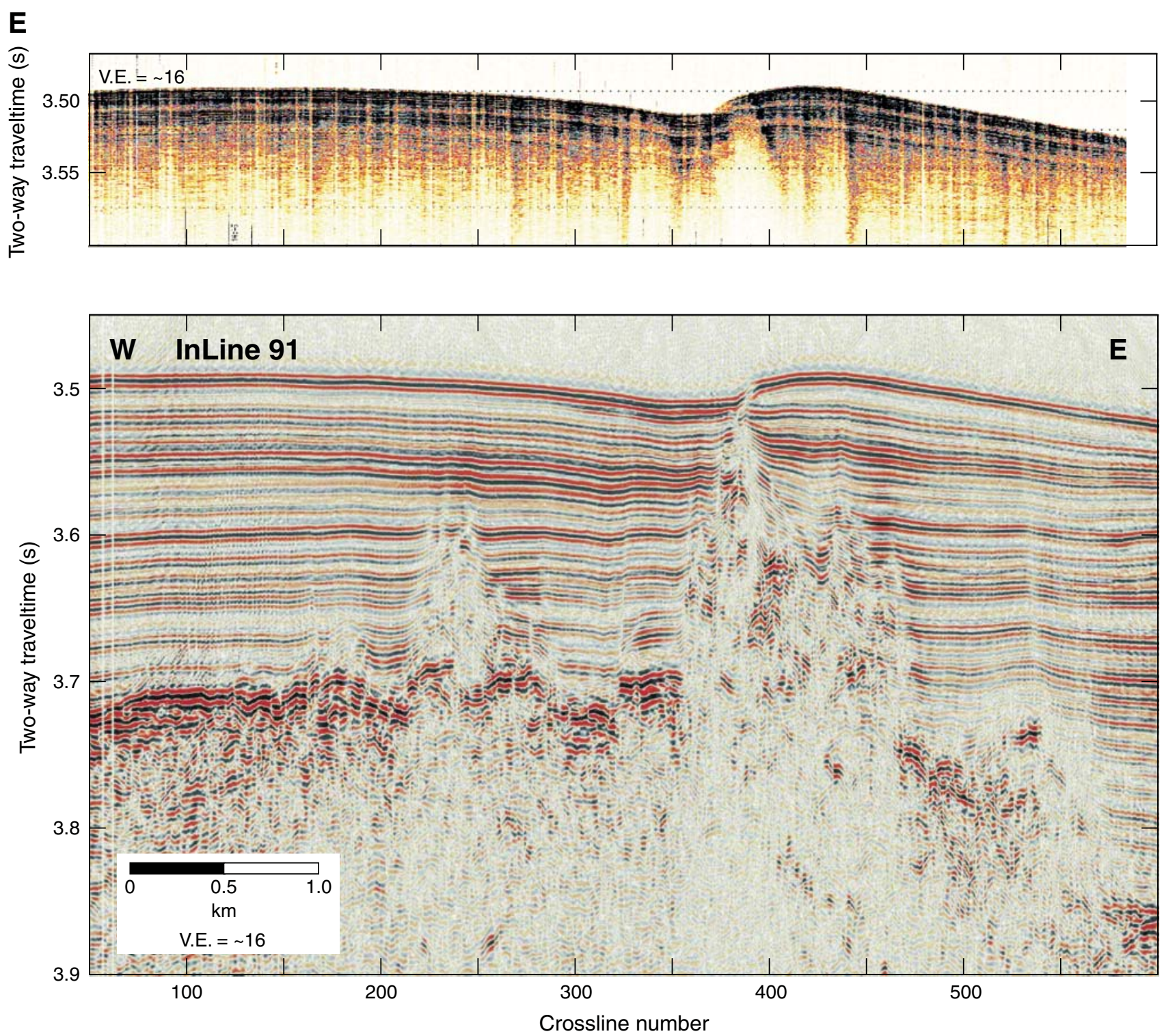


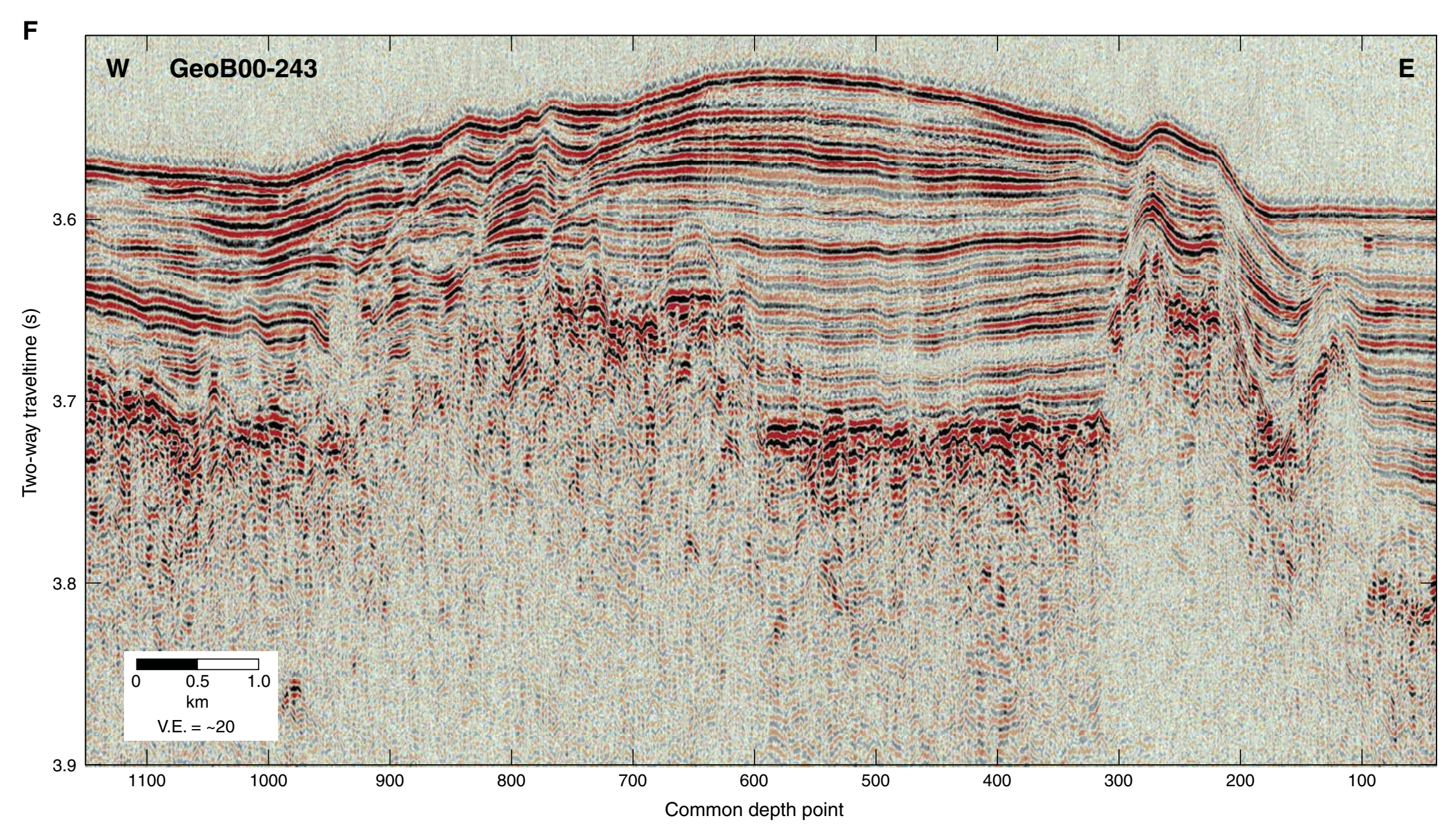


Figure F11. Track chart for Deep Ridge and section of EW0207 Line 1. Bathymetric data are plotted using the same depth scale and color palette as used in Figure F3. In contrast to all other seismic displays presented in this paper, automatic gain control was applied to Deep Ridge data in order to better image deep reflections and basement Layer 2A/2B boundary. $\mathrm{CDP}=$ common depth point.
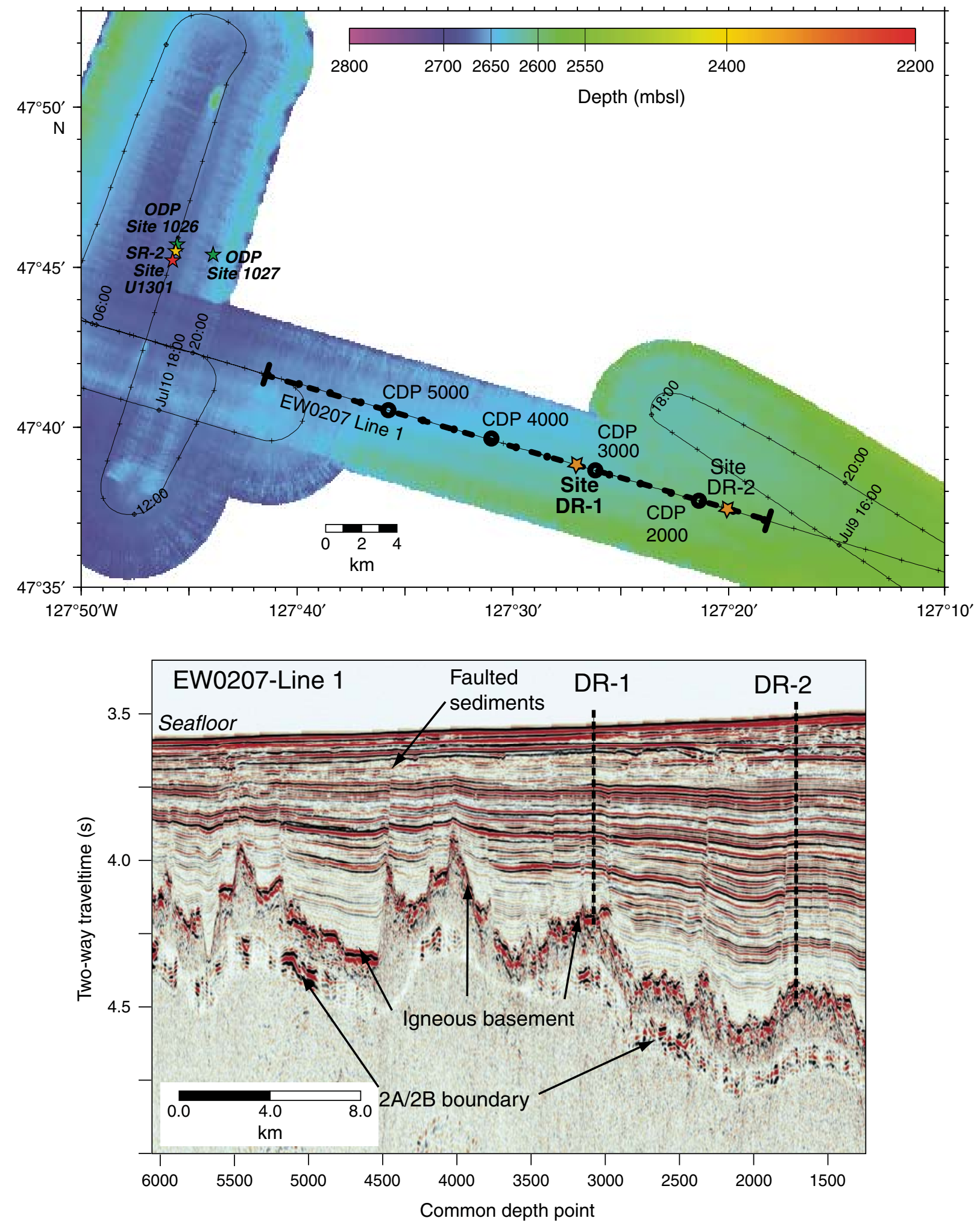
Figure F12. Histograms of heat flow data from young seafloor on the eastern flank of the Juan de Fuca Ridge. A. Complete data set of $\sim 1700$ values. B. Filtered data set of 300 values from 3.4-3.6 Ma seafloor, avoiding areas of basement exposure or significant buried relief, illustrating characteristic "background" heat flow used as a reference for subsequent conductive modeling. Mean of the filtered values is $181 \pm 16 \mathrm{~mW} / \mathrm{m}^{2}$.
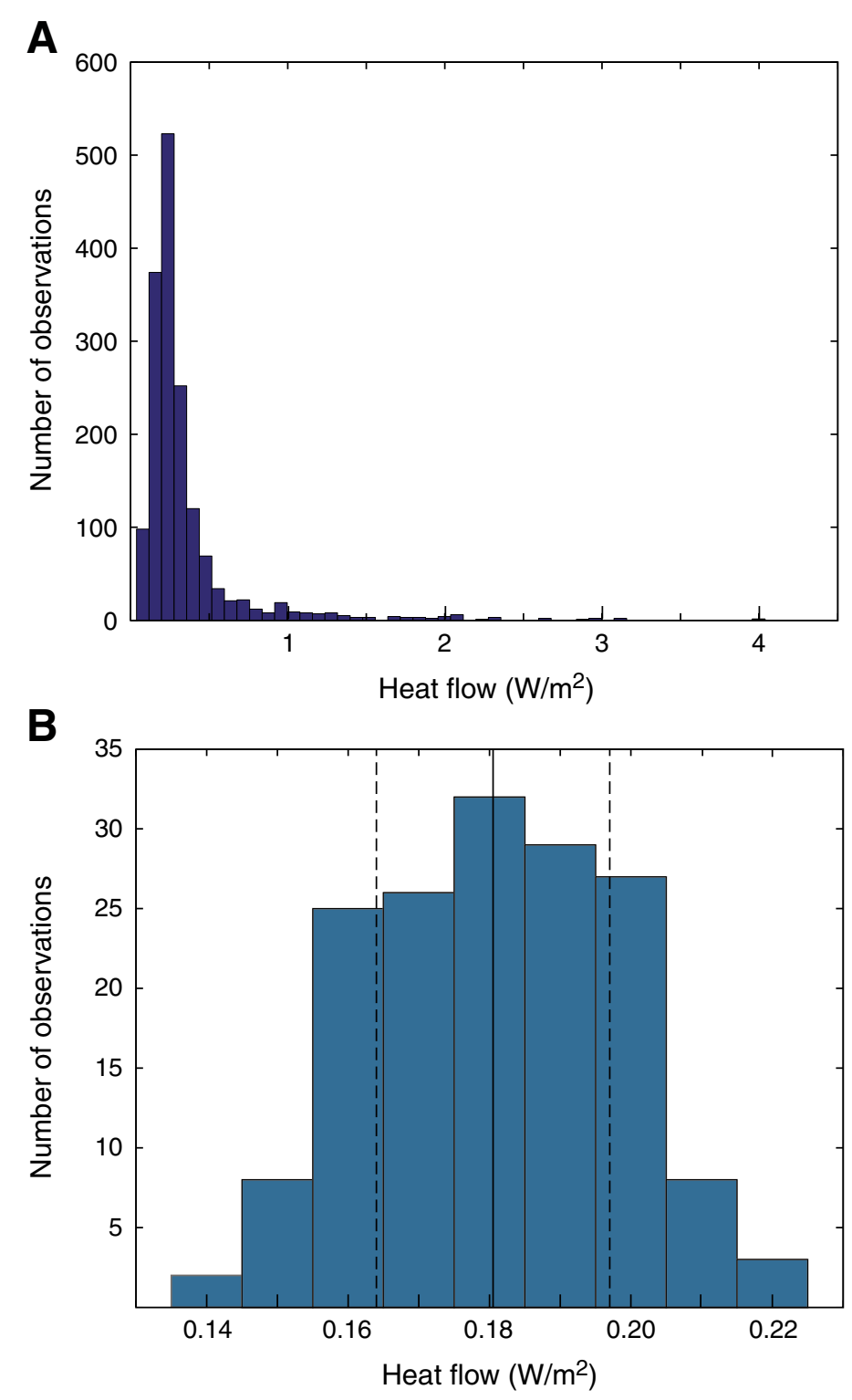
Figure F13. Seismic data, heat flow, and calculated sediment/basement interface (SBI) temperatures along Line 950802g (line location shown in Fig. F4). This location is characteristic of an area having heat flow and basement temperatures that are considerably lower than predicted by conductive cooling models for oceanic lithosphere and where there is little significant basement relief. A. Measured seafloor heat flow (open squares), with uncertainties in measured values being smaller than the symbols. Dotted line is output of two dimensional conductive model, using lithospheric cooling curve as lower thermal boundary condition. B. Calculated SBI temperatures (circles) based on heat flow and seismic data and output of two-dimensional conductive model (dotted line). Uncertainties in upper basement temperatures are indicated by vertical bars, based on the accumulation of errors through downward-continuation calculations, as described in the text. C. Seismic data overlain by isotherms calculated from measured seafloor heat flow. Vertical exaggeration $=\sim 3$.
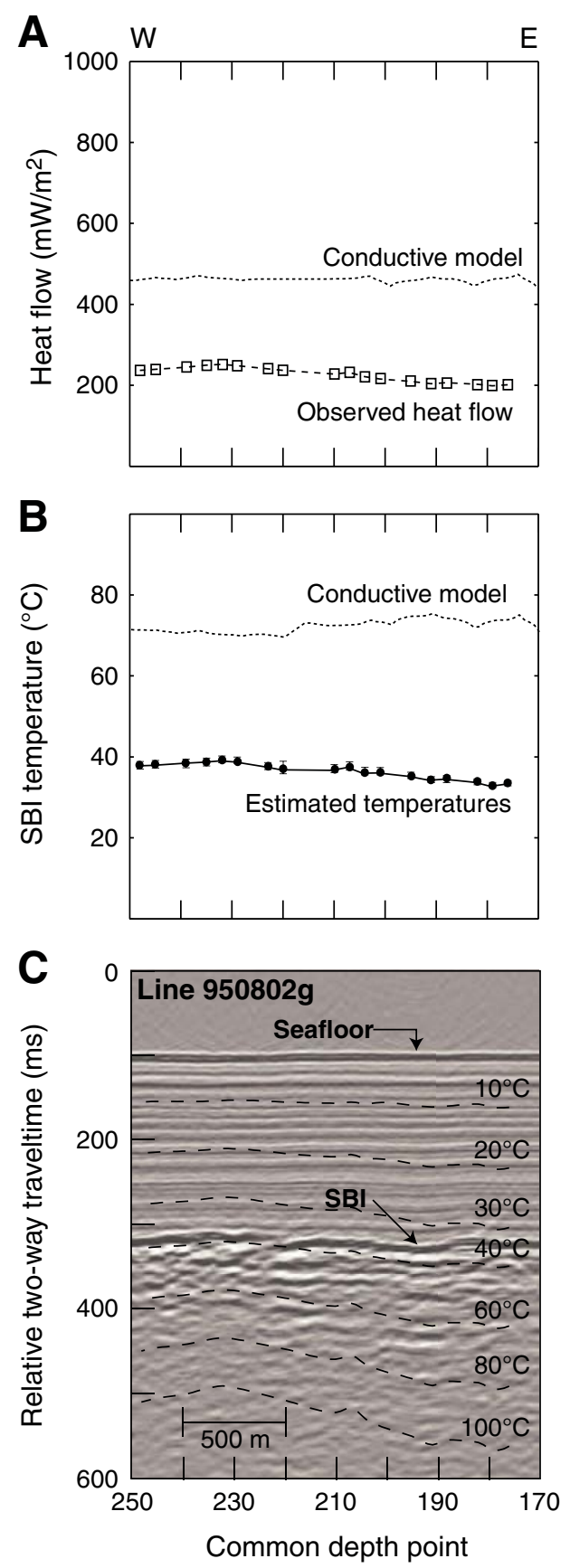
Figure F14. Seismic data, heat flow, and calculated sediment/basement interface (SBI) temperatures along Lines 950804e and GeoB00-252 (line locations shown in Fig. F4). These data cross the hydrothermal transition area and First Ridge, showing a progression in heat flow and basement temperatures. Locations of Lines 950802g (to the north; Fig. F13) and GeoB00-240 (to the south; Fig. F15) are shown, as is the perpendicular distance to the active ridge axis to the west. A. Measured seafloor heat flow (open squares), with uncertainties in measured values being smaller than the symbols. Dotted line is output of two dimensional conductive model, using lithospheric cooling curve as lower thermal boundary condition. B. Calculated SBI temperatures (circles) based on heat flow and seismic data and output of two-dimensional conductive model (dotted line). Uncertainties in upper basement temperatures are indicated by vertical bars, based on the accumulation of errors through downward-continuation calculations, as described in the text. C. Seismic data overlain by isotherms calculated from measured seafloor heat flow. Vertical exaggeration $=\sim 25$.

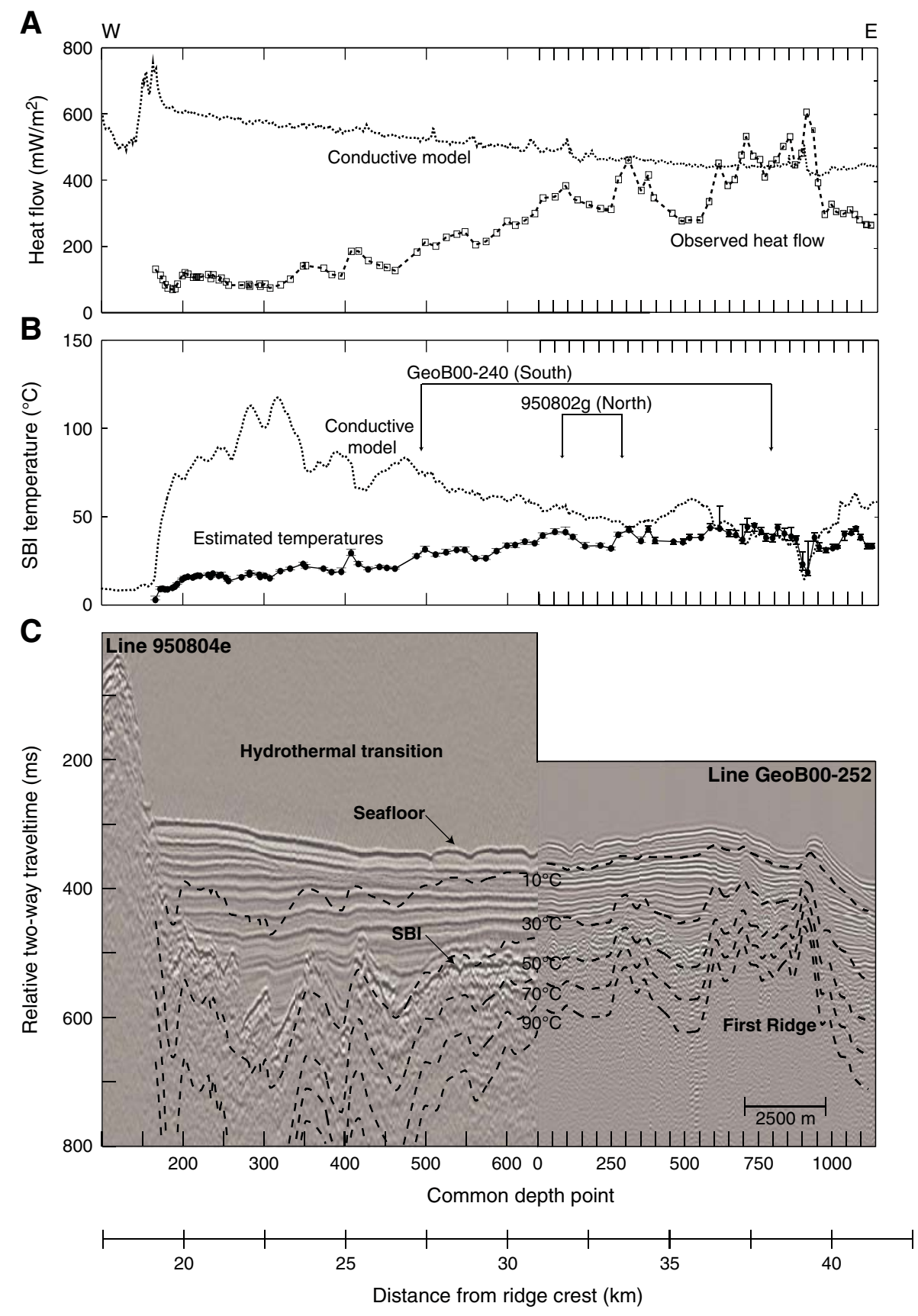


Figure F15. Seismic, heat flow, and calculated sediment/basement interface (SBI) temperatures along seismic Line GeoB00-240, across the eastern part of the hydrothermal transition area and First Ridge (line location shown in Fig. F4). A. Measured seafloor heat flow (open squares), with uncertainties in RetroFlux (eastern) values shown with horizontal bars. Dotted line is output of two dimensional conductive model, using lithospheric cooling curve as lower thermal boundary condition. B. Calculated SBI temperatures (circles) based on heat flow and seismic data and output of two-dimensional conductive model (dotted line). Uncertainties in upper basement temperatures are indicated by vertical bars, based on the accumulation of errors through downward-continuation calculations, as described in the text. C. Seismic data overlain by isotherms calculated from measured seafloor heat flow. Vertical exaggeration $=\sim 10$.
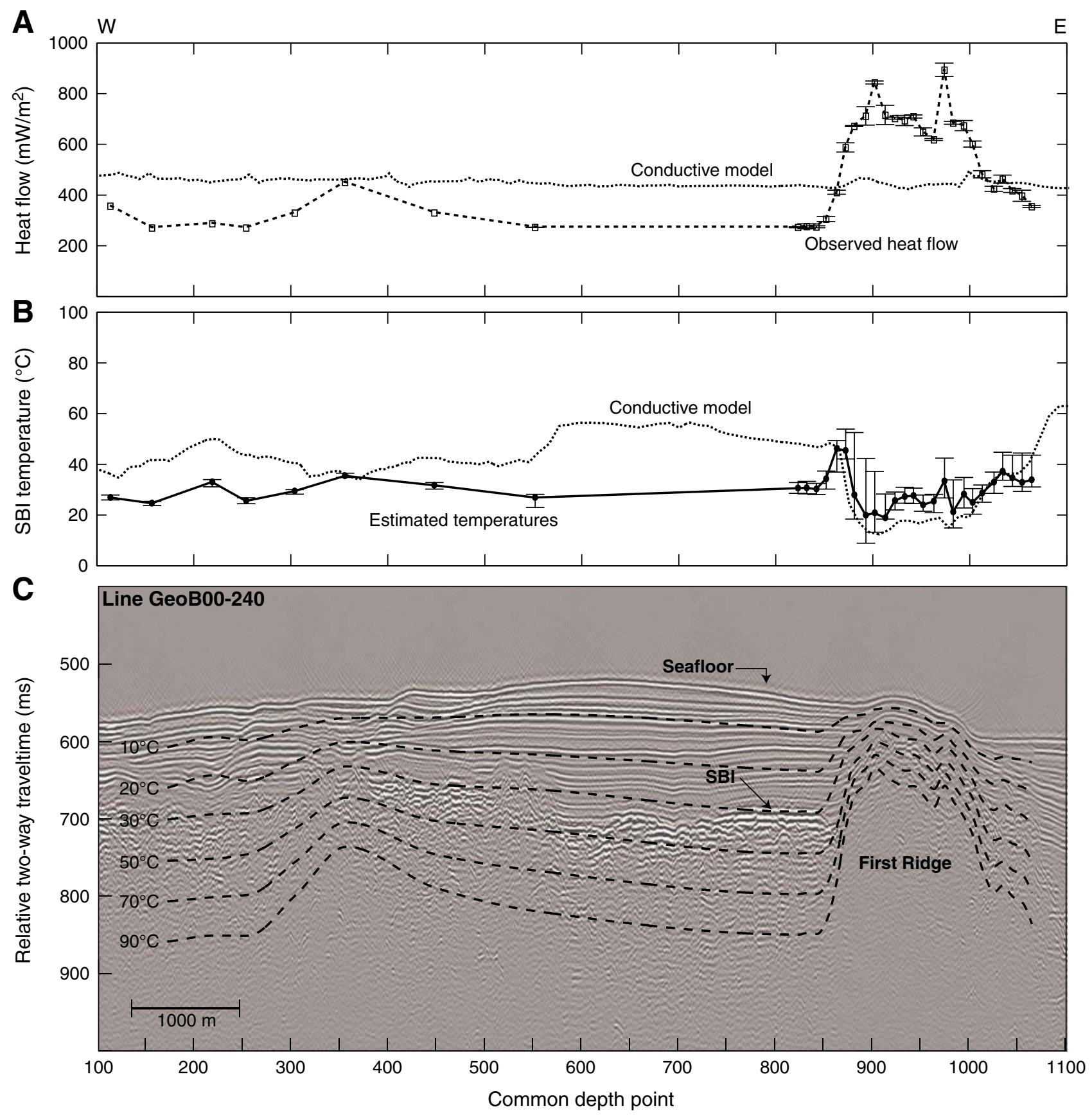
Figure F16. Seismic, heat flow, and calculated sediment/basement interface (SBI) temperatures around and across the Second Ridge along seismic Line GeoB00-194, $4.5 \mathrm{~km}$ south of Baby Bare outcrop (line location in Fig. F3). A. Measured seafloor heat flow (open squares), with uncertainties in measured values being smaller than the symbols. Dotted line is output of two dimensional conductive model, using lithospheric cooling curve as lower thermal boundary condition. B. Calculated SBI temperatures (circles) based on heat flow and seismic data and output of two-dimensional conductive model (dotted line). Uncertainties in upper basement temperatures are indicated by vertical bars, based on the accumulation of errors through downward-continuation calculations, as described in the text. C. Seismic data overlain by isotherms calculated from measured seafloor heat flow. Vertical exaggeration $=\sim 5$.

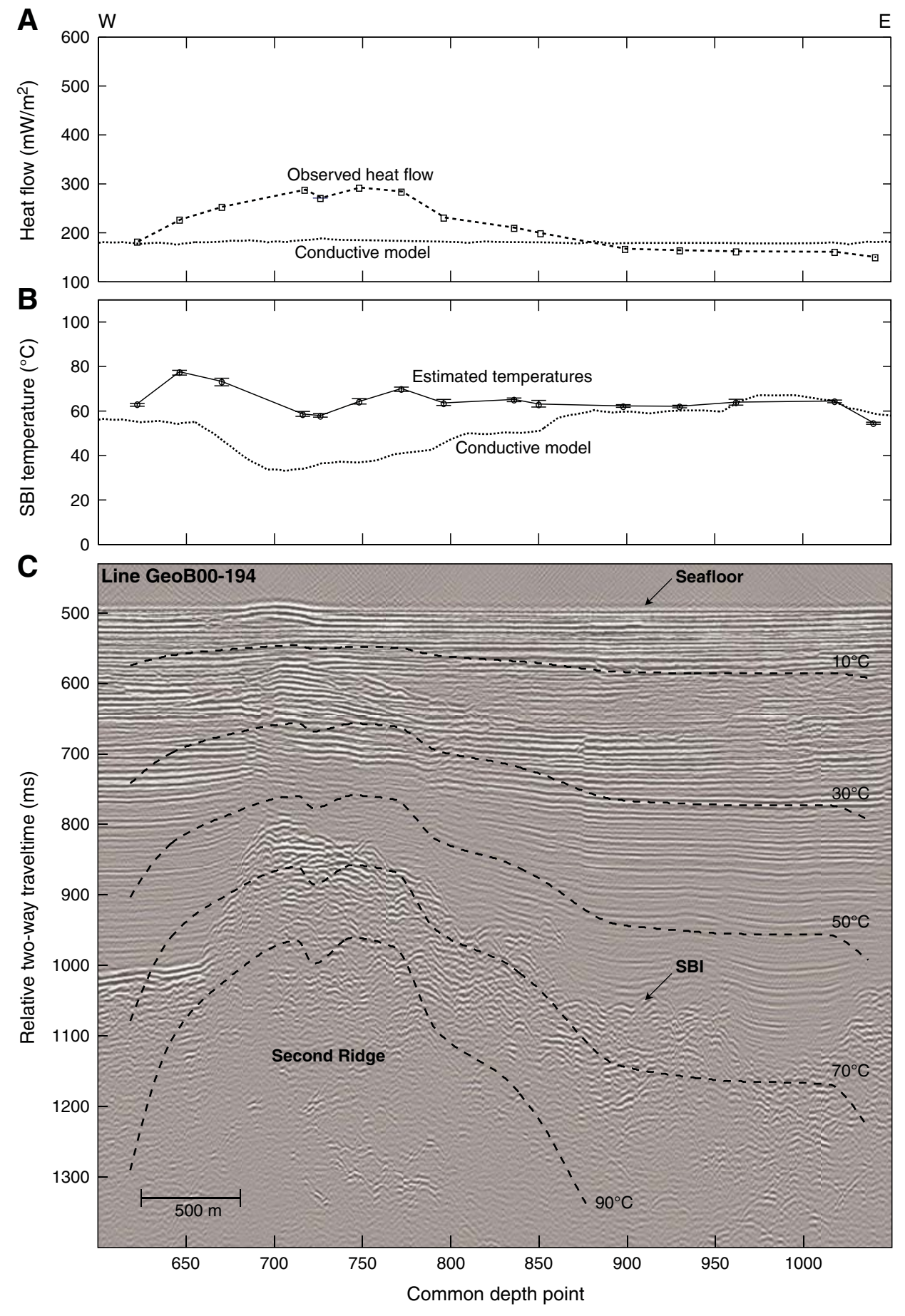


Figure F17. Seismic, heat flow, and calculated sediment/basement interface (SBI) temperatures around and across the Second Ridge along seismic Line 92-1 (Becker et al., 2000), $2 \mathrm{~km}$ north of Baby Bare outcrop (line location in Fig. F3). A. Measured seafloor heat flow (open squares), with uncertainties in measured values being smaller than the symbols. Dotted line is output of two dimensional conductive model, using lithospheric cooling curve as lower thermal boundary condition. B. Calculated SBI temperatures (circles) based on heat flow and seismic data and output of two-dimensional conductive model (dotted line). Uncertainties in upper basement temperatures are indicated by vertical bars, based on the accumulation of errors through downward-continuation calculations, as described in the text. C. Seismic data overlain by isotherms calculated from measured seafloor heat flow. Vertical exaggeration $=\sim 7$.
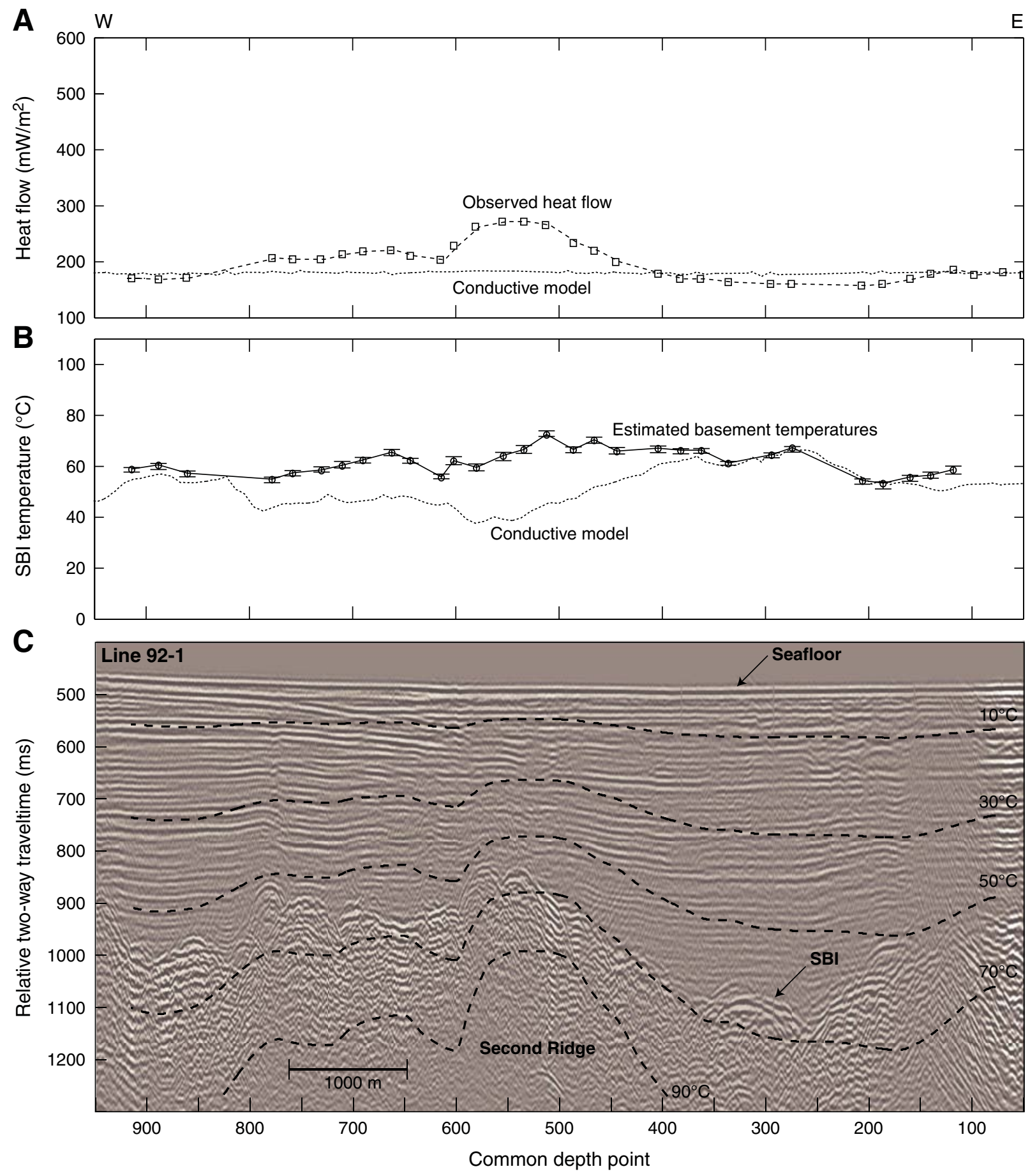
Figure F18. Seismic, heat flow, and calculated sediment/basement interface (SBI) temperatures across the Wuzza Bare subcrop along seismic Lines GeoB00-208 and GeoB00-205, 5 km north-northeast of Site U1301 (line location in Fig. F3). Many of the heat flow values have large uncertainties, as indicated with the error bars, because of insertion difficulties and high frictional heating associated with coarse-grained sediments above this basement high. In combination with difficulties in determining the exact location of steeply dipping basement, this leads to large uncertainties in projected upper-basement temperatures. A. Results along Line GeoB00-208, which appears to pass close to the peak of the buried basement high. Measured seafloor heat flow (open squares), with uncertainties in measured values being smaller than the symbols. Dotted line is output of two dimensional conductive model, using lithospheric cooling curve as lower thermal boundary condition. B. Results from Line GeoB00-205, which passes $\sim 200 \mathrm{~m}$ to the south. Calculated SBI temperatures (circles) based on heat flow and seismic data and output of two-dimensional conductive model (dotted line). Uncertainties in upper basement temperatures are indicated by vertical bars, based on the accumulation of errors through downward-continuation calculations, as described in the text. C. Seismic data overlain by isotherms calculated from measured seafloor heat flow. Vertical exaggeration $=\sim 5$.
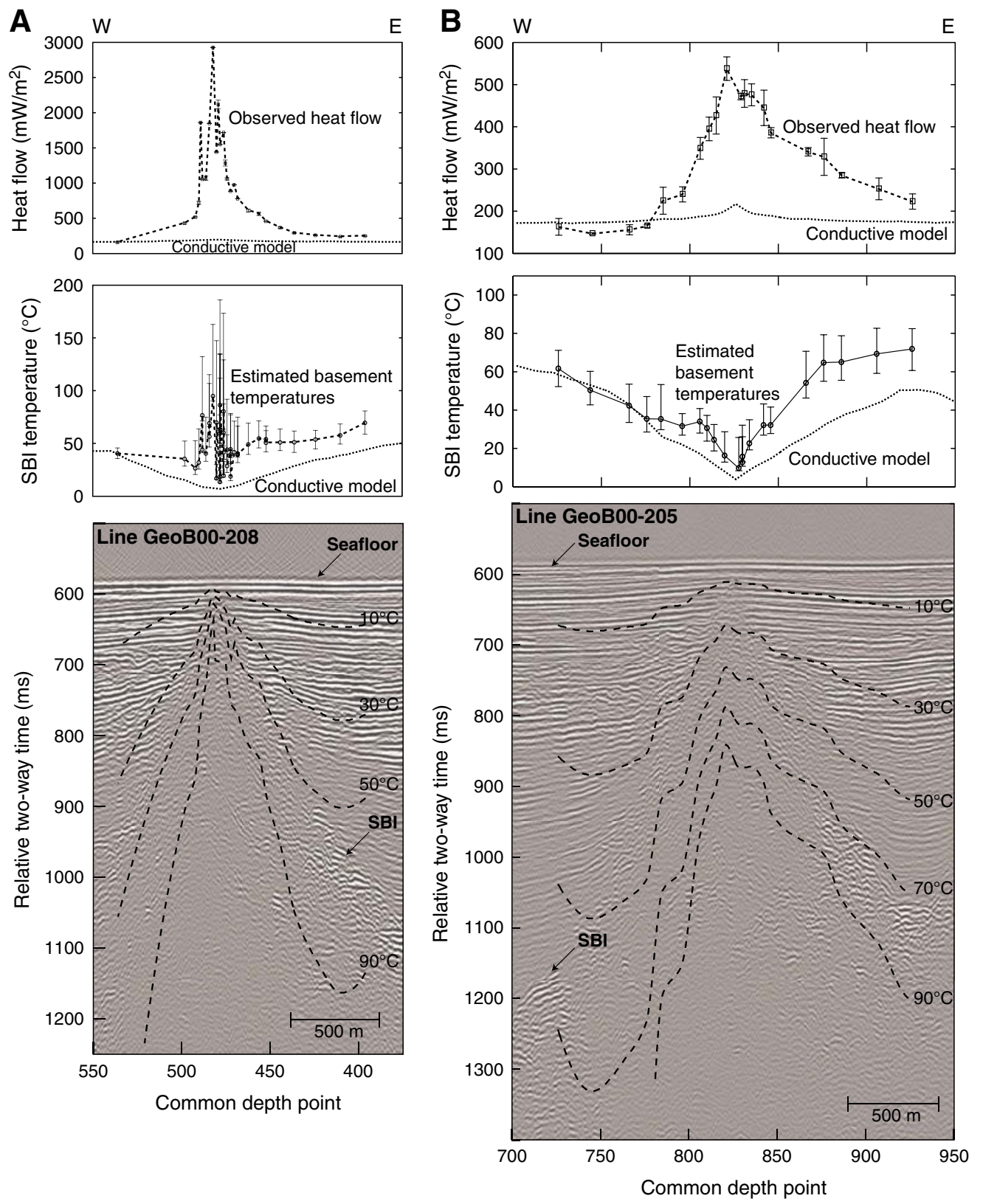
Figure F19. Comparison of stratigraphic and thermal regimes at Baby Bare and Grizzly Bare outcrops (modified from Fisher et al., 2003a). A. Heat flow data. B. Projected isotherms within sediments and shallowest basement, using methods described in the text. C. Seismic data. Note this fundamental difference in the thermal regimes around the two outcrops: heat flow rises abruptly at edge of Baby Bare exposure, whereas heat flow decreases immediately adjacent to Grizzly Bare outcrop. As a result, calculated isotherms are swept upward below Baby Bare outcrop but swept downward into the crust around Grizzly Bare outcrop. Typical sediment thickness away from both outcrops is about the same, as is the background heat flow of $\sim 180 \mathrm{~mW} / \mathrm{m}^{2}$, and there is no indication of broad scale heat flow suppression around either outcrop. Vertical exaggeration in seismic plots $=\sim 3$.
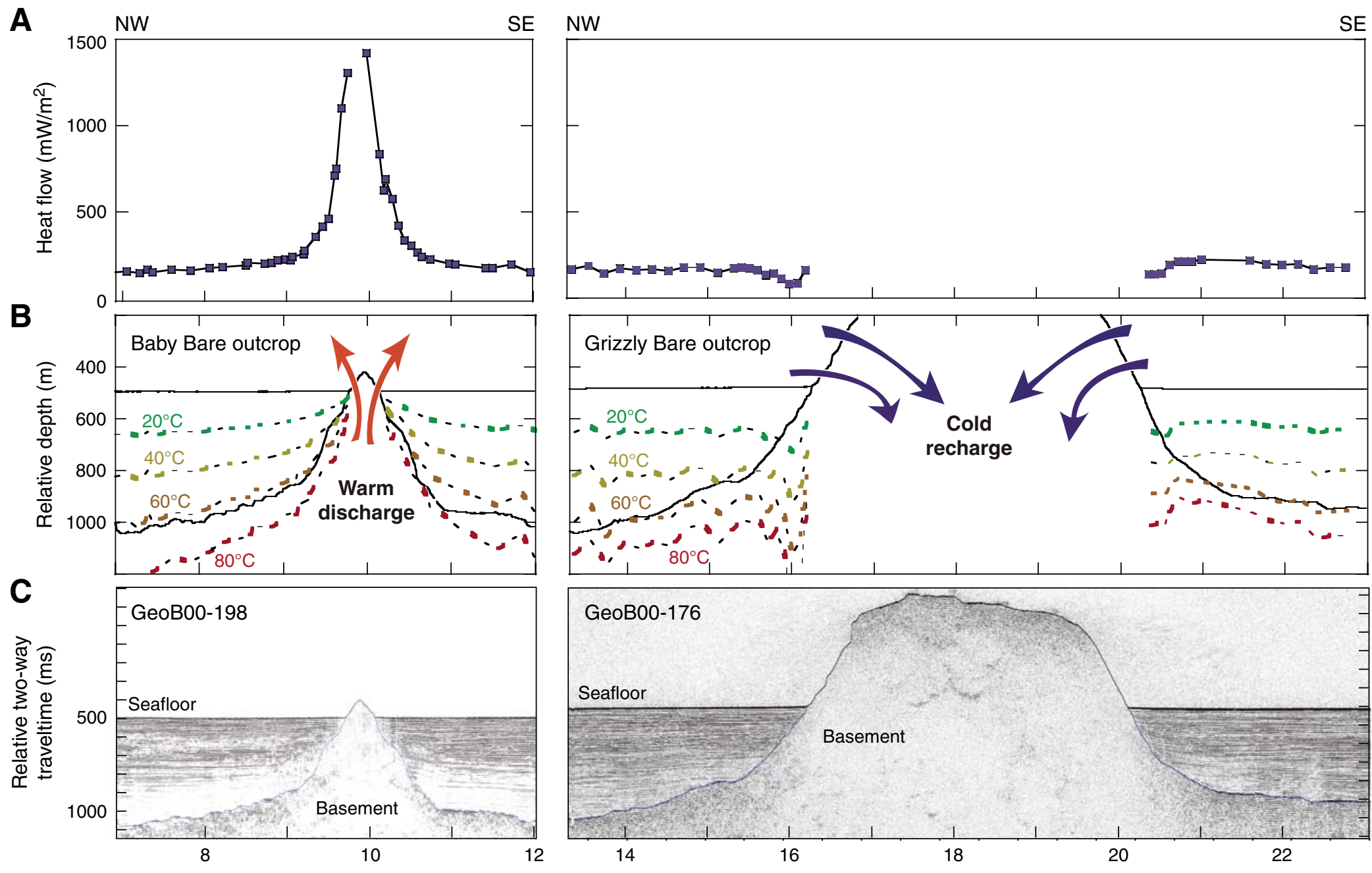

Relative distance along track $(\mathrm{km})$
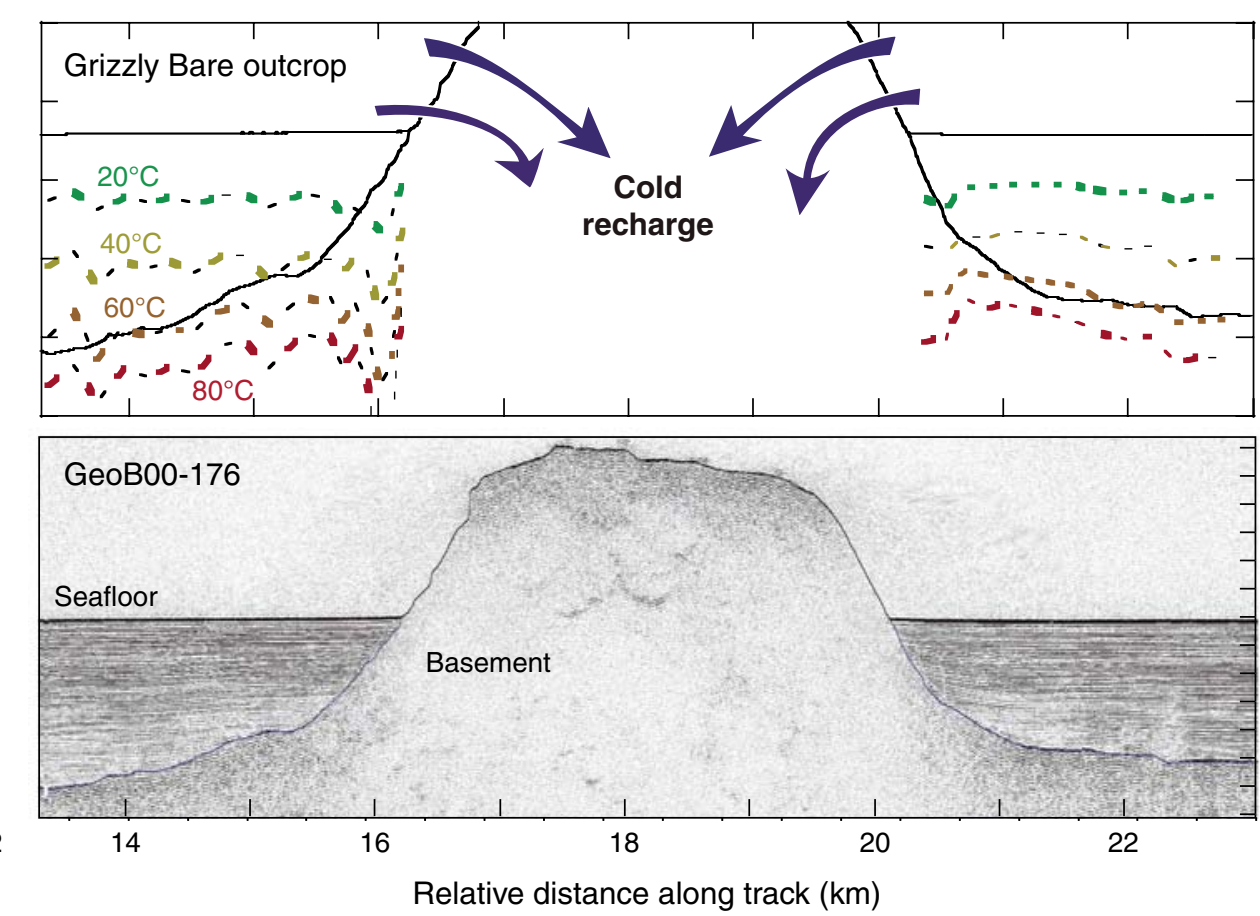